\title{
DESENVOLVIMENTO E VALIDAÇÃO DE UM QUESTIONÁRIO SEMI-QUANTITATIVO DE FREQUÊNCIA ALIMENTAR PARA ADOLESCENTES
}

BETZABETH SLATER VILLAR

Tese de Doutorado apresentada ao Departamento de Nutrição da Faculdade de Saúde Pública da Universidade de São Paulo para obtenção do Grau de Doutor.

Área de concentração:

Nutrição

ORIENTADOR: PROFA. DRA. SONIA TUCUNDUVA PHILIPPI

São Paulo 2001 
Ao Daniel e Lucas, a quem $\sigma$ futuro pertence; a Francisco, $\sigma$ companheiro de mens dias. 
Maisvale estar a dois do que estar sozinho,porque doist trarão maior proveito de seu trabalho.

De fato, se um cair poderá ser levantado pelo companheiro. Azar, porém, de quem está sozinho: se cair não terá ninguém para olevantar.

Se dois se deitam juntos um poderá aquecer ao outro; mas como-poderá alguém sozinho se aquecer? Se um delesfor agredido, dois poderão resistir, e uma corda de trípla não se arrebenta facilmente.

Eclesiastes 4: 10-12

Meuprimeiro sentimento, depois de ler este versiculo da Biblia, foi lembrar-me de Sonia Tucunduva Philippi, Regina Mara Fisberge Maria do Rosário Dias Latorre. Cada uma delas, no que melhor sabe fazer, colaborow para mew crescimento profissional e contribuiu para que eu me tornasse uma mulher diferente: mais humana, tenaze corajosa. Tal contribuição está refletida nesta tese, que sem elas não existiria. 


\section{Agradecimentos}

Agradeço ao coordenador e alunos da Escola Pública Antonio Alves Cruz, por sua colaboração e participação nesta pesquisa.

Ao Prof. Dr. José Maria Pacheco e à Profa. Dra. Denise P. Bergamaschi, que tiraram minhas duvidas nas análises estatistucas.

A minhas queridas "amiguitas", como carinhosamente as chamo, Roberta Stella, Roberta Coutinho, Camila Guimarãese Juliana Miyamoto, por sua ajuda durante a coleta de dados.

A Ana Carolina Colucci, Mariana Nogueira Ferreira e Graziela Mantoanelli, pela dedicação e carinho na hora da digitação e formatação da tese.

A Dirce L. Marchioni, a quem não tenho palauras para agradecer, por permanecer ao meu lado, pela sua ajuda na hora de leitura e discussão de assuntos que permitiram a elaboração desta pesquisa e por sua amizade, pois com ela pude compartir momentos dificeis, assim como de muita alegria.

Ao-professoresda banca: Profa. Dra. Marly Cardoso, Profa. Dra. Nélida Formes, Prof. Dr. Carlos Augusto Monteiro pelas sugestöes oportunas, que contribuiram para a methora do conterido da tese.

A Coordenação de Aperfeicoamento de Pessoal de Nivel Superior - CAPES, pelo apoio financeiro para a realização deste estudo.

Por fum, especial e formalmente, agradeço à Profa. Dra. Sonia Tucunduva Philippi, por sua orientação. 


\section{RESUMO}

Slater VB. Desenvolvimento e validação de um questionário semi-quantitativo de freqüência alimentar para adolescentes. São Paulo 2001. [Tese de Doutorado- Faculdade de Saúde Pública da Universidade de São Paulo].

Objetivo. O principal objetivo deste estudo foi desenvolver um questionário de freqüência alimentar- QFAA para calcular o consumo de energia, carboidrato, proteína, lipídio total, lipídio insaturado, fibra, colesterol, retinol, vitamina $C$, cálcio e ferro de adolescentes freqũentadores de uma escola pública localizada na região oeste da cidade de São Paulo. A validade relativa do QFAA foi testada por meio da comparação entre os valores estimados pelo método de referência (média de 3 dias de R24h) e os calculados pelo QFAA. Metodologia. Depois de identificados os principais alimentos fontes dos nutrientes analisados, o QFAA foi testado em prova piloto. A versão final foi constituída por 76 itens alimentares, agrupados segundo o perfil de cada alimento. $O$ estudo de validade foi realizado durante um período de 6 meses (junho a novembro de 1999) junto a 79 alunos voluntários de ambos os sexos, os quais responderam $4 \mathrm{R} 24 \mathrm{~h}$ com intervalo de 45 dias e 1 QFAA ao final do estudo. Os dados foram calculados pelo Virtual Nutri e analisados utilizando-se coeficiente de correlação de Pearson, ajustados pela caloria e corrigidos pela variância intrapessoal. Resultados. Observou-se uma alta variabilidade no consumo da dieta dos adolescentes, mostrando razōes de variância extremamente altas para o colesterol, retinol e vitamina $C$. Os coeficientes de correlação de Pearson, depois do ajuste e da correção pela variância, variaram entre - 0,10 a 0,72 para os indivíduos de sexo feminino e de 0,16 a 0,91 para os de sexo masculino. A média do coeficiente de correlação para todo o grupo foi de 0,52. Conclusões. Nossos resultados indicam que o QFAA mostrou aceitável desempenho para classificar os indivíduos segundo seu consumo habitual para a maioria dos nutrientes, com exceção do retinol e do ferro. 


\section{ABSTRACT}

Slater VB. Development and validation of a semi-quantitative Food-Frequency Questionnaire for adolescents. São Paulo, 2001. [Doctorate Thesis - Public Health School, University of São Paulo].

Purpose. The main purpose of this study was to develop a Food-Frequency Questionnaire - FFQ to calculate the consumption of energy, carbohydrate, protein, total lipid, unsaturated lipid, fiber, cholesterol, retinol, vitamin $\mathrm{C}$, calcium and iron by adolescents attending a public school located in the western region of the city of São Paulo. The relative validity of the FFQ was tested in a comparison between values estimated by the reference method (average, three days of R24h) and those calculated by the FFQ. Methodology. After identifying the major food sources of the nutrients analyzed, the FFQ was tested in a pilot test. The final version was comprised by seventy-six food items, grouped according to each of their profiles. The validity study was performed over a six-month period (June through November, 1999) on seventy-nine volunteer students of both sexes, which responded four R24h with a 45-day interval and one FFQ at the end of the study. Data was computed by the Virtual Nutri and analyzed by using Pearson's correlation coefficient, energy adjustment and corrected for within-subject variance. Results. High variability was observed in adolescent diet consumption, showing extremely high variance ratios for cholesterol, retinol and vitamin C. Pearson's correlation coefficients, after adjustment and correction for variance, range between -0.10 to 0.72 for females and from 0.16 to 0.91 for males. The average correlation coefficient for the entire group was 0.52 . Conclusions. Our results indicate that the FFQ has shown an acceptable performance to classify individuals according to their habitual consumption for the majority of nutrients, with the exception of retinol and iron. 


\section{ÍNDICE}

\section{INTRODUÇĀO}

1.1 Epidemiologia Nutricional: uma nova disciplina. $\quad 01$

1.1.1 Medição da dieta nos estudos epidemiológicos. 03

1.1.2 Método Recordatório de 24 horas. 04

1.1.3 Diário Alimentar ou Registro Diário. 08

1.1.4 Questionário de Freqüência Alimentar. $\quad 10$

1.2 Consumo diário, evento aleatório. $\quad 18$

1.3 Medindo a exatidão de um instrumento de 29 avaliação do consumo alimentar.

1.4 Questionário de freqũência alimentar para adolescentes. 42 Um exemplo prático.

2. OB]ETIVOS

3. CASUÍSTICA E MÉTODOS

3.1 DELINEAMENTO DO ESTUDO 51

3.2 INSTRUMENTOS DE AVALIAÇĀO DO CONSUMO

3.2.1 Método de Referência - Recordatório de 24 horas. 51

3.2.2 Questionário de Frequeência do Consumo Alimentar para 52 Adolescentes - QFAA.

3.3 DESENVOLVIMENTO DA ESTRUTURA DO QUESTIONÁRIO DE 53

FREQÜÊNCIA ALIMENTAR PARA ADOLESCENTES

3.3.1 Lista de Alimentos. 53

3.3.2 Identificação dos alimentos. $\quad 53$

3.3.3 Freqũência de consumo de alimentos em unidades de tempo. 54

3.3.4 Porcionamento e padronização. $\quad 54$

3.4 PROVA PILOTO

3.5 ESTUDO DE VALIDAÇÃO

3.5.1 Populaçăo e local de estudo. $\quad 56$

3.5.2 Critérios de seleção. $\quad 56$

3.6 DESENHO DO ESTUDO DE VALIDAÇÃO

3.7 VARIÁVEIS DE ESTUDO

3.8 PROCESSAMENTO DOS DADOS

3.9 ANÁLISE ESTATÍSTICA DOS DADOS

4. RESULTADOS 63

5. DISCUSSÃO

6. CONCLUSÃO 97

7. REFERÊNCIAS BIBLIOGRÁFICAS 98

8. ANEXOS

Anexo 1 - Recordatório de 24 horas. A-1

Anexo 2 - Alimentos de maior freqüência de consumo... $\quad$ A-2

Anexo 3 - Alimentos de maior contribuição energética... A-4 
Anexo 4 - Porções de alimentos e preparaçōes que integram o QFAA. 
1. INTRODUÇÃO 
Ahora será conveniente investigar la dieta con la cual los marineros se veen obligados a alimentarse en alta mar.

$Y$ como parece ser la causa principal que ocasionó su enfermedad, puede ser útil considerar las provisiones maritimas en su mejor estado, ya que ha experiencia há demostrado que, a pesar de la calidad del aguay des las provisiones, a menudo la calamidad se desencadena com gran violencia, y puede etiminarse solamente mediante el cambio de la dieta.

James Lind, 1753 
Quem conhece o desenvolvimento histórico dos estudos da nutrição humana pode observar que o interesse pelos alimentos, pela dieta e pela saúde é muito antigo e pertence mais à história da religião que à da medicina. As associações entre a dieta e a saúde, que estão implícitas nas regras religiosas, se fazem explícitas no decorrer da história das civilizaçōes.

Os primeiros estudos experimentais em humanos, resultado de observações simples no século XVIII, encontraram que limões e laranjas tinham bons efeitos na cura do escorbuto e que a falta de consumo de leite poderia ser a causa da pelagra, conhecida como o "mal de la rosa" (OPS 1988). Com o decorrer do tempo, as bases da ciência da nutrição moderna surgem paralelamente à aparição do método científico e com grande força junto ao descobrimento das vitaminas, demostrando a existência da relação entre certas doenças já conhecidas e o consumo habitual de dietas carentes de uma ou outra vitamina.

Já pela segunda metade do século $\mathrm{XX}$, juntamente com os grandes avanços tecnológicos, confirma-se a relação entre a composiçāo da dieta e o desenvolvimento das chamadas enfermidades crônico-não transmissíveis como a primeira causa de morte nos países em desenvolvimento. Este fato dá lugar ao surgimento de uma nova disciplina dentro da área da nutriçăo humana: a Epidemiologia Nutricional (GRANDE 1995).

Esta nova disciplina de investigação tem como objetivo descrever a distribuição e magnitude das doenças relacionadas com a nutrição e os desequilibrios nutricionais e alimentares na população, assim como elucidar as causas da enfermidade e proporcionar informaçōes necessárias para o planejamento de ações de saúde destinadas a prevenir, controlar e tratar tais doenças (NELSON 1997). 
Embora a Epidemiologia Nutricional (EN) use o método epidemiológico para determinar as relaçōes entre os fatores dietéticos e a ocorrência da doença, a EN não é uma especialização da epidemiologia e para definir o conceito é necessário entender a dimensão da nutrição como ciência da saúde.

Com muita frequêencia, alguns autores têm restringido e considerado a EN como o estudo quantitativo de consumo de energia e nutrientes e a avaliação do estado nutricional do indivíduo. No entanto, o âmbito de atuação da EN é muito maior e inclui diferentes temas, dentre os quais vem se destacando o desenvolvimento e avaliação de instrumentos de mediçăo do consumo alimentar em nível individual e populacional (MAJEM \& BARTRINA 1995).

A medição da informação dietética é realizada através de diversos métodos de avaliações ou inquéritos alimentares, os quais serão escolhidos de acordo com os objetivos da pesquisa ou tipo de estudo e com os recursos disponíveis; entretanto, em pesquisas clínicas e epidemiológicas são necessários instrumentos de avaliação do consumo alimentar que devem reger-se pelos princípios de validade e reprodutibilidade, além de serem capazes de caracterizar a dieta dos indivíduos (PENNINGTON 1991; WILLETT 1998).

A escolha do método, segundo ARMSTRONG et al. (1995), não é uma tarefa simples e depende mais da prática do que de considerações teóricas. Além das considerações antes mencionadas, o autor assinala como importantes: o impacto da exposição na vida dos indivíduos, a sensibilidade dos sujeitos no questionamento da exposição, a frequiência da exposição e a variabilidade na frequêência e o nivel da exposição sobre o tempo. Todos estes são fatores decisivos para se determinar qual será o instrumento de medição utilizado no estudo. Neste sentido, a avaliação da dieta é um tópico importante e crucial 
nos estudos epidemiológicos, pois a fidedignidade dos resultados encontrados dependerá da qualidade da informação obtida por mejo desses instrumentos.

\subsubsection{Medição da dieta nos estudos epidemiológicos.}

Durante as últimas décadas, o consumo alimentar vem sendo estudado, por sua potencial relação com doenças crônico-não transmissiveis. A correta avaliação do consumo alimentar em estudos epidemiológicos representa um grande desafio para os pesquisadores. Esta afirmação baseia-se em dois fatos: a complexidade da dieta como variável de exposição (considerando a dieta como evento aleatório) e a dimensão do "tempo" no surgimento da enfermidade (MAJEM \& BARTRINA 1995; WILLETT 1998).

Por estes fatores, a avaliação da dieta torna-se complexa e muitas vezes difícil, pois os conceitos relativos à dieta dos indivíduos são mal interpretados. A ingestão ou consumo verdadeiro de um indivíduo ou de uma coletividade não será igual ao seu consumo habitual e suas diferenças derivam da maneira como os métodos coihem e mensuram a informaçăo dletético-nutricional (MAJEM 1995). Conceitos de dieta atual e dieta habitual possuem diferenças sutis, mas muito importantes. Sabe-se que, se a epidemiologia nutricional descritiva (estudos transversais e ecológicos) permite o conhecimento da dieta atual, a EN analitica (estudos caso controle e de coorte) possibilita que se conheça a dieta habitual de períodos prolongados; a primeira é relativamente fácil de medir, enquanto a segunda requer um trabalho metodológico muito bem sistematizado (THOMPSON \& BYERS 1994).

Para se avaliar a dieta atual ou habitual em estudos epidemiológicos existem três formas de abordagens que podem ser usadas:

- informação do consumo de alimentos, que pode ser usada diretamente para calcular a ingestão de nutrientes; 
- medidas bioquímicas de sangue ou tecido, que provêem indicadores da dieta;

- medidas das dimensões ou composição corporal, que refletem os efeitos da dieta de períodos prolongados (WILLETT 1996).

Neste estudo serão descritas as características, vantagens e limitações dos métodos de avaliação dietética utilizados na primeira abordagem, ou seja, o da informação sobre consumo de alimentos.

A informação dietética pode ser obtida em niveis nacional, regional, local, familiar e individual, mediante o uso de metodologias que se baseiam: na disponibilidade de alimentos de um país, região ou localidade na distribuiçăo interna do orçamento familiar destinado à aquisição de alimentos, e na ingestžo de alimentos pelo indivíduo. Estes dados posteriormente serão transformados em energia e nutrientes por meio de tabelas e softwares de composição de alimentos.

Com a finalidade de se obter informação do consumo de alimentos em nivel individual, as metodologias foram classificadas segundo o período de tempo em que colhem a informação. Desta maneira, existem: métodos prospectivos, que registram a informação presente, e métodos retrospectivos, os quais colhem a informação do passado imediato ou de longo prazo (SHILS et al. 1994).

\subsubsection{Método Recordatório de 24 horas - R24hs}

Os inquéritos dietéticos foram usados pela primeira vez nos anos 30 do século passado para descrever o estado nutricional das populações. O método R24hs foi apresentado por sua autora, BERTHA BURCKE, como método básico para ensinar as mães a registrar o consumo de alimentos por seus filhos. 
Anos mais tarde, WIEHL utilizou o método pela primeira vez para quantificar o consumo de energia e nutrientes de trabalhadores industriais (CLOSAS 1995). O R24hs pode ser considerado o instrumento mais utilizado para a avaliaçāo da ingestão de alimentos e nutrientes de indivíduos e diferentes grupos populacionais no mundo todo e também aqui no Brasil. Grandes pesquisas como a da Saúde e Nutrição das crianças de São Paulo (1988) (MONTEIRO 1988) e o estudo Multicêntrico (pesquisa não publicada) usaram a citada metodologia para recolher a informação dietética.

O recordatório de 24 horas, como o nome indica, consiste em definir e quantificar todos os alimentos e bebidas ingeridas no período anterior à entrevista, que pode ser as $\mathbf{2 4}$ horas precedentes ou, mais comumente, o dia anterior (TOMPSOM \& BYERS 1994; WILLETT 1998; GIBSON 1990). Segundo BUZZARD (1998), este método mostra-se útil quando se deseja conhecer a ingestão média de energia e nutrientes de grupos culturalmente diferentes, isto é, o método é sensível às diferenças culturais, já que pode descrever um amplo número de alimentos e hábitos alimentares.

Trata-se de uma entrevista pessoal em profundidade e conduzida por um entrevistador treinado, podendo também ser realizada por telefone. É possível também que $o$ indivíduo responda seu próprio recordatôrio, listando os alimentos e bebidas que consumiu. Esta forma de abordagem, no entanto, raramente é usada, por dificultar a obtenção de informação adicional ao consumo (WILLETT 1998a; DUNKER \& PHILIPPI 1999).

A qualidade da informaçăo dependerá da memória e cooperação do entrevistado, assim como da capacidade do entrevistador em estabelecer um canal de comunicação onde se obtenha a informação por meio do diálogo. 
A informaçăo obtida por este método está determinada pela habilidade do indivíduo em recordar, de forma precisa, seu consumo de alimentos. Esta habilidade estará influenciada pela idade, sexo, nível de escolaridade (MAJEM \& BARBA 1995), entre outros fatores. A idade é o fator que mais influencia as respostas, sobretudo nas idades extremas, onde se requer que uma pessoa responsável relate a informação. Isto também é válido para pessoas com algum tipo de deficiência. TREIBER (1990), DOMEL et al. (1994) e FRANK (1994) assinalam que crianças a partir de 12 ou 13 anos podem responder a entrevistas com precisão, sem ajuda de adultos.

Para a correta coleta da informação por este método é necessária uma etapa fundamental antes da execução do trabalho de campo. O desenho da pesquisa deverá contemplar a elaboração de um manual para treinamento dos trabalhadores de campo. Neste treinamento, o pesquisador ou coordenador deverá passar informações sobre técnicas gerais, apresentação e entrevista. Os entrevistadores deverão possuir amplo conhecimento dos hábitos e costumes da comunidade, assim como dos alimentos e modos de prepará-los. Respostas precisas e não tendenciosas exigem respeito e atitude neutra frente a hábitos e consumo de alimentos socialmente censurados (TOMPSOM \& BYERS 1994; FRANK et al. 1984).

É necessário, portanto, que o sujeito responda detalhadamente sobre o tamanho e volume da porção consumida. Para isto acontecer, o entrevistador poderá fazer uso de álbuns de fotografias, medidas geométricas ou de medidas caseiras. $\mathrm{O}$ alimento pode ser registrado em unidades específicas como: uma fatia, uma banana média, uma bala, um pacote de biscoito. Em nosso meio, esta forma de quantificação tem se aprimorado bastante, pois se conta com softwares como o VIRTUAL NUTRI (PHILIPPI et al. 1996), que possui diferentes formas de porcionamento em unidades, medidas caseiras e marcas comerciais de alimentos tradicionais para a população de São Paulo. 
É importante que se interrogue sobre a quantidade realmente consumida e que se faça perguntas que possibilitem quantificar as sobras, em especial quando o R24hs é realizado em crianças.

Pelo fato de uma cidade estar integrada com indivíduos culturalmente diferentes, é preciso perguntar a forma de preparação (frito, assado, cozido...). Uma mesma preparação, embora receba nomes semelhantes, pode ter receita diferente e estar composta de ingredientes distintos, de acordo com a região do país. Isto é evidente no caso de pessoas migrantes. Exemplo: "Cuscuz". Pessoas nascidas na Paraíba, que moram em São Paulo, continuam comendo o cuscuz ao estilo nordestino, feito de farinha de milho, água e sal, enquanto o paulista come o cuscuz ao estilo português, com sardinha, azeitona, entre outros.

Uma das vantagens deste método é a rápida aplicação e o imediato periodo de recordação, condições que predispõem a uma maior participação. Tanto o método recordatório de $\mathbf{2 4}$ horas como o diário alimentar avaliam a dieta atual e estimam valores absolutos ou relativos da ingestão de energia e nutrientes amplamente distribuídos no total de alimentos oferecidos ao indivíduo (BUZZARD 1998). Isto pode ser feito porque o método permite um ilimitado nivel de especificidade.

Outras vantagens são: a população estudada não precisa ser alfabetizada e o método é o que menos propicia alteração no comportamento alimentar, desde que a informação seja coletada após o fato.

A maior limitação recai na memória para identificação e quantificação do tamanho das porçōes, determinantes críticos da qualidade da informação (GUTHRIE 1984; BROWN et al. 1990; FAGGIANO et al. 1992). O último autor afirma que existe uma tendência dos indivíduos em superestimar as 
porçōes pequenas e subestimar as porçōes grandes, num fenômeno conhecido como "flat slope syndrome", em que a inclinação da reta na regressão é menor que 1,0. Esta dificuldade se apresenta quando o recordatório de 24 horas é realizado sem elementos de ajuda visual.

KRALL et al. (1988) encontram que existem outros fatores que afetam a habilidade da pessoa em recordar com exatidão seu consumo passado. Entre estes fatores que influenciam a memória estão a inteligência, o humor, a atenção, a importância da informação e a freqūência da exposição.

No entanto, a maior limitação do método R24 horas é que um único dia de recordatório provavelmente não representa a ingestão habitual de um individuo (SERRA-MAJEM \& BARBAS 1995; BUZZARD 1998). Esta limitação deve-se à elevada variabilidade intrapessoal/interpessoal, o que confere ao método R24hs pouca representatividade do consumo habitual. Neste sentido, a credibilidade do método dependerá do número de indivíduos avaliados e da variabilidade interpessoal. De forma diferente, quando as medidas são repetidas (mais de duas vezes) a confiabilidade do método dependerá da variabilidade intrapessoal, que por sua vez depende da população e dos nutrientes em estudo (BEATON et al. 1979, 1983; SEMPOS et al. 1985). Tais fatos tornam os estudos epidemiológicos altamente dificeis e dispendiosos.

\subsubsection{Diário alimentar ou registro diário.}

Da mesma forma que o R24hs, o Diário alimentar (DA) recolhe informação sobre a ingestão atual de um indivíduo ou de grupo populacional. Este método, chamado também de registro diário, consiste em que o próprio indivíduo ou a pessoa responsável anote, em formulários especialmente desenhados, todos os alimentos e bebidas consumidos ao longo de um dia. 
Deve considerar-se os alimentos consumidos dentro e fora do lar (BARTRINA \& PEREZ 1995; WHITNEY \& ROLFES 1993).

Segundo THOMPSON \& BYRES (1994), este método pode ser aplicado durante períodos de 3, 5 ou 7 dias consecutivos. Os autores afirmam, também, que periodos de registro de mais de 7 dias são usualmente insatisfatórios, porque levam o respondente à fadiga.

O DA pode se aplicado de duas maneiras: na primeira, que inclui o uso de uma balança, todos os alimentos devem ser pesados e registrados antes de serem consumidos; na segunda, o participante deverá registrar o tamanho da porção consumida. Em ambos os casos o indivíduo registrará, de forma detalhada, o nome da preparação, os ingredientes que a conformam, marca do alimento e forma de preparação. No caso do DA com uso de balança, todos os alimentos terão que ser pesados e logo anotados. No segundo, o participante poderá contar com a ajuda de fotografias de diferentes tamanhos de porçōes, modelos tridimensionais e a representação do que foi consumido em medidas caseiras tradicionalmente usadas, que ajudaram a estimar a porção consumida.

Este método é útil quando se deseja quantificar as dletas atual e habitual de um grupo, sempre e quando se planeje um período de tempo e número de dias adequado (FREUDENHEIM 1987). Segundo MARR (1971), o DA que inclui o uso de uma balança pode ser considerado um método de avaliaçăo bastante preciso, mas requer treinamento, esforço e muita vontade de colaboração, fatores que fazem com que seja pouco usado, pois é difícil manter as taxas de resposta que garantem a representatividade de uma amostra populacional.

Uma das limitações é a tendência de se modificar os hábitos alimentares, diminuindo o consumo de alimentos para ser mais simples o registro (MELA \& 
AARON 1997; JOHNSON et al. 1994). Outra limitação é que não pode ser usado em pessoas analfabetas. Este método requer uma constante supervisão para se constatar a compreensão das intrusões, 0 uso da balança e o correto preenchimento dos formulários, os quais terão que ser novamente revisados para constatar a qualidade da informação para posterior tratamento informático, fatos estes que elevam sobremaneira os custos das pesquisas.

O DA por estimativa do peso pressupōe menos incômodo para o indivíduo, porque, ao invés de se pesar os alimentos no momento do consumo, calcula-se o peso da porção consumida por estimativa. Este é o motivo que torna esta forma de aplicação do método preferida pelos pesquisadores. Cabe assinalar que uma característica importante é que, pelo fato de registrar a estimativa no mesmo momento do consumo, ele reduz ou "elimina" o viés da memória. Esta característica faz com que seja utilizado como método padrăo em estudo de validação (Mc PHERSON et al. 2000). Além das limitaçōes descritas para o DA por pesada, esta forma de aplicação adiciona o risco de erro da estimativa do peso.

Atualmente este método vem sendo utilizado com fitas magnéticas de reconhecimentos de voz (Audiotaping) como uma alternativa ao lápis e formulário em papel (Van Horn et al. 2000).

\subsubsection{Questionário de Freqūência alimentar.}

Está amplamente documentado, em numerosos estudos prospectivos internacionais, que o questionário de freqüência alimentar - QFA, é freqüentemente considerado como o mais prático e informativo método de avaliação da ingestão dietética e fundamentalmente importante em estudos epidemiológicos que relacionam a dieta com a ocorrência de doenças crônicas (SAMPSON 1985; OCKE et al. 1997; WILLETT 1994). 
O trabalho precursor dos questionários foi também desenvolvido por BERTHA BURKE, Universidade de Harvard, na década de 40. Este instrumento incluía uma lista de questóes agrupadas em uma detalhada entrevista de História Alimentar, que constava de: recordatórios de $\mathbf{2 4}$ horas, registro dos cardápios de 3 dias e uma lista de alimentos consumidos no último mês (BURKE 1947).

Durante a década de 60 foram estabelecidas as bases teóricas para as avaliações dietéticas por meio do QFA, que se fundamentam nos resultados de um grupo de investigadores britânicos, os quais afirmam que o consumo total de alimentos é determinado em primeiro lugar pela freqüência, a qual tem maior influência do que o peso dos alimentos consumidos (HEADY $1961 \mathrm{em}$ WILLETT 1994).

Na mesma época foram desenvolvidos QFA para os primeiros estudos de incidência de câncer. ABRAMSON et al. (1963) concluíram que o método de frequência alimentar pode ser usado em estudos epidemiológicos por ser uma ferramenta simples, econômica, e capaz de distinguir os diferentes padrões de consumo entre os indivíduos.

No final da década de 60 , desenvolveram-se os primeiros questionários de frequêencia alimentar com maior rigor metodológico. HANKIN et al. (1968), a partir de um banco de dados correspondente a 7 dias de diário alimentar, identificaram um total de 23 grupos de alimentos com suas respectivas porções médias. E, fazendo uso de análise de regressão múltipla (stepwise), os autores chegaram a equaçōes que explicaram 5 fatores dietéticos (energia, carboidrato, proteína, gordura e sódio). Neste estudo concluiu-se que, antes de se aplicar este método em outra população, é necessário identificar os alimentos e as porçōes em uma amostra populacional, para depois elaborar o 
instrumento. Anos depois, em 1973, foi recomendado entre os métodos de avaliação dietética pela "American Public Health Association" (ZULKIFLI \& YU 1992).

A partir desse momento, propõe-se 0 desenvolvimento de reprodutibilidade e validade, que comparam o QFA com múltiplos diários alimentares, R24hs ou marcadores bioquímicos.

Desses esforços, tem-se uma nova geração de instrumentos que foram empregados em muitos estudos de coorte na Europa e nos Estados Unidos (WILLETT et al. 1985; PIETINEN 1988a e b; RIMM et al. 1992).

O QFA foi desenhado para obter informação qualitativa ou semiquantitativa sobre o padrăo alimentar e a ingestão de alimentos ou nutrientes específicos. Conceitualmente, o método prevê a medição da exposição e sua relação com o tempo, de maneira que reflita características de como começa, quando termina e qual a sua dlstribuiçăo no período de intervenção (GIBSON 1990; ARMSTRONG et al. 1995).

O QFA possui basicamente dois componentes: uma lista de alimentos e um espaço, no qual o indivíduo responderá com que freqūência consome cada alimento. A lista é constituída pelo maior número possível de alimentos que aportam nutrientes à dieta (ZULKIFLI \& YU 1992). Quando se trata da elaboração de um questionário novo, a lista de alimentos pode ser obtida por meio de diferentes estratégias, desde a mais simples até a mais complexa, embora esta última seja sempre a mais apropriada.

Quando o objetivo da pesquisa é analisar um ou alguns nutrientes, a lista de alimentos pode ser elaborada a partir da identificação dos alimentos com 
maior conteúdo do nutriente em questáo. Os alimentos podem ser selecionados por meio de tabelas de composição de alimentos ou solicitando-se a assessoria de um especialista em nutrição. Esta forma de elaboração tem grandes limitaçōes, pois pode incluir alimentos importantes por seu conteúdo, mas pouco relevantes do ponto de vista de consumo pela população.

Quando o objetivo do estudo é estratificar os individuos segundo seu consumo, a lista de alimentos deve ser cuidadosamente selecionada para que os itens sejam o mais informativo possível. Os alimentos selecionados devem cumprir as seguintes características:

a) ser razoavelmente utilizado por uma proporçāo representativa de individuos;

b) apresentar o nutriente de interesse;

c) seu uso deve variar de pessoa para pessoa.

A lista pode ser completada com informações básicas ou procedentes de estudos epidemiológicos, onde se verifique a existência de associaçð̃es entre o consumo de um certo alimento e a presença de doença.

Depois de elaborada a lista, o instrumento terá que ser testado em estudo piloto para descartar os alimentos menos freqüentes. Este procedimento, útil e válido, pode conduzir à exclusão de alimentos importantes, devido ao fato de ignorar os alimentos com alta variabilidade de consumo interpessoal, isto é, alimentos mais informativos do que aqueles que se consome de forma similar (quantidade e freqũência) entre distintos individuos (JIMENES \& MARTINMORENO 1995).

Para contornar esta dificuldade, deve-se conduzir análise de regressão múltipla stepwise para cada nutriente, onde a ingestão total do nutriente é variável dependente. Neste procedimento, identificam-se os alimentos que 
explicam a maior variância interpessoal da ingestão do nutriente como variáveis independentes. A inclusão passo a passo dos alimentos e sua contribuição à ingestão total do nutriente se refletirão nas mudanças do $R^{21}$ (quanto mais próximo a $100 \%$ melhor). É desejável, portanto, acumular um $R^{2}$ de pelo menos $80 \%$.

Algumas precauçōes devem ser tomadas quando se usa esta técnica para desenhar um formulário do $\mathrm{QFA}$, já que alguns alimentos preditores, não importantes mas estatisticamente significativos, podem estar presentes na dieta. Isto pode acontecer porque, ocasionalmente, alguns alimentos têm uma contribuição modesta, não no sentido de predizer o conteúdo, mas porque estão correlacionados a outros alimentos ricos em determinado nutriente (exemplo: consumo de milho relacionado com colesterol, não pelo milho em si mas pela manteiga) (WILLETT 1998).

Existe ainda uma terceira abordagem, proposta por BLOCK et al. (1986), que é considerada talvez a mais apropriada. Esta consiste na obtençăo preliminar de uma lista não restrita de alimentos, que é gerada a partir da aplicação de vários recordatórios de $\mathbf{2 4}$ horas ou diários alimentares em uma população objeto de estudo. Esta estratégia, além de fornecer os nomes dos alimentos, proporciona também a descrição do tamanho das porções.

Este procedimento será descrito detalhadamente no capítulo de material e métodos, uma vez que é a técnica escolhida para o desenho do instrumento utilizado nesta pesquisa.

Um dos objetivos implícitos do QFA é conhecer o consumo habitual de 、 alimentos por um grupo populacional; neste sentido, a estrutura do instrumento contempla o registro da freqũência de consumo de alimentos em unidades de

\footnotetext{
${ }^{1}\left(\mathrm{R}^{2}\right)$ Coeficiente de determinação da reta , expressa a medida de precisão da inclinação da reta.
} 
tempo. Na maioria dos estudos observa-se que as dietas se correlacionam de ano para ano e, portanto, a unidade de tempo mais usada para estimar a freqũência de consumo de alimentos é o ano precedente, já que prevê um ciclo completo de estaçóes e as respostas poderiam ser independentes. Outros pontos a serem considerados para eleger a unidade de tempo são os aspectos fisiológicos da doença estudada, e do metabolismo do fator dietético que está sendo analisado.

O formato sugerido é o de perguntas simples e fechadas, com năo menos de 5 e não mais de 10 opções, deixando um espaço em branco para aqueles itens de alimentos que ultrapassam o consumo previsto. Este leque de opçōes produz uma grande e detalhada escala de freqũência, o que é importante, pois os alimentos consumidos menos de uma vez por semana podem ter pouca representatividade no total de nutrientes consumido (WILLETT 1998).

A inclusão da informação do tamanho de porção consumida dentro do QFA vem sendo um tópico muito discutido, pois autores encontram que a coleta desta informação não contribui significativamente para melhorar a validade dos QFAs (WILLETT 1998). Existem três formas possiveis de se apresentar os questionários: a primeira é a que prevê a coleta da informação sem a adiçăo do tamanho de porções, ou seja, um questionário simples (qualitativo). A segunda possibilidade é especificar o tamanho de uma porção de referência como parte da pergunta. Assim, por exemplo, a pergunta seria "com que freqüência uma xícara de leite é consumida?", ao invés de se perguntar "quantas vezes o leite é consumido?". Para alimentos que vêm em unidades -- como um ovo, uma banana, um pão -- esta especificação adicional pode proporcionar clareza à questão. A terceira possibilidade seria se incluir um espaço adicional para cada alimento, no qual o entrevistado descreveria o 
tamanho de porção usualmente consumida, normalmente com ajuda de instrumentos visuais.

Comparado com outros métodos, como o da História Alimentar ou o R24hs, o QFA requer menos especialização do entrevistador e pode ser aplicado em entrevista pessoa a pessoa, auto-administrado e enviado via correio. Estas vantagens se traduzem em baixo custo, fato que deve ser considerado importante no desenho de estudos epidemiológicos.

Entre as vantagens que oferece o QFA estão a rapidez da aplicação e a eficiência na prática epidemiológica para identificar o consumo habitual de alimentos. O QFA, comparado a outros métodos, substitui a medição da ingestão alimentar de um ou vários dias pela informação global da ingestão de um periodo amplo de tempo (JIMENES \& MARTIN-MORENO 1995).

O QFA oferece a possibilidade de uma correta estratificação dos resultados em quartis de consumo de nutrientes para análise de tendências de risco segundo ou grau de exposição e diferenças entre os níveis extremos da ingestão (WILLETT 1998).

Em contrapartida, o pesquisador necessita de um esforço preliminar no desenho do questionário antes de proceder a sua utilização no trabalho de campo. Listas pequenas de alimentos não avaliam corretamente e listas muito grandes favorecem a fadiga ou tédio.

É importante salientar que, para o sucesso de um estudo, não devemos perder de vista os objetivos que se pretendem atingir, assim como o contexto em que se desenvolverá a pesquisa, o tamanho da amostra, e as características étnicas e demográficas da população objeto do estudo. 
Para finalizar, o QFA pode ser uma ferramenta útil nos estudos epidemiológicos sempre e quando o desenvolvimento do método tenha sido precedido por procedimentos metodológicos cuidadosamente planejados, que posteriormente garantirāo maior confiabilidade e precisão dos dados. 
Existe um real desejo de que tenhamos melhor entendimento dos erros das informaçóes dietéticas e que melhoremos nossa abordagem para análise $e$ interpretacão. Nós precisamos fazer isso porque as análises dietéticas continuam a ser chave no entendimento das relaciós entre este aspecto principal de nosso ambiente e saride humana.

Beaton 1994

\subsection{Consumo diário, evento aleatório}


A característica central do consumo alimentar de um indivíduo ou uma população sadia é a variabilidade diária da dieta (WILLETT 1998). Ainda que os indivíduos tenham um padrão estável de consumo, não existem elementos de consistência, considerando-se, portanto, o consumo diário de alimentos como um evento completamente aleatório.

Existem fatores tais como o dia-a-dia, o dia da semana, a sazonalidade, entre outros, que contribuem para a variabilidade diária de uma maneira sistemática. Tais fatores, por sua vez, são potencializados por aspectos sócioculturais, econômicos e ecológicos, sem esquecer os aspectos relacionados com a agroindústria e disponibilidade no mercado, geralmente influenciada pelo desenvolvimento econômico do país.

A variabilidade depende de dois componentes: a variaçăo real dos alimentos consumidos pelos individuos, entendendo-se isto pela diversificação, heterogeneidade e flutuações da alimentação e as variações decorrentes do processo de medição ou mensuração.

Neste sentido, quando se fala de variação real de alimentos consumidos está se referindo a fonte de variação biológica. Ou seja, duas pessoas possuem características intrínsecas diferentes e uma mesma pessoa pode reagir diferentemente em ocasiões distintas (BERGAMASCHI 1999).

Entretanto, as variaçōes devido ao processo de mediçăo ou pelo componente medição podem ser causadas por falta de padronização dos instrumentos, falta de treinamento dos entrevistadores, falhas mecânicas, e também devido ao acaso, o qual desenvolve um papel muito importante durante este processo. 
A variação real vem sendo estudada em profundidade desde os anos 70 . BEATON et al. (1979), LUl et al. (1978) e SEMPOS et al. (1985), utilizando técnicas estatísticas de análise de variância, demonstraram que a variabilidade diária do consumo de nutrientes observada dentro de um grupo é composta essencialmente por duas fontes: a variação interindividual e a variação intraindividual, que inclui uma mistura de erros metodológicos. $\mathrm{O}$ primeiro autor afirma que a influência de outros fatores tais como a sazonalidade, dias da semana, seqüência, ou diferentes entrevistadores, explicam uma pequena proporção da variabilidade do consumo. Portanto, o consumo diário poderia ser explicado pelo seguinte modelo:

$$
\mathrm{Y}=\boldsymbol{\mu}+\text { indivíduo }_{\mathrm{i}}+\varepsilon
$$

$$
\begin{aligned}
& \text { Onde: } \quad \begin{array}{l}
Y=\text { consumo do nutriente } \\
\mu=\text { média de consumo } \\
\text { Individuo } i=\text { variância entre os indivíduos, } \\
\varepsilon=\text { termo erro que está representado pela variância intra } \\
\text { pessoal chamada também como resíduo. }
\end{array}
\end{aligned}
$$

Pode-se afirmar que os autores convergem em uma mesma afirmação, ou seja, que "a natureza variável da dieta" é a principal fonte de erro na estimação do consumo habitual, sendo que consumo habitual ou usual pode ser definido como a média de consumo sobre um período de tempo determinado (meses ou um ano), que costumeiramente é avaliado como a média de um número finito de dias (TARASUK \& BEATON 1992). Nesta mesma linha, LUI et al. (1978) consideram que, para o indivíduo, a média verdadeira de um fator é a média hipotética sobre a qual o indivíduo varia durante um período em que um padrão habitual de dieta é mantido. 
Todos esses estudos conduzem a se pensar que as estimativas do consumo alimentar não poderiam estar isentas de erros, sendo imprescindivel entender o "erro" como um conceito estatístico e năo no sentido de "equivoco" na coleta dos dados.

\section{Classificação dos erros}

Nos dados de consumo alimentar, pode-se reconhecer duas categorias de erros: erro sistemático (bias), e erro aleatório (random error).

Erro sistemático é aquele que tende a superestimar ou subestimar o que se pretende medir (intencional ou não intencional), provocando um viés no valor da estimativa, ocorrendo de forma sistemática e repetida uma diferença entre o valor medido e o esperado.

Erro aleatório é o valor médio de muitas medidas repetidas que se aproximam do valor verdadeiro. Em outras palavras, o erro aleatório é a fração de variaçăo que se produz em uma medida que não está relacionada aparentemente com nenhuma outra variável, que se considera produto do azar e representa uma diminuição na precisão do instrumento (WILLETT 1998; ARMSTRONG et al. 1995). Sabe-se que tanto o erro sistemático como o aleatório podem ocorrer de forma combinada, assim como em dois níveis: intrapessoal e interpessoal.

Segundo WILLETT (1998), o erro aleatório intrapessoalé caracterizado pela flutuação cotidiana na ingestão alimentar. Esta variação aleatória aparentemente deve-se tanto às mudanças na ingestăo de alimentos no dia a dia quanto aos erros na medição da ingestão em um dia qualquer. 
O erro aleatório interpessoal pode ser resultado de uma ou poucas medições por individuo na presença de um erro aleatório intrapessoal ou como conseqũência de um erro sistemático intrapessoal que está distribuído aleatoriamente em uma amostra (BEATON 1994). Neste sentido, afirma-se que os erros aleatórios entre os individuos que superestimam a informação de consumo se contrabalançam com aqueles que subestimam. Portanto, a média de um grupo grande de indivíduos pode ser considerada como a média verdadeira para o mesmo grupo. Por outro lado, o desvio padrăo para o mesmo grupo é exagerado (WILLETT 1998).

O erro sistemático intrapessoal ocorre particularmente quando são usados questionários padronizados: tanto um item pode ser omitido pelo questionário, quanto mal interpretado pelo individuo, o que se repetirá quantas vezes seja replicado o instrumento de medição naquele individuo.

O erro sistemático interpessoa/ resulta do erro sistemático intrapessoal que afeta os sujeitos de forma não aleatória. $O$ valor médio para um grupo de pessoas é, portanto, incorreto. Se o erro sistemático aplica-se igualmente para todos os sujeitos e é simplesmente adicionado, o desvio padrão observado é correto para esse grupo. Entretanto, se os indivíduos são afetados em vários graus, ou se o erro tem ação multiplicadora, o desvio padrão também será incorreto. Os erros sistemáticos interpessoais costumam ser freqüentes e ter muitas causas, dentre as quais destacam-se: a omissão de um alimento comumente consumido em um questionário padronizado ou o uso de tabelas incorretas de composição de nutrientes para um dado alimento, o que afetará todos os indivíduos na mesma direção, mas não no mesmo grau, já que o uso de dado alimento difere entre os indivíduos.

Neste sentido, a chave para um desenho e análise correta de um estudo epidemiológico nutricional não está somente na habilidade de descrever o 
consumo habitual e de caracterizar a natureza e a magnitude dos erros, mas também na capacidade de identificar o impacto dos mesmos na análise e interpretação dos resultados.

A variação intraindividual $\left(\sigma_{w}^{2}\right)$, isto é, erro aleatório, também pode ser definida como a variação do indivíduo com respeito a sua própria média.

Já a variação interindividual, denotada por $\sigma_{b}{ }^{2}$, é a variação verdadeira do consumo usual entre os sujeitos de uma população. Sabe-se, também, que o consumo é um fenômeno altamente individual, portanto a forma e amplitude dos padrões observados são características de cada indivíduo; isto é, dentro de um mesmo grupo a variedade de padrões é tremendamente grande, devido à presença dos fatores antes mencionados (ambientais, culturais e fisiológicos) (TARASUK et al. 1991a).

É amplamente demonstrado que a variação intraindividual atenua ou infla as estimativas da regressão e da análise univariada de variáveis com distribuição normal e tem efeitos na redução do poder dos testes estatísticos que relacionam dieta e saúde (LIU et al. 1978; LOZY 1983; ROSNER \& WILLETT 1988; FREUDENHEIM et al. 1989). Estes tópicos serão abordados mais adiante.

A respeito da média e distribuição em quantis

Em um estudo com mulheres adultas, FREUDENHEIM et al. (1987, 1989) observou que um, dois, três ou 7 dias de ingestão por pessoa podem permitir uma avaliação acurada das médias de um grupo, mas, não permite a classificação do consumo individual. A estimativa média do consumo de um grupo pode estar enviesada quando no consumo individual são detectados erros aleatórios (variância intrapessoal), o que se traduz em uma distribuição dos 
valores em torno da média exagerada. Nestes estudos, com modelos hipotéticos de análise, o autor demonstrou que, com sete dias de diário alimentar indivíduos estudados foram melhor classificados (52-76\%) nos quintis extremos quando comparados com aqueles que registraram um dia de diário alimentar $(43-67 \%)$.

\section{A respeito do coeficiente de correlação}

Segundo LUl et al. (1978), o coeficiente de correlação é freqüentemente usado para se medir associações entre duas variáveis. Portanto, se assumirmos que $\mathrm{X}$ e $\mathrm{Y}$ estão correlacionados, o coeficiente de correlaçăo $\rho_{x y}$ (medida linear de associação entre as médias verdadeiras de duas variáveis) do consumo habitual do fator dietético $(x)$ e o nível usual do fator de risco fisiológico $(y)$ (como por exemplo, gordura saturada da dieta e colesterol sérico, respectivamente), poderá ser afetado principalmente pela variância intraindividual, quando se tem um pequeno número de medições realizadas tanto em $x$ como em y. Neste sentido, para se obter uma correlação correta $\left(\rho_{\mathrm{T}}\right)$ é necessário considerar um termo de erro que indicará a influência deste componente de variação sobre a estimativa.

Quando x e y são afetados pela variação intraindividual, a relação entre a correlação correta $\left(\rho_{\mathrm{T}}\right)$ e a correlação observada pode ser escrita da seguinte maneira:

$$
\rho_{\mathrm{T}=} \rho_{0} \sqrt{ }\left(1+\lambda_{\overline{\mathrm{x}}} / \mathrm{k}_{\mathrm{x}}\right)\left(1+\lambda_{\mathrm{y}} / \mathrm{k}_{\mathrm{y}}\right)
$$

Onde:

$\lambda_{\mathrm{x}}=\sigma_{\mathrm{w}}{ }^{2} / \sigma_{\mathrm{b}}{ }^{2}$, isto é a razão entre intraindividual e interindividual de $\mathrm{x}$.

$\lambda_{y}=\sigma_{w}{ }^{2} / \sigma_{b}{ }^{2}$ para $y$

$\mathrm{k}_{\mathrm{x}}=$ número de medidas replicadas para cada indivíduo para variável $\mathrm{x}$

$\mathrm{k}_{\mathrm{y}}=$ número de medidas replicadas para cada indivíduo para variável $\mathbf{y}$. 
Se afirmarmos que só o fator dietético possui variação intraindividual, a equação pode reduzir-se a:

$$
\rho_{\mathrm{T}}=\rho_{0} \sqrt{ }\left(1+\lambda_{\mathrm{x}} / \mathrm{k}_{\mathrm{x}}\right)
$$

Nesta equação o termo erro decresce quando o número de medições por indivíduo ( $k$ ) é incrementado. Desta maneira, o erro introduzido pela ampla variação intrapessoal pode ser progressivamente reduzido aumentando-se as medições do fator dietético.

Outra solução segundo ROSNRES \& WILLETT (1988), para estimar a verdadeira correlação $(\rho)$ será se proceder à coleta de um número grande de medidas repetidas por cada indivíduo e usar as médias de $x$ e y para se aproximar ao valor verdadeiro $(\mu, x \mu, y)$ no cálculo do coeficiente de correlação. Para muitos fatores biológicos, a variaçāo intrapessoal é muito grande. LIU et al. (1979), demonstraram que 14 coletas de urina de 24 horas por sujeito seriam suficientes para se obter uma correlação entre o sódio de excreção urinária e a pressāo arterial.

\section{A respeito do coeficiente de regressão}

LIU (1988) e BEATON (1994), observaram que tanto a dieta como fatores bioquímicos de risco variam de tempo em tempo e, portanto, poderiam atenuar a associação entre duas variáveis. Na análise de regressão linear simples, a inclinação da reta é atenuada (tendendo a zero) pela presença do erro aleatório na variável independente $X$, e não na variável dependente $Y$. Não obstante, o erro de medição (parte do erro aleatório) em Y não atenuará o coeficiente de regressão $\left(\beta_{1}\right)$ de $X$, mas poderá reduzir 0 poder do correspondente teste estatístico para $\mathrm{Ho}_{0}: \beta_{1}=0$. 
Segundo o mesmo autor, na análise de correlação parcial e na regressão linear múltipla o impacto do erro é extremamente dificil de se medir. Isto pode explicar-se por que as variáveis de controle estạo geralmente correlacionadas com a variável independente. As variáveis de controle, que também possuem erros de medição, nem sempre atenuam o coeficiente de regressão mas, pelo contrário, podem inflar esta estimativa.

\section{A respeito da odds-ratio}

O efeito sobre a odds ratio - $O R$ e o risco relativo - RR é menos óbvio mas não deixa de ser importante. Em estudos realizados com poucos registros por indivíduos, a OR pode estar com viés (tendência à unidade); o erro de classificação devido ao uso de um dia de diário alimentar resulta na redução de aproximadamente $\mathbf{5 0} \%$ da estimativa, o que poderá ser melhorado na medida em que se incrementem mais dias no modelo. Neste tipo de análise, o significado do erro aleatório se dá em função de que um certo indivíduo pode estar colocado em um intervalo errado. Da mesma forma que nas outras análises, pode-se observar a atenuação da possivel associação e perigosas conclusões falso-negativas (BEATON 1994; WILLETT 1998).

\section{A respeito do poder do teste}

Também é necessário levar em consideração o erro aleatório intrapessoal em pesquisas que envolvam comparações de populações, como são os estudos de intervenção onde se compara um grupo de pessoas saudáveis com outro em condiçōes metabólicas controladas. Imagine-se uma situação hipotética em que se tenha que comparar dois grupos de pessoas categorizados em altos e baixos segundo seu consumo dietético de colesterol. Ambos os grupos possuem o mesmo número de pessoas e se conhece as médias $\left(\mu_{a} ; \mu_{\mathrm{b}}\right)$ e variância $\left(\sigma_{a}^{2} ; \sigma_{b}^{2}\right)$. 
Pelo fato de que a média verdadeira é estimada pela média por um número finito (k) de medidas (R24hs), o poder do teste dependerá de k.

As médias do consumo dos grupos alto e baixo, segundo o consumo de colesterol dietético, podem ser comparadas e estabelecidas diferenças. Neste sentido, se a variabilidade intrapessoal é grande e o número de medidas do fator dietético (colesterol da dieta) para cada indivíduo é pequeno, o poder desta comparação pode ser bastante baixo. Em outras palavras, a probabilidade de se rejeitar a hipótese nula da não diferença do fator dietético entre os dois níveis pode ser pequena, embora as diferenças verdadeiras sejam grandes e a hipótese nula seja falsa.

A importância de se conhecer as fontes de variação do consumo diário de alimentos e nutrientes deve ser considerada durante o planejamento e desenho de uma pesquisa. O principal uso destes componentes recai no planejamento do número de registros dietéticos e/ou mediçōes de parâmetros fisiológicos necessários para se obter estimativas exatas (van STAVEREN et al. 1986; HARTMAN et al. 1990), assim como na obtenção de correlaçōes corretas entre um único questionário de freqũência alimentar e o consumo médio verdadeiro através de um número maior de registros em um período de tempo amplo (ROSNER \& WILLETT 1988).

$\mathrm{Na}$ análise dos dados da ingestão usual existem outros aspectos não aleatórios que são observados e reconhecidos na variação intrapessoal. É uma prática comum incluir-se nas pesquisas dias de final de semana e dias de semana. Sabe-se, também, que estas diferenças derivam de padrōes sociais que promovem ciclos sistemáticos de comportamento alimentar dentro dos indivíduos (BEATON 1994). 
St. JEOR et al. (1983), HARTMAN et al. (1990) e TARASUK \& BEATON (1991a) identificaram fatores que influenciam o comportamento de ingestão de energia e observaram que os períodos de equilíbrio são resultado de mudanças durante a coleta de dados ou procedimentos do estudo e que padrões de comportamento semanal são afetados por padrões culturais.

Na mesma linha, TARASUK \& BEATON (1992) confirmam que, pela heterogeneidade dos padrōes de consumo, os dias de semana e de final de semana devem ser proporcionalmente amostrados. Os autores também assinalam que nem a magnitude nem a direção das variaçōes sistemáticas da ingestão de energia e nutrientes nos dias da semana são inteiramente consistentes entre os indivíduos de um grupo. No entanto, as análises deste estudo sugerem que existe um incremento sistemático no consumo de energia nos finais de semana.

Existem claras evidências de que estados fisiológicos, ou efeito biológico da doença, sintomas e os efeitos do tratamento podem influenciar a variação diária da ingestão de energia e nutrientes de um grupo de indivíduos (TARASUK \& BEATON 1991b; LISSENER et al. 1988; ARMSTRONG et al. 1995). Embora se tenha conhecimento da influência destes fatores, as interpretações dos resultados se vêem afetadas pela ausência de informação do estilo de vida e niveis de atividade durante a coleta dos dados.

Quando se trata de estimar o consumo usual de um indivíduo, é de grande importância se considerar as diferenças entre a coleta dos dados em dias consecutivos e não consecutivos. Porém, existem divergências sobre este assunto. HARTMAN et al. (1990) observaram uma aparente perda de informação quando usados dias consecutivos e MORGAN et al. (1987) encontraram resultados divergentes. As diferenças residem, segundo TARASUK \& BEATON (1992), na impossibilidade de se ter uma amostra completa de 
dias que representem o consumo de períodos prolongados de tempo. Para compensar esta dificuldade, BEATON (1994) sugere uma amostra aleatória de dias do período de tempo em questão.

O desenho de um estudo em epidemiologia nutricional dependerá do reconhecimento de que todos os métodos de avaliação do consumo alimentar possuem erros de estimativas e que é necessário identificar a natureza e magnitude dos erros, além de que tais erros procedem da metodologia empregada e dos indivíduos selecionados para o estudo. 
$O$ mais elegante desenho do estudo não superará $\sigma$ dano causado petas mediços falsas ou imprecisas.

(Fleiss 1986)

1.3 Medindo a exatidão de um instrumento de avaliação do consumo alimentar 
Os dados de consumo alimentar são coletados por várias razões, usandose uma ampla variedade de métodos e procedimentos. Tais informações são coletadas em pesquisas que têm como objetivo monitorar a dieta de um grupo de indivíduos, assim como avaliar as condições de saúde nutricional da população (GUENTHER et al. 1997).

Entretanto, os dados de consumo alimentar têm sido o principal impedimento na interpretação da associação entre dieta e doença. Segundo BLOCK (1982) e NELSON (1997), deve-se reconhecer que é impossível estimar o consumo alimentar sem erro, já que estes erros são inerentes aos indivíduos e ao método escolhido para se realizar a avaliação do consumo alimentar.

Sabe-se que a variabilidade da dieta depende de dois componentes: a variação real dos alimentos consumidos (já discutida anteriormente), e os erros de medição próprios do instrumento empregado, o que afetará diretamente a qualidade dos dados obtidos.

Os erros de medição, vistos como a principal fonte de viés nos estudos epidemiológicos, vêm estimulando o desenvolvimento de estudos metodológicos, chamados estudos de validação, que propiciam o entendimento entre o que se deseja medir e o que é realmente verdadeiro.

A validade se define como o grau com que um instrumento mede o que realmente se deseja medir. Diz-se, então, que uma medição é validada quando está livre de erros sistemáticos (VIOQUE 1995; WILLETT 1998). Portanto, estudos de validação estimam parâmetros estatísticos desconhecidos dentro de um modelo que especifica relações entre a medição da ingestão e o consumo verdadeiro (KAAKS et al. 1994) 
Os estudos de validação são o primeiro passo para se entender a dieta como fator de risco e são importantes no desenvolvimento de métodos de avaliação dietética como o são os QFA.

Os estudos de validação são processos longos e dificeis, nos quais as estimativas do consumo de alimentos ou de nutrientes pelo método escoihido "test method" - são comparadas com outro método de avaliação dietética julgado como mais exato e considerado como padrão de referência. $O$ procedimento de validação descreve a identificaçăo dos erros de medição e não o método do qual se derivam as medidas. A validação, portanto, considera o contexto dentro no qual o método será usado (NELSON 1997).

Quando se decide validar um instrumento, os propósitos da avaliação dietética e o marco de referência devem estar claramente definidos. Tendo claros os propósitos, pode-se eleger a técnica mais apropriada; e com o marco de referência bem definido, pode-se identificar fatores que irão confundir o processo de validação.

Neste sentido, é necessário considerar-se as seguintes recomendações, que têm como intenção ajudar os epidemiologistas no desenho e análise de estudos de epidemiologia nutricional, nos quais existam erros de medição na variável de exposição (BGA 1993).

\section{Dieta atual ou passada:}

Antes de se quantificar a dieta e o erro de medição, deve-se definir claramente o período de tempo e a intensidade da variável de exposição como determinante de risco. Por exemplo: na epidemiologia da obesidade, deve-se considerar de forma integrada o consumo de alimentos e nutrientes e o período mínimo de tempo de vida em que se desenvolverá a doença. 
Para isso, são necessários conceitos claros de dieta atual e dieta habitual, sobretudo em estudos que examinam o papel etiológico da dieta em algum tempo do passado.

Validar um QFA exige o questionamento e a definição do período de tempo no qual o processo de validação terá lugar. Os QFA avaliam o consumo usual em um período específico de tempo do passado. Teoricamente, para validar um instrumento como este se precisará de uma medida de referência que avalie o mesmo período relatado. Na prática, os estudos de validação têm mostrado que as estimativas de consumo do QFA são comparadas com as médias de consumo calculadas por várias mediçōes da dieta feitas por metodologias como DA e R24hs, distribuídas no mesmo período de avaliação do QFA (LOPEZ 1995).

Quando os resultados do questionário são comparados com poucos registros da dieta, a pouca concordância desta comparação pode ser explicada, segundo NELSON (1997), pela variância intrapessoal inerente às avaliações dietéticas de períodos curtos realizados por métodos mais exatos.

Consumo de alimentos vs. consumo de nutrientes:

Para um estudo de validação é necessário lembrar as evidências que a literatura traz a respeito do consumo de alimentos e nutrientes e sua relação com a prevenção ou o risco de algumas doenças (PETO et al. 1981). Isto poderá orientar na seleção dos alimentos que devem ser incluídos na lista de um QFA. No campo da nutrição, usualmente descreve-se a dieta em termos de conteúdo de nutrientes. Mas ela pode ser também descrita em termos de alimentos e grupos de alimentos, sobretudo na apresentação dos resultados. Ambas formas de abordagem apresentam vantagens e desvantagens. Segundo 
MERTZ (1984), a abordagem científica de se dividir os alimentos em nutrientes $\mathrm{e}$ estudar os efeitos sobre a saúde tem sido benéfica para 0 desenvolvimento dos seres humanos. Entretanto, esta abordagem apresenta 0 risco de substituir conhecimentos incompletos de nutrientes por lições aprendidas, fruto de experiências históricas com alimentos. Neste sentido, é necessário se adotar cuidados para não se chegar a conclusões erradas.

A relação de causalidade é forte quando se observa o consumo elevado de um determinado nutriente, principalmente quando se tem mais de um alimento fonte e particularmente quando as fontes se apresentam de maneiras diferentes (WILLETT 1996).

Em certo sentido, a associação pode ser confundida pela presença de outros nutrientes ou substâncias. Ou seja, mesmo que tenha sido observada uma associação somente com um alimento fonte, outros fatores contidos em tal alimento poderão ter relaçōes similares com a doença. Exemplo: a hipótese de que a ingestão de álcool causa câncer de mama foi reforçada pela observação não apenas da associação entre ingestão de álcool e câncer de mama, mas também por associações independentes com o consumo de cerveja e bebidas destiladas, fazendo com que seja menos provável que algum outro fator, além do álcool nestas bebidas, seja responsável pelo incremento do risco da doença (câncer de mama) (WILLETT 1998a).

Outras preocupaçōes a se considerar no contexto da validação são as inter-relaçőes que derivam dos padrões de comportamento dos indivíduos. Muitas relações recíprocas emergem do uso de alimentos típicos - consumidores de margarina tendem a não comer manteiga e usuários de pão integral consumirão pouco ou nada de pão branco. Por isto, é recomendável calcular-se a ingestão de nutrientes dos vários grupos de alimentos. 
A escolha do método de referência mais adequado:

Quando do desenho de um estudo de validação, deve-se levar em consideração dois aspectos: avaliar quanto é bom o método para se estimar o consumo e a correção dos erros de classificação dos indivíduos de acordo com sua ingestão. Para estimar a exatidão será necessário comparar o método a ser testado (QFA) com outro método (referência) que se julgue superior. Idealmente, o método de referência deverá ser essencialmente diferente e, se possível, conter erros independentes, ou seja, erros não correlacionados com os erros do QFA (BGA 1993; WILLETT 1998).

Sabe-se que a maior fonte de erros relacionados ao QFA deve-se a: restrições impostas por uma lista fixa de alimentos, memória, percepção das porçōes e interpretaçăo das perguntas. Caso se tivesse que eleger um método de referência, a primeira escolha seria o "DA", pois é um método que não depende da memória e os alimentos consumidos são diretamente pesados. Portanto, diminuiriam os erros de percepção e interpretação.

Em situações onde a população é analfabeta, tem baixa participação ou pouca motivação, múltiplos R24hs são uma opção razoável. Neste caso, os erros provavelmente estarão parcialmente correlacionados, pois ambos os métodos dependem da memória e da percepção das porções consumidas.

Muitos estudos de validação fazem uso de indicadores bioquímicos e isótopos com o intuito de utilizá-los como "padrão ouro" (BLACK et al. 1993; PRENTICE et al. 1985). As principais desvantagens são que tais procedimentos são extremamente caros e avaliam um nutriente de cada vez. Mas, por outro lado, devido ao fato de possuírem erros independentes, garantem e robustecem a precisão do método de referência (WILLETT 1996). 
Segundo NELSON (1997), existem três fontes de erros quando se comparam os resultados da avaliação dietética com parâmetros bioquímicos de referência:

1. existe diferença entre a avaliação dietética e o consumo verdadeiro;

2. os processos de digestão, absorção, utilização, metabolismo, excreção, mecanismos homeostáticos, podem ter efeitos sobre a relação entre a quantidade ingerida e a medição bioquímica;

3. existem erros associados com o próprio ensaio bioquímico (HUNTER 1998).

Em certas circunstâncias, este tipo de metodologia é muito útil, sobretudo quando o método de referência depende de tabelas de composição incompletas. Um exemplo claro é o uso da excreçăo de sódio urinário para avaliar o consumo de sal dos alimentos.

Seqüência de administração dos métodos:

Os estudos de validação implicam na administração de mediçōes repetidas no espaço e períodos de tempo apropriados. Este é um tópico importante durante o delineamento do estudo, pois é possivel que a coleta de dados por um método influencie as respostas do outro. NELSON (1997) sugere que o QFA seja administrado antes que o método de referência, por dois motivos: o primeiro é que os indivíduos participantes da pesquisa se encontram independentes de qualquer outra avaliação dietética que poderia influenciar o procedimento de validação. $O$ segundo é que $o$ ato de preencher os formulários do método de referência poderá direcionar a atenção a suas próprias dietas. Por outro lado, se o QFA é preenchido depois do método padrão, os indivíduos poderão modificar suas respostas. Uma forma de solucionar este problema seria que os participantes da pesquisa respondessem simultaneamente a ambos os métodos (WILLETT 1998). Uma correta 
sequeência, tanto do método padrão como do QFA, permitirá o conhecimento da confiabilidade.

Número de pessoas necessárias para um estudo de validação:

O que a literatura traz a respeito deste assunto tem sido mais ou menos arbitrário. A seleção apropriada do número de participantes necessários para um estudo de validação pode ser calculada seguindo a proposta de WILLLETT 1998), que se baseia em uma fórmula padrão², na qual se usa transformação de $Z$ de Fisher.

Em geral, poucos indivíduos são necessários para se obter alto grau de validade. Recomendam-se estudos entre 100 a 200 pessoas, pois estudos com mais de 200 pessoas contribuiriam com pouca precisão para se ter um intervalo de confiança correto. Já estudos de validade com menos de 30 pessoas aumentariam a amplitude do intervalo de confiança. Documento mais recente, produto de uma jornada de trabalho, recomenda uma amostra ainda menor, entre 50 e 100 pessoas para cada grupo demográfico (BURLEY \& CADE 2000).

Número de mediçōes necessárias para um estudo de validação:

Outro aspecto a se considerar é o número de mediçōes necessárias (método referência). Segundo as consideraçōes abordadas anteriormente, o número de dias necessários para se descrever a dieta habitual estaria entre $14 \mathrm{e}$ 28 dias sobre o perfodo de referência. Esta situação pode ser substituída por um pequeno número de mediçōes (por exemplo, 2 R24hs) combinados com ajuste estatístico para remover os efeitos da variabilidade intrapessoal. Estudos

$2 n=(Z \alpha+Z \beta) 2 \sigma^{2} / d^{2}$ 
de DONNER e ELIASZIW (1987), STRAM et al. (1995) e CARROLL et al. (1997) confirmam que, com 2 ou até 5 medidas repetidas, pode-se obter adequados coeficientes de correlação. Esta abordagem é muito útil em termos econômicos ou quando se observa alteraçōes no comportamento alimentar da população.

\section{Consideraçōes estatísticas:}

Segundo o BGA (1993), tanto a ciência da nutrição como da estatística sāo necessárias para se analisar, interpretar e validar um método de avaliaçăo dietética.

Neste sentido, a comissão recomenda que nutricionistas e estatísticos trabalhem juntos, principalmente porque, para se entender validação, é necessário identificar e definir erro de medição. Segundo PÉREZ (1995) os erros de medição podem ocorrer em qualquer fase do estudo:

- durante o desenho do instrumento;

- por omissão no protocolo para uso do instrumento (instrumento pouco detalhado);

- por fraca execução do protocolo durante a coleta dos dados (influência da idade, sexo, raça, etc. do indivíduo que responde);

- por limitaçōes devido às características dos sujeitos (memória fraca para exposição passada);

- erros durante o processamento e análise dos dados.

A prática nos mostra que existem também outras formas de erros, de particular interesse. Os erros diferenciais da medição diferem dos anteriormente mencionados, pois estão associados à doença. Estes erros são próprios do viés 
da memória. É o que ocorre, por exemplo, quando alguns dos sujeitos reportam a exposição diferentemente de outros, porque têm conhecimentos sobre a enfermidade. Estas fontes de erros incluem:

- efeitos biológicos da doença ou do tratamento;

- efeitos dos sintomas na fase de pré-diagnóstico da doença;

- a consciência do risco da doença.

O erro de mediçăo da exposição, neste caso a dieta, pode ser definido como a diferença entre a exposição medida e a verdadeira exposição (ARMSTRONG et al. 1995).

Modelo do erro de medição:

Um simples modelo de erro de medição na população pode ser:

$$
X_{i}=T_{i}+b+E_{i}
$$

Neste modelo, a medida observada $\left(X_{i}\right)$ para um dado indivíduo $i$ difere do valor verdadeiro $\left(T_{i}\right)$ para o mesmo indivíduo, como uma conseqũência de dois tipos de erros de medição: o primeiro é o erro sistemático ou viés " $b$ ", 0 que poderia ocorrer em média para todos os sujeitos medidos; o segundo tipo

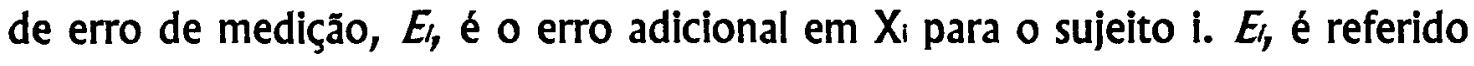
como erro aleatório intrapessoal para indicar que ele varia de indivíduo para indivíduo (ARMSTONG et al. 1995; KAAKS et al. 1994). 
Figura 1 : Erro de medição na medida da exposição $X_{1}$

$$
X_{i}=|\underbrace{T_{1}}_{\text {Vator verdaditio }}|
$$

Neste modelo, o erro de mediçăo se expressa por uma constante $b$, que difere de zero (0). Por conseguinte, a média populaclonal do erro individual, $\mu E$, é igual a zero (0).

A tabela 1 mostra um exemplo do que pode ser observado em uma amostra.

Tabela 1. Exemplo de erro de mediçăo usando balança portátl para pesar mulheres idosas em um estudo de peso e fratura de quadril (extraído de Armstrong et al. 1995)

\begin{tabular}{lllll}
\hline & 1 & Individuos & & \\
\hline$X_{1}(\mathrm{~kg})$ & 61 & 2 & 3 & $4 \ldots$ \\
\hline$T_{1}(\mathrm{~kg})$ & 59 & 50 & 70 & 63 \\
\hline Erro de medicso & 2 & 52 & 69 & 60 \\
\hline$b$ ou viés & 1 & -2 & 1 & 3 \\
\hline
\end{tabular}

$\mathrm{Na}$ tabela, $\mathrm{X}$ /representa a medida observada; a verdadeira exposiçăo, $\mathrm{T}$, é a média de pesos obtidos em um período de 5 anos; e o Erro de mediçăo está dividido em dois componentes: o erro $b$, ou erro sistemático e $E$ erro individual. Neste exemplo, o viés $(b)$ em $X$, é de $1 \mathrm{~kg}$, o qual afeta a todos os individuos da mesma maneira. A fonte deste erro poderia ser explicada por uma balança mal calibrada. Já no erro individual acontecem mecanismos aleatórios, tais como as flutuações da hora ou o dia em que os individuos foram pesados ou a leitura errada do peso pelos entrevistados. 


\section{Medidas de Validade:}

A validade da medição da dieta obtida por diversas metodologias é usualmente estudada pela avaliação da concordância em relaçăo ao método de referência. Várias são as propostas existentes que avaliam as medidas de concordância. Dentre elas, as mais usadas e recomendadas são: a comparação de médias (diferenças entre o grupo de médias ou as diferenças entre as medições dentro dos individuos), análise de correlação (os coeficientes de correlação de Pearson, Spearman e intraclasse) e a distribuição comparativa por quartis, quintis etc. da ingestão de nutriente.

A primeira proposta é a do viés ou da média do erro de medição na população, que é a diferença entre a média da população de $X$ (valor observado) e a média da população de $\mathrm{T}$ (valor verdadeiro) .

Neste caso, a comparação entre o QFA e o método de referêncla será melhor examinada usando-se o teste - $t$ emparelhado, com prévia transformação logarítmica, se for necessário. Os resultados desta análise se expressarão em termos de subestimação ou superestimação do consumo de nutriente.

Em estudos de validação em que o objetivo é se comparar a medida do método testado $X_{i}$ com o que é considerado padrão ouro (valor verdadeiro, $T_{i}$ ) a medida utilizada de exatidăo utilizada é a correlaçăo de $T$ com $X$ ( $\rho T x)$, chamada de coeficiente de validade de $X$. No modelo a seguir, pode-se mostrar que a raiz quadrada de $\rho r x$ é 1 menos a razão da variância de $\mathrm{E}$ com a variância de $X$. 


$$
\rho^{2} T X=1-\frac{\sigma^{2} E}{\sigma_{x}^{2}}=\frac{\sigma^{2} T}{\sigma^{2}}
$$

$\rho \tau x$ é também uma proporção da variância de $X$ explicada por T. $O$ valor da $\rho т x$ pode estar entre 0 e 1 . Portanto, 1 indicará que $X$ é uma medida perfeitamente exata do valor $T$; mas quando $\rho \tau x$ é próximo a zero (0), pode-se afirmar que $X$ está gradativamente correlacionado com $T$. Em outras palavras, quanto mais próximo de 1 melhor, pois a $\sigma^{2} \mathrm{E}=0$

No exemplo da tabela 1 encontramos que o viés é a diferença entre a média populacional de $X$ e a média populacional de $T$, sendo esta diferença igual a $1 \mathrm{Kg}$. Neste caso, a precisão pode ser explicada como uma medida de correlação entre as variáveis $\mathrm{T}$ e $\mathrm{X}$. Suponhamos, $\rho r x=0.8$. Isto significa que somente $64 \%$ da variância em $X(0.8)^{2}$ é explicada por T. O resto da variância existe devido ao erro.

O coeficiente de correlação é um valor limitado, pois descreve só um aspecto da concordância. Em outras palavras, o coeficiente de correlação reflete a relação de aproximação linear entre ambos os métodos dentro de uma população específica.

Segundo NELSON (1997), quando os coeficientes de correlação são baixos se incrementa o número de pessoas mal classificadas no topo ou nos extremos da distribuição do consumo. Isto pode ser demonstrado quando a sensibilidade do questionário é pobre ou limitada para demonstrar a existência da associação dieta-doença, porque muitos indivíduos estão incorretamente classificados. Significância estatística do coeficiente de correlação $(p<0.05)$ 
somente indica a improbabilidade de ser igual a zero, o que não se estende para a concordância entre as duas medições.

Finalmente, os indivíduos podem ser classificados de acordo com a sua posição na distribuição das mediçōes em tercis, quartis ou quintis. A validaçāo pode ser feita em forma de comparação entre as classificações de acordo com os valores obtidos do QFA e do método de referência. Se há uma concordância perfeita entre os métodos, todos os indivíduos serão classificados na mesma fração da distribuição (topo, meio, cauda) segundo ambos os métodos.

Concordâncias perfeitas podem ser mostradas, porque $100 \%$ da população caiu na mesma categoria e $0 \%$ na categoria adjacente ou no quartil oposto.

Segundo ARMSTRONG (1995), o erro de medição não é uma propriedade inerente a um instrumento e sim uma propriedade de um instrumento aplicado de uma maneira particular em uma população especifica. Por tal razão, o erro pode variar não somente entre dois instrumentos que medem a mesma exposição, mas também em um único instrumento quando aplicado de forma diferente ou aplicado em diferentes grupos populacionais.

A terminologia usada para erro de medição da exposição difere segundo as áreas de conhecimento. Usa-se validade e acurácia como termos que descrevem a exatidão de $X$ como medida de $T$. No entanto, segundo ARMSTRONG (1995) ambos incluem conceitos de viés e precisão. 
No processo de busca dos fatos são mais importantes $\sigma$ desenvolvimento e a perfeicão dos métodos de obtenção de dados do que as técnicas de manuseio das mesmas. (Hills 1953)

\subsection{Questionário de freqüência alimentar para adolescentes. Um exemplo prático.}


Quando se aborda o tema alimentação da criança e do adolescente, não se pode deixar de analisá-lo dentro de uma conjuntura histórica, geográfica e social. Transformações importantes vêm ocorrendo nos últimos anos na região da América Latina, as quais são acompanhadas por mudanças epidemiológicas e nutricionais que caracterizam e definem o estado de transição conhecido e documentado por OMRAN (1971), POPKIN (1993), POPKIN et al. (1993) e OPAS (2000).

Sociedades modernas e industrializadas parecem convergir em um padrão dietético de alto conteúdo de gorduras totais, colesterol, açúcar, alimentos refinados, baixo teor de ácidos graxos insaturados, baixo teor de fibra, padrão que é denominado "dieta ocidental" e que se encontra freqüentemente ligado ao aumento de uma vida sedentária (MONTEIRO et al. 1995a).

Embora continuem prevalecendo os problemas de desnutrição na América Latina, onde aproximadamente $11 \%$ da populaçăo infantil menor de 5 anos sofre de desnutriçáo energética protéica, as condiçōes de saúde das Américas vêm sofrendo mudanças (WHO 1995). Existem evidências de alterações da estrutura da dieta. Segundo POPKIN (1994), citado em MONTEIRO et al. (1995b), as coortes mais jovens estão mudando mais rapidamente $e$, portanto, o predomínio da dieta ocidental e $o$ aumento da obesidade tendem a crescer.

Segundo a OPAS (1994), verificam-se mudanças no padrão de morbimortalidade em que predominam as doenças cardiovasculares, câncer e outras enfermidades crônicas não transmissiveis (ECNT). Cita-se, como exemplo, que ao comparar os anos 1975 e 1985 na América Latina se observou um incremento relativo da mortalidade proporcional, em especial das doenças cardiovasculares, as quais passaram de 27/1000 habitantes a $34 / 1000$ habitantes. 
Neste panorama de transição (incremento relativo das ECNT associadas à dieta e persistência de doenças infecciosas e desnutrição) chama atenção as prevalências da obesidade infantil e de adultos no Brasil. Publicação recente de MONTEIRO (2000) assinala que, embora a prevalência de crianças obesas tenha permanecido inalterada no período de 15 anos (1974 - 1989), a proporção de adultos obesos quase duplicou, passando de $5,7 \%$ para $9,6 \%$. Em relação aos resultados das crianças, estes dados, quando analisados segundo os distintos estratos sócio-econômicos, indicaram, em ambas pesquisas, que à medida que aumentam as rendas familiares diminui a desnutrição e aumenta a obesidade. Já nos adultos, observou-se nos três segmentos de renda um aumento da obesidade em ambos os sexos, tendendo a ser maior nas familias com menos recursos materiais.

Segundo OPAS \& OMS (1995) e UAUY (1999), a prevenção da obesidade e co-morbidades pode e deve aplicar-se em todas as etapas do ciclo vital, começando pela concepção para garantir uma nutrição adequada e prevenir futuras complicações na vida adulta e também no primeiro ano de vida, onde lactância natural e alimentação complementar são decisivas para a saúde futura. Mas especial atenção deve ser dada à adolescência, tanto na avaliação nutricional como no monitoramento de suas necessidades (SPLETT \& STORY 1991), por ser um período vulnerável e sensível a fatores relacionados com a alimentação e nutrição. Sabe-se que estes fatores são de diversas índoles e dependem das complexas interações entre as necessidades nutricionais, fatores ambientais e valores sociais do consumo de alimentos, além da atividade fisica (HIMES \& DIETZ 1994).

FISBERG et al. (2000) afirmam que o comportamento alimentar do adolescente está fortemente influenciado pelos hábitos familiares, mas também está vinculado a hábitos e costumes do grupo etário e à crescente preocupação com a imagem corporal. Algumas características observadas: omissão de uma 
refeição (especialmente café da manhã), consumo de alimentos altamente energéticos e pobres em nutrientes, início do consumo de bebidas alcoólicas e tendência a fazer restrições dietéticas, fatores que podem levar à obesidade e, em alguns casos, à anorexia nervosa.

Neste sentido, a avaliação exata do consumo alimentar de crianças e adolescentes é de grande preocupação, porque a formaçăo de hábitos alimentares inadequados pode ser potencial fator de risco para ECNT (OPS \& OMS 1995).

Estudos longitudinais com adolescentes em nosso meio são limitados e a grande maioria das pesquisas são de delineamento transversal, pequenas e de amostras não representativas, as quais têm como objetivo avaliar o estado nutricional por meio de indicadores antropométricos (BONILHA \& EGASHIRA 1999; PRIORE \& SIGULEM 1999).

Estudos como os de NUZZO (1998), DUNKER (1999) e SILVA et al. (1999a e b) utilizaram DA ou R24hs para avaliar o consumo de alimentos de forma quantitativa. As metodologias usadas nestes estudos são conceitualmente aceitas como provedoras de informação válida sobre a dieta atual.

Entretanto, somente o estudo de GAMA (1999) realizado em escolas da rede estadual e particular de ensino em um bairro da cidade de São Paulo, apresenta o uso do QFA para avaliar o consumo alimentar de adolescentes, cabendo salientar que o instrumento utilizado nesta pesquisa não foi validado.

A validade dos QFA vem sendo analisada em vários estudos desde a década de oitenta. A grande maioria dos pesquisadores conclui que QFAs são confiáveis e razoavelmente acurados para descrever o consumo habitual de homens e mulheres adultas. (WILLETT et al. 1985; PIETINEN et al. 1988a e 
b; RIMM et al. 1992; MARTIN-MORENO 1993; MARGETTES \& PIETINEN 1997)

No âmbito internacional, poucos estudos de validação têm sido conduzidos em crianças e adolescentes. O estudo de TREIBER et al. (1990) com parentes de crianças entre 3 e 5 anos, mostrou que o QFA estimou valores de energia significativamente maiores do que os obtidos pelo recordatório de 24 horas. Já o resultado do estudo de confiabilidade (Testereteste de confiabilidade) computado entre a primeira e segunda visita, mostrou coeficientes de correlação entre $r=0,42$ a $r=0,83$ para todas as categorias dos nutrientes analisados. Os autores concluem que, se o estudo de validação fosse bem sucedido, o QFA poderia ser usado em estudos epidemiológicos.

O estudo de LIVINGSTONE et al. (1992), utilizando a metodologia da água duplamente marcada - ADM (avalia o gasto total de energia), como método de referência, sugere que o método de história alimentar superestimou - consumo de energia de crianças de 3, 7 e 12 anos em, aproximadamente, $15 \%$. Nos outros grupos etários $(5,9,15$, e 18 anos) as diferenças entre ambos os métodos não foram significativas.

FRANK et al. (1992), comparando um QFA e 7 R24hs, encontraram altas porcentagens $(96 \%)$ de concordância entre ambos os métodos, sobretudo para alimentos de grande preferência (margarina, maionese, pão, balas e panquecas). Por outro lado, em alimentos como frango, bife e algumas bebidas, as porcentagens de concordância se situaram entre $26 \%$ e $40 \%$.

GALLAGHER et al. (1993) testaram a validade de um QFA de 35 itens alimentares desenhado para avaliar o consumo alimentar de adultos e adolescentes. O estudo demonstrou que o QFA foi capaz de identificar os 
padróes alimentares tanto dos adolescentes quanto dos adultos. Os adolescentes diferenciaram-se dos adultos pelo seu consumo de frutas, vegetais e açúcar; já os adultos, pelo consumo de álcool

Crianças de 4 a 6 anos estudadas por KASKOUN et al. (1994), superestimaram em $53 \%$ seu consumo de energia obtido por QFA (Média $=2,145 ; \mathrm{DP}=535 \mathrm{kcal} / \mathrm{dia}$ ) e $53 \%$ quando comparado ao total do gasto energético obtido pelo método água duplamente marcada (Média $=1403 ; \mathrm{DP}=276 \mathrm{kcal} / \mathrm{dia} ; P<0,001$ ). Os pesquisadores afirmam que as diferenças encontradas não foram significativamente influenciadas pelo gênero, pela composição corporal e nem pelas características da composição corporal dos pais.

Embora não seja um estudo de validade e sim de reprodutibilidade, FRAZIER et al. (1995), realizaram um estudo para avaliar a dieta e o consumo de álcool de adolescentes dentro do conhecido estudo de coorte em mulheres. (Nurses ' Health Study - NHS). Em 1994 foram sorteadas aleatoriamente 257 mulheres que tivessem 40 anos no momento da pesquisa (1986) e que responderam os QFA durante 1986 e 1988.

Tanto no primeiro momento (1986), como em 1994 estas mulheres tiveram que reportar seu consumo alimentar e de álcool durante o período escolar e um QFA composto por 25 itens alimentares, chamado de QFA-R. O objetivo do estudo foi avaliar a confiabilidade da memória do passado distante, portanto as participantes tiveram que lembrar seus consumos quando tinham entre 13 e 18 anos de idade. Os resultados mostraram uma correlação média $r=0,57$ entre os 2 QFA-R de alimentos consumidos durante a escola ( 25 itens de alimentos) e de $r=0,25$ quando comparado o primeiro QFA-R em 1986 e a dieta atual no mesmo ano. Este estudo chega à conclusão de que a idade não afeta a reprodutibilidade das respostas e, portanto, pode-se utilizar QFA em 
estudos epidemiológicos onde se relacionem o consumo alimentar remoto e presença de alguma doença.

O estudo publicado por ROCKETT et al. (1995), o qual teve como premissa que o processo cognitivo de crianças acima de 10 anos é similar ao dos adultos, mostrou que o QFA desenhado para crianças e adolescentes pode ser usado no ambiente escolar e na comunidade. A reprodutibilidade variou entre 0,26 para proteína e 0,58 para cálcio e ferro, verificando-se uma média de reprodutibilidade maior entre as meninas, em comparação com os meninos.

Um estudo de validação de um QFA em adolescentes noruegueses encontrou correlaçōes entre $r=0,63$, para porcentagem de energia derivada do consumo de açúcar, e $r=0,91$ para álcool. $O$ coeficiente mediano foi de $r=0,85$ e as diferenças medianas entre os dois instrumentos foram geralmente mais altas para as meninas do que para os meninos. Os autores concluem que 0 QFA é um instrumento capaz de classificar os individuos de acordo com os nutrientes avaliados, com exceção de vitamina D e fibra (ANDERSEN et al. 1995).

Em 1998, foi validado um breve QFA para avaliar o consumo de cálcio de crianças de 3 a 6 anos de idade. Os resultados da comparação do QFA e a média de 4 dias de diário alimentar demonstraram que o QFA superestimou o consumo de cálcio das crianças em $144 \mathrm{mg}$ (IC $95 \%=57$ - 232) mas, por outro lado, demonstrou bom desempenho para classificar os indivíduos nos quartis extremos do consumo de cálcio por ambos os métodos (TAYLOR \& GOULDING 1998).

Um total de 101 mulheres grávidas entre 14 e 43 anos, da cidade de Massachusetts, foram participantes de um estudo com o propósito de testar a validade de um QFA para avaliar 25 nutrientes. As participantes responderam 
a um QFA e 3 dias de diário alimentar, no periodo de um mês. Os resultados deste estudo encontraram uma correlação média de 0,47 , sendo que $54 \%$ dos coeficientes estavam acima de 0,40 (antes e depois do ajuste pela energia e após a correção pela variância), embora o estudo mostre correlações baixas para o caroteno $(r=0,28)$ e para a vitamina B12 $(r=0,07)$. (WEl et al. 1999)

Como pode-se observar na epidemiologia nutricional, o estudo de validação de instrumentos de medição, especialmente para questionários de freqüência alimentar, é um passo importante que ajuda ao pesquisador a compreender e analisar melhor os resultados de consumo alimentar.

Embora de suma importância, em nosso meio são ainda escassos os trabalhos realizados com este tema. Contamos com os trabalhos de CARDOSO et al. (2001), FORNES et al. (2000) e de SICHIERE (1998), realizados com adultos e inseridos em estudos que pretendem relacionar os fatores dietéticos a um certo agravo da saúde. Por outro lado, são inexistentes trabalhos que envolvam adolescentes.

Imersas em um processo de transiçāo epidemiológica nutricional, as sociedades industrializadas manifestam quadros de morbimortalidade: ECNT, enfermidades infecciosas, violência e uso de drogas. É neste contexto que se observam mudanças na composição da dieta. Neste sentido, o comportamento alimentar do adolescente é extremamente importante, pois o indivíduo está influenciado por fatores ambientais, familiares, sócio-culturais e estilo de vida que poderão conduzí-lo a uma alimentaçāo distorcida, que tem conseqüências sobre sua saúde atual e durante sua vida adulta.

O decorrer da obesidade desde a infância até à vida adulta, o risco de padecimento de ECNT e a inexistência de dados sobre o consumo alimentar de 
adolescentes levaram a uma pergunta: o que os jovens da cidade de São Paulo consomem? Obtiveram-se respostas, mas todas elas derivadas de pequenas pesquisas, das quais não se pode fazer nenhuma inferência. Foi a partir deste questionamento que surgiu a idéia de uma futura pesquisa com o intuito de se monitorar a dieta e verificar se esta tem efeitos sobre mudanças da composição corporal. Considera-se que, a partir de pesquisas de base populacional, poderão surgir medidas preventivas necessários ao controle da obesidade. A literatura tem mostrado que, à medida que um maior número de indivíduos se torna obeso na infância, cresce a preocupação no sentido de que a obesidade possa se tomar um problema de saúde. Entretanto, o problema pode ser solucionado, já que a maioria dos fatores relacionados à obesidade săo suscetíveis de intervençōes.

Mas para isto acontecer são imprescindiveis instrumentos capazes de avaliar corretamente o consumo alimentar. Neste sentido, considera-se que é necessário desenvolver estudos que possibilitem o desenvolvimento de instrumentos que realmente meçam o consumo com suficiente validade $\mathrm{e}$ confiabilidade.

Pelo exposto, este estudo tem o propósito de desenvolver e avaliar a exatidão do questionário de freqūência alimentar para adolescentes (QFAA), que será utillzado em futuro estudo o qual pretende avaliar os padrões alimentares e sua relação com estilo de vida e saúde dos adolescentes. 
2. OBJETIVOS 
1. Desenvolver um questionário de freqüência alimentar adequado para estudos epidemiológicos com adolescentes.

2. Determinar a validade relativa das estimativas do consumo de energia e nutrientes do Questionário de Freqüência Alimentar para Adolescentes (QFAA) por meio da comparação dos valores obtidos entre o QFAA e os Recordatórios de 24 horas.

3. Categorizar os indivíduos segundo seu consumo habitual de energia, proteína, carboidrato, lipídio total, lipídio insaturado, fibra, colesterol, vitamina A, vitamina $C$, cálcio e ferro. 
3. CASUÍSTICA E MÉTODOS 


\subsection{DELINEAMENTO DO ESTUDO}

O delineamento desta pesquisa corresponde a um estudo metodológico realizado em duas fases: a primeira, o desenvolvimento da estrutura do QFAA e a prova piloto; e a segunda, o estudo de validaçăo.

\subsection{INSTRUMENTOS DE AVALIAÇĀO DO CONSUMO}

\subsubsection{Método de Referência - Recordatório de $\mathbf{2 4}$ horas.}

O R24hs foi eleito como método de referência por ser rápido, simples e interferir menos nos hábitos alimentares das pessoas, além de, quando usado repetidas vezes, poder estimar a ingestão habitual (MAJEM 1995). Estudos populacionais em adolescentes que utilizaram Diário Alimentar relatam que a principal falha deste método é o baixo índice de devolução do formulário, refletindo assim pouca adesão ao método. Por esta razão, optou-se pela utilização do R24hs proposto por DUNKER e PHILIPPI (1999), o qual é aplicado em grupos e preenchido pela própria pessoa (Anexo1).

Para sua aplicação foi necessária a presença do pesquisador no local, para as devidas orientaçōes sobre o preenchimento. Para se obter um melhor registro das quantidades, foi necessária a utilização de um "Kit" de utensílios e medidas caseiras, os quais foram mostrados antes de se começar o registro da informação e durante o registro, quando solicitado pelo aluno.

Cada participante foi avaliado por este método pelo mesmo entrevistador em 4 momentos, com intervalos de 45 dias aproximadamente, durante um período de 6 meses. 
Os alunos registraram seu consumo dos alimentos separadamente, seguindo a ordem das refeições principais, incluindo a primeira refeição pela manhã, até a última, antes de dormir. Registraram-se não somente o tipo de alimento e a quantidade, mas também a forma de preparação do alimento e a hora de consumo, já que muitas vezes os alimentos que se consome durante o almoço se repetem no jantar, em forma de outra preparação. Também foram registrados todos os alimentos consumidos na escola, assinalando-se, sempre que possivel, a marca comercial de alimentos industrializados. Desta maneira, constatou-se maior facilidade operacional na coleta de dados e um elevado percentual de devolução.

\subsubsection{Questionário de Frequêencia do Consumo Alimentar para Adolescentes - QFAA}

Este instrumento de medição do consumo alimentar requereu atividades preliminares para seu desenvolvimento antes de se proceder à sua utilização no trabalho de campo desta pesquisa.

Para o desenho da estrutura do QFAA foi necessário: a elaboração de uma lista de alimentos, identificação dos alimentos de maior contribuição energética, sistematização da frequêencia de consumo em unidades de tempo e o porcionamento padronizado estabelecido para cada item de alimento.

É importante mencionar que o objetivo subjacente deste instrumento é categorizar os indivíduos segundo seu consumo passado de alimentos, em particular segundo sua ingestão de energia, proteína, carboidratos, gordura, colesterol, vitamina $A$, vitamina $C$, ferro e cálcio. 


\subsection{DESENVOLVIMENTO DA ESTRUTURA DO QUESTIONÁRIO DE FREQÜÊNCIA ALIMENTAR PARA ADOLESCENTES}

3.3.1 Lista de Alimentos: A lista de alimentos foi elaborada a partir dos dados de consumo alimentar pertencentes a uma pesquisa de avaliação nutricional realizada por NUZZO (1998). A informação dietética nesta pesquisa corresponde à aplicação de 2 dias do método Diário Alimentar em 200 adolescentes de ambos os sexos com idades entre 10 e 19 anos, freqũentadores de escola particular de ensino situada no município de Guarulhos

Posteriormente procedeu-se à listagem de todos os alimentos consumidos pelos alunos, obtendo-se uma lista preliminar de 616 alimentos, os quais foram agrupados segundo suas características fisicas e perfil de nutrientes em 140 itens de alimentos relativamente homogêneos (COLUCCl et al. 1999) (Anexo 2).

3.3.2 Identificação dos alimentos: A partir desta segunda lista, foram identificados os alimentos de maior contribuição energética, usando-se a técnica de análise estatística de proporção ponderada utilizada por BLOCK et al. (1985); HOWE et al. (1986) e COLUCCl et al. (1999) (Anexo 3). Estes autores propõem que a quantidade total de energia consumida pela população seja estimada pela somatória das calorias em todas a refeições e todos os alimentos registrados. Desta maneira, a contribuição relativa (CR) de um alimento em particular foi dada por:

Total de energia proveniente do alimento $i$

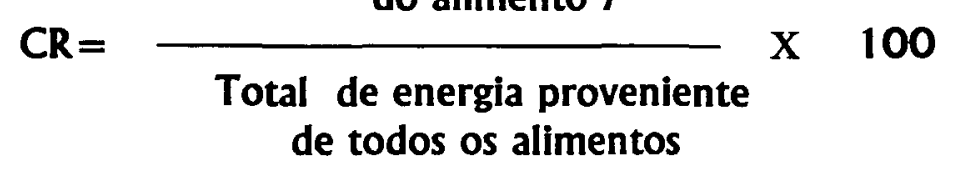


3.3.3 Freqūência de consumo de alimentos em unidades de tempo: $O$ QFAA avalia as quantidades de alimentos e nutrientes consumidos no período de 6 meses precedentes. $O$ formato das perguntas de freqüência de consumo do instrumento corresponde ao de perguntas simples e de respostas múltiplas e fechadas, por cada item de alimentos. Foram estabelecidas 7 categorias de resposta em unidades de tempo, sendo estas: nunca, menos de 1 vez por mês, 1 a 3 vezes por mês, 1 vez por semana, 2 a 4 vezes por semana, 1 vez por dia e 2 ou mais vezes por dia.

3.3.4 Porcionamento e padronização: Esta forma de abordagem proporcionou informações valiosas a respeito dos nomes e descrição dos alimentos consumidos por este grupo populacional, mas também forneceu a descrição das quantidades e tamanhos dos alimentos de maior consumo.

As porçōes referidas no instrumento foram definidas a partir dos dados de consumo do banco de dados mencionado anteriormente (NUZZO 1998). A maioria das porçōes expressam o consumo médio em gramas para cada item alimentar ou unidades de alimento com exceçáo de 10 alimentos que apresentaram diferenças entre ambos os sexos. Para estes, procedeu-se à utilização do valor mediano (Anexo 4).

\subsection{PROVA PILOTO}

Após a definição da estrutura preliminar do QFAA, com 89 itens alimentares, procedeu-se ao teste através de um estudo piloto.

O QFAA foi aplicado em 26 alunos voluntários de ambos os sexos, entre 14 e 17 anos, em uma escola particular, representando $10 \%$ do total de alunos matriculados no segundo colegial. Os alunos preencheram o QFAA, 
assim como também o consumo alimentar de 2 dias, por meio do método R24hs (utilizado como método de referência).

O estudo piloto permitiu, em primeiro lugar, uma avaliação preliminar do grau de exatidão da estimativa do consumo alimentar e, ein segundo, a detecção de possiveis problemas relacionados ao preenchimento deste novo instrumento.

O anexo 5 mostra os valores médios, desvios padrão e coeficiente de correlação de Pearson de energia e nutrientes calculados a partir dos R24 h e do QFAA do estudo piloto. Encontrou-se que o QFAA mostrou subestimação em mais de $10 \%$ na média para a maioria dos nutrientes analisados, com exceção do lipídio total, lipídios insaturados e carboidratos e somente o cálcio apresentou-se superestimado na média em $12 \%$.

Os coeficientes de correlação encontrados para energia $(r=0,10)$, proteína $(r=0,10)$, retinol $(r=0,05)$ e ferro $(r=0,11)$ foram baixos. Para carboidratos, lipídios, colesterol, vitamina C e cálcio, a correlação foi moderada, variando entre 0,20 a 0,42 . Estes achados orientaram uma reavaliação do porcionamento e o reagrupamento dos alimentos.

O QFAA inclui uma lista definitiva de 76 itens alimentares previamente identiflcados e selecionados, os quais formam parte do hábito alimentar deste grupo populacional. O questionário está estruturado em 9 categorias (I. Doces, salgadinhos e guloseimas, II. Salgados e preparaçōes, III. Leites e produtos lácteos, etc.) e para cada alimento consta seu respectivo porcionamento em medidas caseiras e em gramas (Anexo 6). 


\subsection{ESTUDO DE VALIDAÇÃO}

\subsubsection{População e local de estudo}

A população de estudo foi constituída por 106 adolescentes voluntários de ambos os sexos, matriculados no primeiro colegial da Escola Estadual de segundo grau "Antônio Alves Cruz", localizada na região oeste da cidade de São Paulo.

\subsubsection{Critérios de seleção e exclusão}

Foram convidados a participar todos os alunos do $1^{\circ}$ colegial período da manhã, entre 14 e 18 anos e 11 meses, e todos aqueles que completaram o QFAA e pelo menos três (3) recordatórios de $24 \mathrm{~h}$.

Foram excluídos os alunos com mais de 19 anos. Por este critério não se avaliou os adolescentes do segundo e terceiro colegial, devido à possibilidade de se encontrar muitos alunos ultrapassando esta idade.

\subsection{DESENHO DO ESTUDO DE VALIDAÇĀO}

A coleta de dados do estudo de validação foi conduzida de junho a dezembro de 1999. A validade relativa foi avaliada pela comparação entre a medida de referência e os dados coletados pelo QFAA. Durante este período os alunos completaram 4 R24hs (3 dias da semana -- Terça, Quarta e Quinta -e um dia feriado), com intervalo de 45 dias e 1 QFAA ao final, de acordo com o seguinte esquema: 
Figura 2: Esquema do delineamento da pesquisa

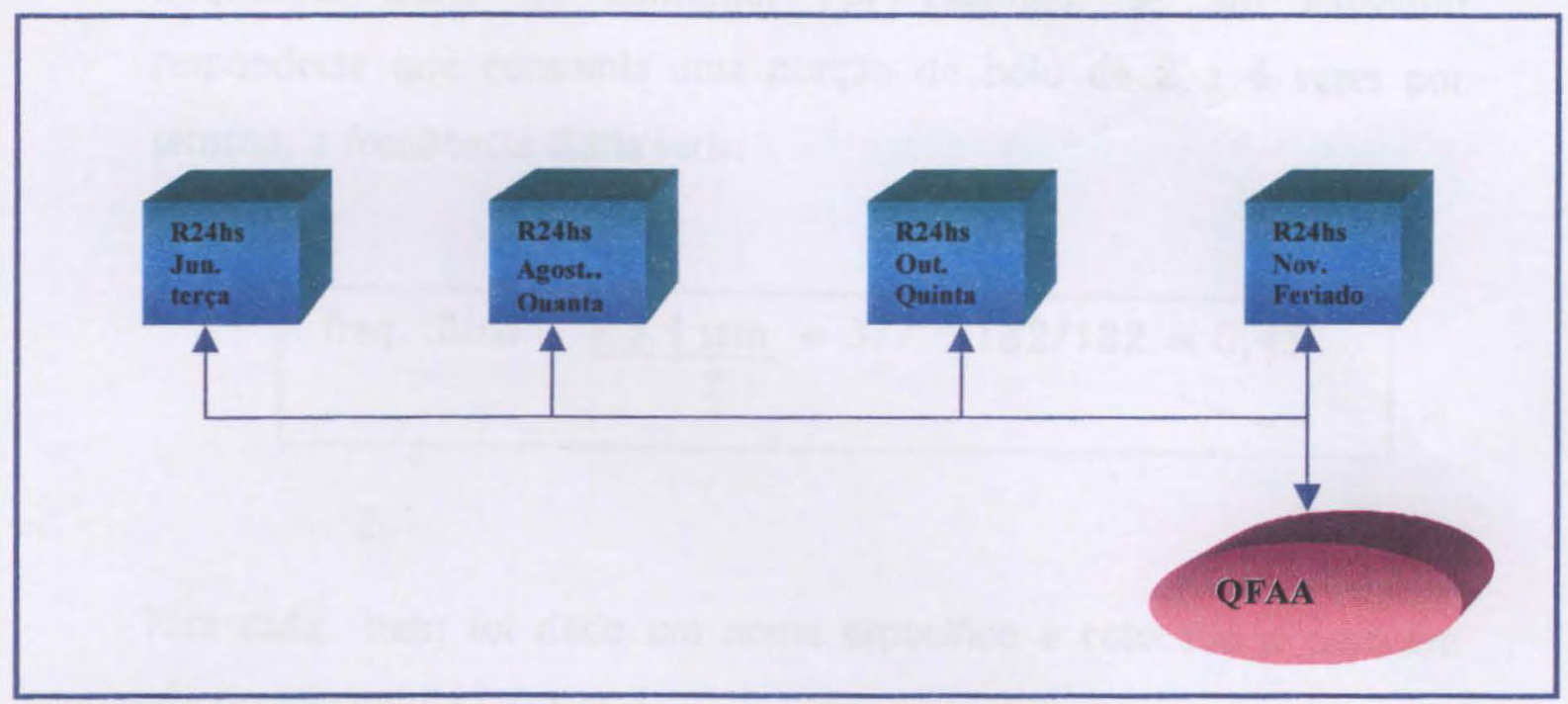

\subsection{VARIÁVEIS DE ESTUDO}

Para descrever algumas características da populaçăo foram eleitas as variáveis sexo e Idade, e para avaliar o consumo médio e testar a validade relativa do QFAA se utilizaram as varlávels energia, proteina, carboidrato, lipidio total, lipidio insaturado, fibra, colesterol, retinol, vitamina C cálcio e ferro.

\subsection{PROCESSAMENTO DOS DADOS}

Realizado o levantamento dos dados, o consumo de alimentos registrado pelo R24hs foi transformado em energia e nutrientes pelo programa VIRTUAL NUTRI (PHILIPPI et al. 1996).

Para analisar o valor nutritivo dos alimentos do QFAA foram necessários três passos preliminares Importantes: 
1. As categorias de freqüência em unidades de tempo do consumo diário, semanal e mensal de cada item de alimento foram transformadas em freqüência diária de consumo. Por exemplo: se um individuo respondesse que consumia uma porção de bolo de 2 a 4 vezes por semana, a freqũência diária seria:

$$
\text { freq. diária : } \frac{2 \cdot a 4 \text { sem }}{? ?}=3 / 7 * 182 / 182=0,43
$$

Para cada item foi dado um nome especifico e colocado o peso em gramas da porção média (Anexo 4).

2. Desta maneira, os nutrientes contidos em uma porção de cada item do QFAA foram multiplicados pela frequeência diária de consumo dos alimentos específicos para proporcionar a ingestăo diária dos diversos nutrientes para cada um dos indivíduos integrantes deste estudo.

\subsection{ANÁLISE ESTATÍSTICA DOS DADOS}

Foram calculadas médias e desvios padrão do consumo de energia e nutrientes para o questionário de freqüência alimentar - QFAA e para os 4 dias do Recordatório de $24 \mathrm{~h}$ por meio dos programas SPSS Versão 8.0 e Excel 97 para Windows.

A distribuição observada para a maioria dos nutrientes foi assimétrica, com tendência a valores elevados (Caloria/qfaa, Caloria/24h, proteína/qfaa, HC/24h, LipT/qfaa, Lins/qfaa, Lins/24h, Fibra/qfaa, coles/qfaa, colest,24h, retinol/24h, VitC/qfaa, VitC/24h, Calcio/24h e ferro/qfaa). Por esta razão, os 
valores dos nutrientes na sua forma bruta. sofreram transformação logarítmica ( $\left.\log _{\mathrm{e}}\right)$, procedimento que conferiu normalidade a quase todas as variáveis, com exceção do Loghc/24h e Logca/24h. Posteriormente foi realizado o teste de Kolmogorov-Smirnov para avaliar a aderência dos valores de consumo bruto e loge à distribuição normal, sendo esta suposição importante no cálculo do coeficiente de correlação de Pearson. (Anexo 7)

O teste $t$ - student emparelhado foi utilizado para verificar as diferenças entre as médias do consumo de energia e nutrientes obtidas pelo QFAA e os recordatórios de 24 horas.

Para estimar a validade, utilizou-se o coeficiente de correlação de Pearson (interclasse), o qual permite comparar os valores de energia e nutrientes do questionário (valor estimado), com a média dos 3 Recordatórios de $24 \mathrm{~h}$ (valor verdadeiro). Para aquelas variáveis sem distribuição normal optou-se pelo coeficiente de correlação de Spearman.

O coeficiente de correlação ( $r$ ) foi calculado antes e depois do ajuste pela energia. Neste tratamento, chamado "Ajustado pela energia" ou "Método residual", proposto por WILLET \& STAMFER (1986), propõe-se controlar os fatores de confusão dados pelo consumo total de energia e remover as variaç̋̃es externas. Para isto é necessário realizar análise de regressão linear simples, com o total de caloria ingerida como variável independente e o valor absoluto do nutriente como variável dependente.

Para este cálculo utilizou-se equação geral da regressão linear:

$$
Y_{n}=\beta_{0}+\left(\beta_{1}{ }^{*} \operatorname{Ln} \text {. Energia media individual }\right)
$$


Após a definição do $\beta_{0}$ e $\beta$ ı calculou-se o resíduo. $O$ resíduo da regressão representa a diferença entre o consumo observado para cada um dos indivíduos e o consumo estimado para seu consumo total de energia.

$$
Y_{0}-Y_{e}=Y_{0}-\left(\beta_{0}+\beta_{1} \text { Ln. Energia media individual }\right)
$$

Devido ao fato de o resíduo variar de pessoa para pessoa e apresentar média zero $(0)$, por incluir valores negativos e positivos, é necessário que seja adicionada uma constante para todos os valores. A constante é estatisticamente arbitrária, mas poderia ser o consumo do nutriente estimado $(\mathrm{Y})$ para a média do total de energia consumida da população de estudo (WILLET et al. 1997 e WILLETT 1998).

Calculou-se uma constante:

$$
C=\left(\beta_{0}+\beta_{1 e^{*}} \text { Ln. Energia média do grupo }\right)
$$

$$
Y_{\text {alussado }}=\text { (residuo }+\mathrm{C} \text { ) }
$$

Conceituaimente, o "nutriente residual" ou "nutriente ajustado" prevê um valor do nutriente ingerido não correlacionado com a energia total consumida. Portanto, este procedimento isola a variação na ingestão do nutriente (devida unicamente à composição do mesmo na dieta) da variação geral na ingestăo de nutriente (a qual deve-se tanto à composição em si dos alimentos quanto ao seu consumo total) (WILLETT 1998).

Como já mencionado anteriormente, a presença do erro aleatório intrapessoal na medição da ingestão, ou variação intraindividual pelo "dia a dia", tende a atenuar a correlação entre os valores do QFAA e os valores dos R24hs. 
Para se obter a medida da validade corrigida pelos componentes de variação intrapessoal e interpessoal na dieta foi necessário usar análise de variância (ANOVA). Nesta análise, a unidade de observação aleatória foi o consumo médio de energia e nutrientes registrados pelos três dias de R24hs, seguindo o modelo proposto por WILLETT (1998).

Logo estimou-se a $S^{2}{ }_{b s}$ (variância interpessoal) e $S^{2}{ }_{w s}$ (variância intrapessoal), para o que foi necessário primeiro calcular a média quadrática esperada (MQE).

ANOVA

\begin{tabular}{|l|l|l|l|}
\hline Efeito & $\mathrm{GL}$ & Media quadrática & $\begin{array}{l}\text { Média quadrática esperada } \\
(\mathrm{MQE})\end{array}$ \\
\hline Indivíduo & $\mathrm{n}-1$ & $\begin{array}{l}\text { Media quadrática } \\
\text { interpessoal (MQB) }\end{array}$ & \multicolumn{1}{|c|}{$\mathbf{k s}^{2} \mathrm{bs}+\mathrm{s}^{2}$ ws } \\
\hline Erro & $\mathrm{n}(\mathrm{k}-1)$ & $\begin{array}{l}\text { Média quadrática } \\
\text { intrapessoal (MQW) }\end{array}$ & \multicolumn{1}{|c|}{$\mathrm{s}^{2}$ ws } \\
\hline
\end{tabular}

$\mathrm{GL}=$ graus de liberdade

$\mathrm{n}=$ número da amostra

$\mathrm{k}=$ número de aplicaçōes do R24hs

Como pode-se observar, a média quadrática para os indivíduos (MQB $=$ "between groups") e o erro (MQW = "within groups") são parte dos resultados da ANOVA. O MQW é um dos componentes da variância que se necessita (MQW $=s^{2}$ ws variância intrapessoal) para calcular o outro componente de interesse, $s^{2}$ bs . 
Portanto:

$$
\mathrm{s}_{\mathrm{bs}}^{2}=\frac{\mathrm{MQB}-\mathrm{MQW}}{\mathrm{k}}
$$

Onde $\mathrm{k}$ = número de medidas repetidas, $\mathrm{o}$ qual corresponde ao número de R24hs aplicados na população.

Para interpretar estes dois componentes de variância, calculou-se a razăo de ambos.

$$
\lambda=\mathrm{s}^{2}{ }_{w s} / \mathrm{s}^{2}{ }_{\mathrm{bs}}
$$

Assim, com este valor calcula-se o coeficiente de correlação "corrigido" ou De-atenuado (de-attenuated).

$$
r_{c}=r_{0} \sqrt{ } 1+\lambda / n
$$

A avaliação da validade do QFAA quanto à classificação dos indivíduos segundo a distribuição do seu consumo dos nutrientes foi examinada pela comparação da classificação em quartis por ambos os métodos. O Ponto de corte foi determinado separadamente para o questionário, assim como para a média dos R24hs. Desta maneira, a concordância e discordância entre as categorias foram avaliadas pela proporção total de participantes corretamente classificados no mesmo quartil e nos quartis opostos.

Para todas as análises estatísticas utilizou-se o nível de significância $\alpha=\mathbf{5 \%}$ $(p<0,05)$. 
De 106 alunos, 80 foram acompanhados durante o periodo de junho a novembro de 1999. Aproximadamente 24 alunos (23\%) encontravam-se ausentes nos dias da avaliaçăo e somente um se recusou a ser avaliado. $O$ gráfico 1 mostra o número total de alunos avaliados em cada visita.

Gráfico 1: Distribulçăo de alunos avaliados segundo visita. Escola estadual de segundo grau Antonio Alves Cruz, São Paulo 1999.

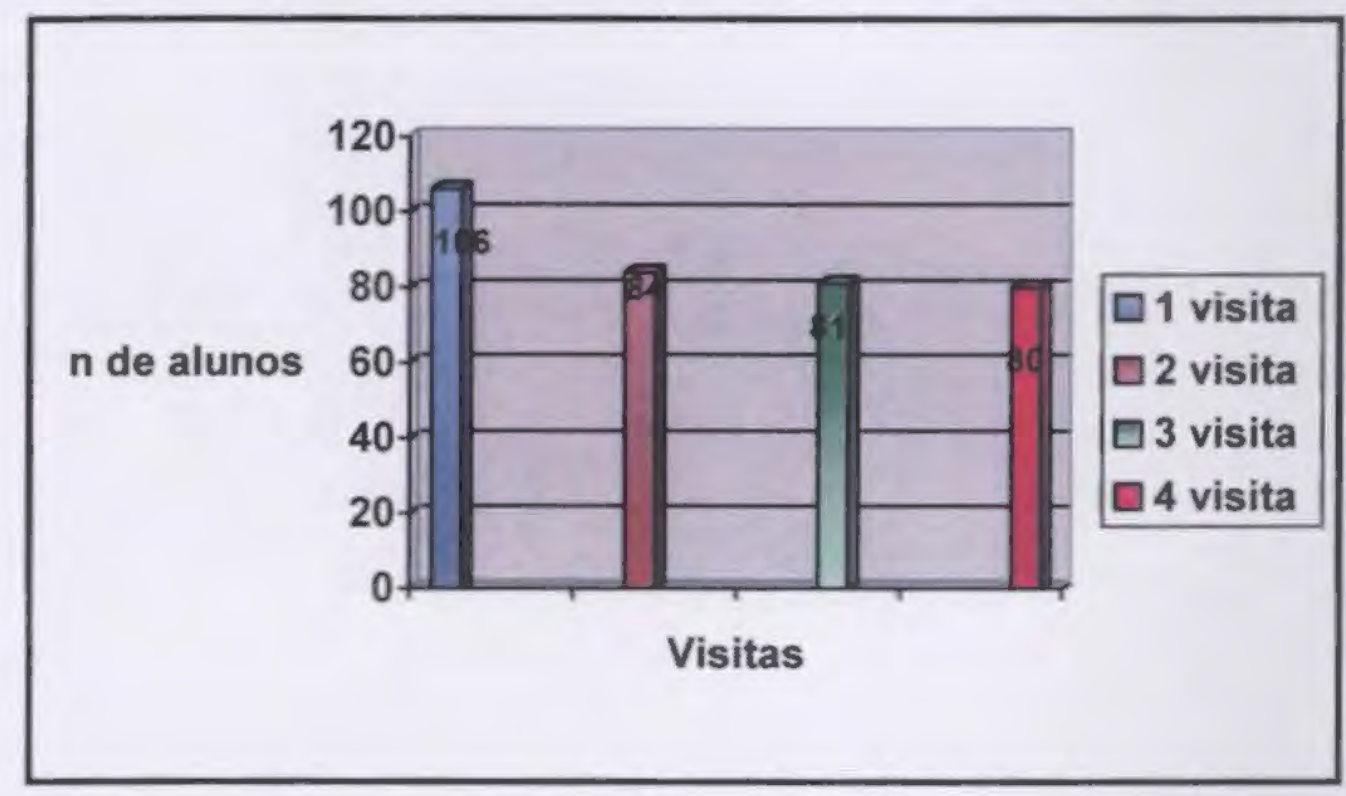

Desses alunos, somente 79 completaram o QFAA e pelo menos 3 recordatórios de R24hs, de acordo com um dos critérios de seleçăo da amostra para o estudo de validaçăo.

Do total de alunos selecionados (79), $50,6 \%$ são do sexo feminino e $49,4 \%$ do sexo masculino, podendo ser definido como um grupo bastante equilibrado quanto ao sexo.

A idade mínima foi de 14 anos e a máxima de 19 anos incompletos, com média de idade de 15,7 anos (desvio padrăo $=1,09$ ) na primeira avaliaçăo e de 16,2 anos (desvio padrăo $=1,14$ ) na última avaliaçăo. 
4. RESULTADOS 
A tabela 2 mostra a distribuição das idades dos alunos no começo e no final do estudo. Pode-se observar que mais de $50 \%$ dos adolescentes encontravam-se entre 15 e 17 anos de idade.

Tabela 2. Número e porcentagem de individuos avaliados segundo idade. Escola Pública Antonio Alves Cruz, São Paulo. Junho a Novembro de 1999.

\begin{tabular}{|c|c|c|c|c|}
\hline \multirow[t]{2}{*}{ Idade } & \multicolumn{2}{|c|}{ Junho1999 } & \multicolumn{2}{|c|}{ Novembro 1999} \\
\hline & $\mathbf{N}^{\circ}$ & $\%$ & $\mathbf{N}^{\circ}$ & $\%$ \\
\hline 14 & 8 & 10,1 & 1 & 1,3 \\
\hline 15 & 31 & 39,2 & 28 & 35,4 \\
\hline 16 & 19 & 24,1 & 21 & 26,6 \\
\hline 17 & 16 & 20,3 & 18 & 22,8 \\
\hline 18 & 5 & 6,3 & 9 & 11,4 \\
\hline 19 & - & - & 2 & 2,5 \\
\hline Total & 79 & 100 & 79 & 100 \\
\hline
\end{tabular}

A ingestão média diária, desvio padrão e intervalo de confiança de energia e nutrientes para o sexo feminino e masculino são apresentados na tabela 3 Nesta tabela, os dados representam a média de consumo estimada por 3 recordatórios de 24 horas. Os valores mostram que o consumo médio dos homens foi superior ao das mulheres para todos os nutrientes estudados, observando-se também uma ampla dispersão de valores, isto é, coeficientes de variaçăo acima de $50 \%$ para os lipídios insaturados, fibra, colesterol e cálcio, e ainda maiores para retinol e vitamina $C$, que axibem desvios padrão superiores à média.

A tabela 4 apresenta os valores encontrados de consumo médio diário de energia e nutrientes pelo questionário cie freqūência alimentar para adolescentes 
- QFAA. Igualmente à tabela anterior, o consumo médio diário de energia e nutrientes dos homens foi superior ao das mulheres, mas não se observou a mesma dispersão dos valores com relação à média. O coeficiente de variação mais alto encontrado foi para vitamina $C(52 \%)$. Para os outros nutrientes os percentuais não superaram $40 \%$.

Tais constatações levaram a se considerar a verificação da distribuição das variáveis de consumo. Dos 11 nutrientes estudados por ambos os métodos, a Proteína./R24hs, carboidrato/QFAA, Lipídio Total/R24hs, Fibra/R24hs, Retinol./QFAA, Cálcio/QFAA e Ferro/R24hs apresentaram distribuição normal; o restante requereu transformaçăo logarítmica (Anexo7).

A tabela 5 mostra o consumo dos macronutrientes segundo sua relação com o Valor Calórico Total (VCT). As porcentagens variaram entre $12,3 \%$ e $18,9 \%$ para proteina, $42,1 \%$ e $60,3 \%$ para carboidrato e $30,5 \%$ a $40,2 \%$ para lipídio total.

A validade relativa, expressa pela comparação das médias do consumo diário de energia e nutrientes obtidas a partir dos recordatórios de $\mathbf{2 4}$ horas e do QFAA, é mostrada na tabela 6. O QFAA subestimou os valores de proteína, lipidio total, lipídio insaturado, colesterol, retinol, cálcio e ferro.

Os valores de energia, carboidrato, fibra e vitamina $C$ foram superestimados pelo QFAA. As diferenças foram maiores para o consumo diário de energia e fibra nas mulheres e carboidrato e vitamina $C$ nos homens.

Foram observadas médias estatisticamente diferentes para proteína, carboidrato, lipídio insaturado, colesterol, retinol e ferro. Entre as mulheres, dos 11 nutrientes estudados somente 2 apresentaram médias significativamente diferentes de zero $(p<0,05)$, sendo mais relevante a superestimação do 
consumo de fibra em aproximadamente $30 \%(p<0,001)$. Os resultados indicam que os homens tendem a distorcer mais a informaçăo do seu consumo, já que subestimam ou superestimam mais que as mulheres. Isto pode ser verificado em seis dos nutrientes estudados e, principalmente, para o retinol.

A tabela 7 e a tabela 8 mostram a razão entre os componentes de variância intrapessoal e interpessoal e os coeficientes de variação (CV\%) do consumo de energia e nutrientes calculados pelos recordatórios de 24 horas aplicados 3 vezes em cada indivíduo.

Na tabela 7, observam-se razões de variância entre 1 e 2 para energia, proteína, carboidrato, fibra e ferro para todo o grupo de indivíduos; e maiores que 2 para o restante dos nutrientes estudados, constatando-se que os homens mostraram padrōes de variabilidade intrapessoal maiores que os verificados entre as mulheres, com exceção do retinol, no qual o padrão de variabilidade foi maior entre as mulheres. Chamam muita atenção os valores, entre o sexo masculino, de colesterol e vitamina $C$, que se mostraram extremamente altos. Cabe salientar também que o valor mais alto foi verificado para o nutriente retinol, entre o sexo feminino.

O coeficiente de variação observado na tabela 8 expressa a magnitude com que se distribuem os valores ao redor da média. Valores próximos de $100 \%$ indicam que o desvio padrão é igual à média. Quanto menor o CV, mais homogênea será a distribuição dos valores. No caso do retinol e vitamina C, observaram-se coeficientes de variação superiores a 100\%, com desviospadrão superiores à média.

A validade relativa do QFAA pode ser expressa pela correlação entre consumo diário de energia e nutrientes, pelo QFAA, e a média do consumo de 
3 R24hs. Os coeficientes de correlação, na sua forma bruta, ajustados pela caloria e corrigidos pela variância ou de-atenuados, estão resumidos na tabela 9.

Os valores brutos sofreram transformação logarítmica, condição imprescindível para se estimar o coeficiente de correlação. Os resultados desta primeira análise encontraram coeficientes de correlação altos para energia $(r=0,87)$ e adequados para os macro e micronutrientes $(r=0,42-0,77)$, com exceção do retinol, que apresentou $r=0,28$.

A correlaçăo mais baixa verificada foi para o nutriente retinol, em ambos os sexos. No sexo feminino, $o$ valor foi de $r=0,18$, enquanto no sexo masculino a correlação foi de $r=0,39$.

Todos os valores dos coeficientes de correlação tenderam a decrescer após o ajuste pela caloria. Observou-se uma diminuiçăo maior que $50 \% \mathrm{em}$ relação aos valores brutos. As correlaçōes variaram entre 0,06 e 0,54 para todo o grupo, entre $-0,07$ a 0,49 para as mulheres e entre 0,11 a 0,62 para os homens. Teoricamente, este tipo de procedimento isola o nutriente dos efeitos da energia, especialmente quando estes - os nutrientes - estão altamente correlacionados, como ocorreu neste estudo. Este efeito pode ser demonstrado com os resultados da tabela 10 , onde correlaçōes brutas próximas de 1 (um) chegam a valores ajustados iguais ou próximos de zero. Nos gráficos 2 a 5 , o ajuste pela caloria é visualizado com dois exemplos: proteína e colesterol.

A coluna de valores nomeada De-atenuado na tabela 9 mostra as correlaçōes entre ambos os métodos depois de se retirar os efeitos da variância intrapessoal dada pelos R24hs. Como pode-se observar, esta técnica incrementou todos os valores, os quais passaram de $r=0,06$ para $r=0,10$ (retinol) e de 0,54 para 0,67 no caso da fibra. Também foram encontrados valores bastante altos para fibra $(0,91)$ e vitamina $C$, no sexo masculino. 
Embora os valores continuem permanecendo baixos, a correçáo feita para a maioria dos nutrientes confirma altos padrōes de variância intrapessoal, característicos do nutriente examinado e também deste grupo populacional.

Através da técnica estatística denominada classificação cruzada (crossclassification) foi avaliada a habilidade do QFAA em categorizar os individuos no mesmo quartil e no quartil oposto segundo seu consumo de nutrientes (Tabela 11). Uma média de $33 \%$ de indivíduos foram classificados no mesmo quartil e $5 \%$ tiveram classificação de maneira incorreta (quartil oposto).

A primeira coluna apresenta a proporçăo de indivíduos no primeiro quartil dos R24hs que foram também classificados no primeiro quartil do QFAA. Esta proporção variou entre $16 \%$ para ferro e $63 \%$ para cálcio (média de $37 \%$ ). Observou-se, também, que aproximadamente $11 \%$ foram classificados no primeiro quartil do R24hs e no último quartil do QFAA. 
Tabela 3. Média, desvio padrão e intervalo de confiança do consumo de energia e nutrientes dos adolescentes estimados por 3 Recordatórios de 24 horas. Escola Pública Antonio Alves Cruz, São Paulo, 1999.

\begin{tabular}{|c|c|c|c|c|c|}
\hline \multirow[t]{2}{*}{ Nutriente } & \multirow[t]{2}{*}{$\mathbf{N}$} & \multirow[t]{2}{*}{ Média } & \multirow[t]{2}{*}{ DP } & \multicolumn{2}{|c|}{ I.C(95\%) } \\
\hline & & & & Inferior & Superior \\
\hline $\begin{array}{l}\text { feminino } \\
\text { masculino }\end{array}$ & $\begin{array}{l}79 \\
40 \\
39\end{array}$ & $\begin{array}{l}2004,87 \\
1731,94 \\
2284,79\end{array}$ & $\begin{array}{l}728,76 \\
572,58 \\
766,87\end{array}$ & $\begin{array}{c}1050,93 \\
1628,44 \\
214,37\end{array}$ & $\begin{array}{l}2259,43 \\
1835,44 \\
2425,21\end{array}$ \\
\hline $\begin{array}{r}\text { feminino } \\
\text { masculino }\end{array}$ & $\begin{array}{l}79 \\
40 \\
39\end{array}$ & $\begin{array}{l}79,52 \\
66,12 \\
93,27\end{array}$ & $\begin{array}{l}34,83 \\
28,10 \\
35,80\end{array}$ & $\begin{array}{l}75,06 \\
61,034 \\
86,71\end{array}$ & $\begin{array}{l}83,97 \\
71,20 \\
99,82\end{array}$ \\
\hline $\begin{array}{r}\text { Carboidrato(g) } \\
\begin{array}{r}\text { feminino } \\
\text { masculino }\end{array}\end{array}$ & $\begin{array}{l}79 \\
40 \\
39\end{array}$ & $\begin{array}{l}242,18 \\
210,89 \\
274,29\end{array}$ & $\begin{array}{l}90,23 \\
78,22 \\
90,73\end{array}$ & $\begin{array}{l}230,64 \\
196,75 \\
257,68\end{array}$ & $\begin{array}{l}253,74 \\
225,03 \\
290,91\end{array}$ \\
\hline $\begin{array}{r}\text { Lipidio Total }(\mathrm{g}) \\
\begin{array}{r}\text { feminino } \\
\text { masculino }\end{array}\end{array}$ & $\begin{array}{l}79 \\
40 \\
39\end{array}$ & $\begin{array}{l}78,63 \\
67,87 \\
89,65\end{array}$ & $\begin{array}{l}39,02 \\
30,60 \\
43,53\end{array}$ & $\begin{array}{l}73,63 \\
62,34 \\
81,68\end{array}$ & $\begin{array}{l}83,62 \\
73,40 \\
97,62\end{array}$ \\
\hline $\begin{array}{r}\text { Lipidio Insaturado }(\mathbf{g}) \\
\text { feminino } \\
\text { masculino }\end{array}$ & $\begin{array}{l}79 \\
40 \\
39\end{array}$ & $\begin{array}{l}31,63 \\
26,08 \\
37,33\end{array}$ & $\begin{array}{l}20,79 \\
16,41 \\
23,21\end{array}$ & $\begin{array}{l}29,97 \\
23,12 \\
33,08\end{array}$ & $\begin{array}{l}34,29 \\
29,05 \\
41,57\end{array}$ \\
\hline $\begin{array}{r}\text { feminino } \\
\text { masculino }\end{array}$ & $\begin{array}{l}79 \\
40 \\
39\end{array}$ & $\begin{array}{c}10,56 \\
7,87 \\
13,31\end{array}$ & $\begin{array}{l}6,32 \\
4,82 \\
6,50\end{array}$ & $\begin{array}{l}9,75 \\
7,00 \\
12,12\end{array}$ & $\begin{array}{l}11,36 \\
7,74 \\
14,50\end{array}$ \\
\hline $\begin{array}{r}\text { Colesterol (mg) } \\
\begin{array}{r}\text { feminino } \\
\text { masculino }\end{array}\end{array}$ & $\begin{array}{l}79 \\
40 \\
39\end{array}$ & $\begin{array}{l}239,70 \\
204,60 \\
275,70\end{array}$ & $\begin{array}{l}153,50 \\
138,75 \\
160,02\end{array}$ & $\begin{array}{l}220,05 \\
179,52 \\
246,40\end{array}$ & $\begin{array}{l}259,34 \\
229,68 \\
305,00\end{array}$ \\
\hline $\begin{array}{r}\text { Retinol ( } \mu \mathrm{g} \text { ER) } \\
\begin{array}{r}\text { feminino } \\
\text { masculino }\end{array}\end{array}$ & $\begin{array}{l}79 \\
40 \\
39\end{array}$ & $\begin{array}{l}745,64 \\
608,28 \\
886,52\end{array}$ & $\begin{array}{l}831,98 \\
830,23 \\
813,39\end{array}$ & $\begin{array}{l}639,17 \\
458,22 \\
735,58\end{array}$ & $\begin{array}{c}852,11 \\
758,35 \\
1035,45\end{array}$ \\
\hline Vitamina $C(\mathbf{m g}) \underset{\begin{array}{r}\text { feminino } \\
\text { masculino }\end{array}}{ }$ & $\begin{array}{l}79 \\
40 \\
39\end{array}$ & $\begin{array}{l}69,83 \\
64,28 \\
75,52\end{array}$ & $\begin{array}{l}86,59 \\
81,43 \\
91,58\end{array}$ & $\begin{array}{l}58,74 \\
49,55 \\
58,75\end{array}$ & $\begin{array}{l}80,91 \\
78,99 \\
92,29\end{array}$ \\
\hline $\begin{array}{l}\text { feminino } \\
\text { masculino }\end{array}$ & $\begin{array}{l}79 \\
40 \\
39\end{array}$ & $\begin{array}{l}584,88 \\
481,30 \\
691,12\end{array}$ & $\begin{array}{l}384,17 \\
301,13 \\
429,83\end{array}$ & $\begin{array}{l}535,72 \\
426,86 \\
612,41\end{array}$ & $\begin{array}{l}634,04 \\
535,73 \\
769,82\end{array}$ \\
\hline $\begin{array}{l}\text { feminino } \\
\text { masculino }\end{array}$ & $\begin{array}{l}79 \\
40 \\
39\end{array}$ & $\begin{array}{c}11,73 \\
9,09 \\
14,45\end{array}$ & $\begin{array}{l}5,62 \\
4,18 \\
5,62\end{array}$ & $\begin{array}{c}11,02 \\
8,33 \\
13,42\end{array}$ & $\begin{array}{c}12,45 \\
9,85 \\
15,48\end{array}$ \\
\hline
\end{tabular}


Tabela 4. Média diária, desvio padrão e intervalo de confiança do consumo de energia e nutrientes de adolescentes estimados pelo QFAA. Escola Pública Antonio Alves Cruz, São Paulo, 1999.

\begin{tabular}{|c|c|c|c|c|c|}
\hline \multirow[t]{2}{*}{ Nutrientes } & \multirow[t]{2}{*}{$\mathbf{N}$} & \multirow[t]{2}{*}{ Média } & \multirow[t]{2}{*}{ Desvio Padrão } & \multicolumn{2}{|c|}{ I.C (95\%) } \\
\hline & & & & Inferior & Superior \\
\hline $\begin{array}{r}\text { Energia (kcal) } \\
\text { feminino } \\
\text { masculino }\end{array}$ & $\begin{array}{l}79 \\
40 \\
39\end{array}$ & $\begin{array}{l}2023,59 \\
1763,71 \\
2290,11\end{array}$ & $\begin{array}{l}563,36 \\
451,10 \\
546,46\end{array}$ & $\begin{array}{l}1897,40 \\
1619,45 \\
2112,97\end{array}$ & $\begin{array}{l}2149,77 \\
1907,99 \\
2467,26\end{array}$ \\
\hline $\begin{array}{r}\text { Proteína }(\mathrm{g}) \\
\text { feminino } \\
\text { masculino }\end{array}$ & $\begin{array}{l}79 \\
40 \\
39\end{array}$ & $\begin{array}{l}69,14 \\
62,27 \\
76,18\end{array}$ & $\begin{array}{l}20,04 \\
17,95 \\
19,83\end{array}$ & $\begin{array}{l}64,65 \\
56,53 \\
69,75\end{array}$ & $\begin{array}{l}73,63 \\
68,01 \\
82,61\end{array}$ \\
\hline $\begin{array}{r}\text { Carboidrato }(\mathrm{g}) \\
\text { feminino } \\
\text { masculino }\end{array}$ & $\begin{array}{l}79 \\
40 \\
39\end{array}$ & $\begin{array}{l}265,40 \\
226,82 \\
304,97\end{array}$ & $\begin{array}{l}75,96 \\
61,96 \\
68,76\end{array}$ & $\begin{array}{l}248,39 \\
207,01 \\
282,68\end{array}$ & $\begin{array}{l}282,41 \\
246,64 \\
327,26\end{array}$ \\
\hline $\begin{array}{r}\text { Lipidio Total (g) } \\
\text { feminino } \\
\text { masculino }\end{array}$ & $\begin{array}{l}79 \\
40 \\
39\end{array}$ & $\begin{array}{l}76,60 \\
68,52 \\
84,90\end{array}$ & $\begin{array}{l}24,83 \\
19,96 \\
26,78\end{array}$ & $\begin{array}{l}71,05 \\
62,14 \\
76,22\end{array}$ & $\begin{array}{l}82,17 \\
74,90 \\
93,58\end{array}$ \\
\hline $\begin{array}{r}\text { Lipidio Insaturado (g) } \\
\text { feminino } \\
\text { masculino }\end{array}$ & $\begin{array}{l}79 \\
40 \\
39\end{array}$ & $\begin{array}{l}25,74 \\
22,93 \\
28,62\end{array}$ & $\begin{array}{c}9,54 \\
7,82 \\
10,35\end{array}$ & $\begin{array}{l}23,60 \\
20,43 \\
25,27\end{array}$ & $\begin{array}{l}27,88 \\
25,42 \\
31,98\end{array}$ \\
\hline $\begin{array}{r}\text { Flbra (g) } \begin{array}{r}\text { feminino } \\
\text { masculino }\end{array}\end{array}$ & $\begin{array}{l}79 \\
40 \\
39\end{array}$ & $\begin{array}{l}11,70 \\
10,31 \\
13,13\end{array}$ & $\begin{array}{l}4,40 \\
4,08 \\
4,30\end{array}$ & $\begin{array}{c}10,72 \\
9,00 \\
11,74\end{array}$ & $\begin{array}{l}12,69 \\
11,62 \\
14,53\end{array}$ \\
\hline $\begin{array}{r}\text { Colesterol (mg) } \\
\text { feminino } \\
\text { masculino }\end{array}$ & $\begin{array}{l}79 \\
40 \\
39\end{array}$ & $\begin{array}{l}204,56 \\
182,98 \\
226,70\end{array}$ & $\begin{array}{l}83,38 \\
89,30 \\
71,35\end{array}$ & $\begin{array}{l}185,89 \\
154,42 \\
203,57\end{array}$ & $\begin{array}{l}223,24 \\
211,54 \\
249,82\end{array}$ \\
\hline $\begin{array}{r}\text { Retinol ( } \mu \mathrm{g} \text { ER) } \\
\text { feminino } \\
\text { masculino }\end{array}$ & $\begin{array}{l}79 \\
40 \\
39\end{array}$ & $\begin{array}{l}614,94 \\
596,55 \\
633,80\end{array}$ & $\begin{array}{l}243,50 \\
272,89 \\
211,06\end{array}$ & $\begin{array}{c}560,40 \\
509,28 \\
565,38\end{array}$ & $\begin{array}{c}669,48 \\
683,83 \\
702,22\end{array}$ \\
\hline $\begin{array}{r}\text { Vitamina } C \text { (mg) } \\
\text { feminino } \\
\text { masculino }\end{array}$ & $\begin{array}{l}79 \\
40 \\
39\end{array}$ & $\begin{array}{l}79,91 \\
69,84 \\
90,24\end{array}$ & $\begin{array}{l}41,62 \\
33,43 \\
46,83\end{array}$ & $\begin{array}{l}70,59 \\
59,15 \\
75,06\end{array}$ & $\begin{array}{c}89,24 \\
80,53 \\
105,43\end{array}$ \\
\hline $\begin{array}{r}\text { Cálcio (mg) } \\
\text { feminino } \\
\text { masculino }\end{array}$ & $\begin{array}{l}79 \\
40 \\
39\end{array}$ & $\begin{array}{l}561,40 \\
507,00 \\
617,20\end{array}$ & $\begin{array}{l}223,49 \\
232,67 \\
201,63\end{array}$ & $\begin{array}{l}511,34 \\
432,59 \\
551,84\end{array}$ & $\begin{array}{l}611,46 \\
581,41 \\
682,56\end{array}$ \\
\hline $\begin{array}{r}\text { Ferro (mg) } \\
\begin{array}{r}\text { feminino } \\
\text { masculino }\end{array}\end{array}$ & $\begin{array}{l}79 \\
40 \\
39\end{array}$ & $\begin{array}{c}8,43 \\
8,44 \\
10,15\end{array}$ & $\begin{array}{l}2,49 \\
2,49 \\
2,79\end{array}$ & $\begin{array}{l}7,64 \\
7,64 \\
9,25\end{array}$ & $\begin{array}{l}9,24 \\
9,23 \\
11,06\end{array}$ \\
\hline
\end{tabular}


Tabela 5. Distribuição percentual dos macronutrientes em relação ao valor calórico total, segundo sexo. São Paulo, 1999. Escola Pública Antonio Alves Cruz, São Paulo, 1999.

\begin{tabular}{ccccc}
\hline Nutriente & \multicolumn{2}{c}{ R24HS } & \multicolumn{2}{c}{ QFAA } \\
& Média & VCT (\%) & Média & VCT(\%) \\
\hline Energia (kcal) & 2004,67 & & 2023,59 & \\
feminino & 1731,94 & & 1763,71 & \\
masculino & 2284,79 & & 2290,11 & \\
Proteina(g) & 79,52 & 15,9 & 69,14 & 13,7 \\
feminino & 66,12 & 13,2 & 62,27 & 12,3 \\
masculino & 93,27 & 18,6 & 76,18 & 15,1 \\
Carboidrato(g) & 242,18 & 48,3 & 265,40 & 52,5 \\
feminino & 210,89 & 42,1 & 226,82 & 44,8 \\
masculino & 274,29 & 54,7 & 304,97 & 60,3 \\
Lipídio Total(g) & 78,63 & 35,3 & 76,60 & 34,1 \\
feminino & 67,87 & 30,5 & 68,52 & 30,5 \\
masculino & 89,65 & 40,2 & 84,90 & 37,8 \\
\hline
\end{tabular}


Tabela 6. Diferença de médias e desvio padrão calculados entre a média de 3 R24hs e QFAA. São Paulo, 1999. Escola Pública Antonio Alves Cruz, São Paulo, 1999.

\begin{tabular}{|c|c|c|c|c|c|c|}
\hline \multirow[t]{2}{*}{ Nutrientes } & \multicolumn{2}{|c|}{ R24hs } & \multicolumn{2}{|c|}{ QFAA } & \multirow{2}{*}{$\begin{array}{c}\text { Diferença de } \\
\text { Médias }\end{array}$} & \multirow[t]{2}{*}{$p^{3}$} \\
\hline & Média & DP & Média & DP & & \\
\hline $\begin{array}{r}\text { Energia (kcal) } \\
\text { feminino } \\
\text { masculino }\end{array}$ & $\begin{array}{l}2004,87 \\
1731,94 \\
2284,79\end{array}$ & $\begin{array}{l}728,76 \\
572,58 \\
766,87\end{array}$ & $\begin{array}{l}2023,59 \\
1763,71 \\
2290,11\end{array}$ & $\begin{array}{l}563,36 \\
451,10 \\
546,46\end{array}$ & $\begin{array}{c}18,17 \\
31,78 \\
5,32\end{array}$ & $\begin{array}{l}0,560 \\
0,407 \\
0,919\end{array}$ \\
\hline $\begin{array}{r}\text { Proteína }(\mathrm{g}) \\
\begin{array}{r}\text { feminino } \\
\text { masculino }\end{array}\end{array}$ & $\begin{array}{l}79,52 \\
66,12 \\
93,27\end{array}$ & $\begin{array}{l}34,83 \\
28,10 \\
35,80\end{array}$ & $\begin{array}{l}69,14 \\
62,27 \\
76,18\end{array}$ & $\begin{array}{l}20,04 \\
17,95 \\
19,83\end{array}$ & $\begin{array}{l}-10,38 \\
-3,85 \\
-17,09\end{array}$ & $\begin{array}{l}0,001 \\
0,213 \\
0,001\end{array}$ \\
\hline $\begin{array}{r}\text { Carboidrato (g) } \\
\text { feminino } \\
\text { masculino }\end{array}$ & $\begin{array}{l}242,18 \\
210,89 \\
274,29\end{array}$ & $\begin{array}{l}90,23 \\
78,22 \\
90,73\end{array}$ & $\begin{array}{l}265,40 \\
226,82 \\
304,97\end{array}$ & $\begin{array}{l}75,96 \\
61,96 \\
68,76\end{array}$ & $\begin{array}{l}23,21 \\
15,93 \\
30,68\end{array}$ & $\begin{array}{l}0,001 \\
0,029 \\
0,001\end{array}$ \\
\hline $\begin{array}{l}\text { Lipídio Total (g) } \\
\text { feminino } \\
\text { masculino }\end{array}$ & $\begin{array}{l}78,63 \\
67,87 \\
89,65\end{array}$ & $\begin{array}{l}39,02 \\
30,60 \\
43,53\end{array}$ & $\begin{array}{l}76,60 \\
68,52 \\
84,90\end{array}$ & $\begin{array}{l}24,83 \\
19,96 \\
26,78\end{array}$ & $\begin{array}{l}-2,01 \\
0,65 \\
-4,75\end{array}$ & $\begin{array}{l}0,370 \\
0,826 \\
0,167\end{array}$ \\
\hline $\begin{array}{r}\text { Lipidio Insaturado }(\mathrm{g}) \\
\text { feminino } \\
\text { masculino }\end{array}$ & $\begin{array}{l}31,63 \\
26,08 \\
37,33\end{array}$ & $\begin{array}{l}20,79 \\
16,41 \\
23,21\end{array}$ & $\begin{array}{l}25,74 \\
22,93 \\
28,62\end{array}$ & $\begin{array}{l}9,54 \\
7,82 \\
10,35\end{array}$ & $\begin{array}{l}-5,89 \\
-3,16 \\
-8,70\end{array}$ & $\begin{array}{l}0,001 \\
0,061 \\
0,001\end{array}$ \\
\hline $\begin{array}{l}\text { feminino } \\
\text { masculino }\end{array}$ & $\begin{array}{c}10,56 \\
7,87 \\
13,31\end{array}$ & $\begin{array}{l}6,32 \\
4,82 \\
6,50\end{array}$ & $\begin{array}{l}11,70 \\
10,31 \\
13,13\end{array}$ & $\begin{array}{l}4,40 \\
4,08 \\
4,30\end{array}$ & $\begin{array}{r}1,14 \\
2,44 \\
-0,20\end{array}$ & $\begin{array}{l}0,012 \\
0,001 \\
0,787\end{array}$ \\
\hline $\begin{array}{l}\text { Colesterol (mg) } \\
\text { feminino } \\
\text { masculino }\end{array}$ & $\begin{array}{l}239,70 \\
204,60 \\
275,70\end{array}$ & $\begin{array}{l}153,50 \\
138,75 \\
160,02\end{array}$ & $\begin{array}{l}204,56 \\
182,98 \\
226,70\end{array}$ & $\begin{array}{l}83,38 \\
89,30 \\
71,35\end{array}$ & $\begin{array}{l}-34,37 \\
-21,62 \\
-48,08\end{array}$ & $\begin{array}{l}0,003 \\
0,197 \\
0,003\end{array}$ \\
\hline $\begin{array}{r}\text { Retinol ( } \mu \mathrm{g} \text { ER) } \\
\text { feminino } \\
\text { masculino }\end{array}$ & $\begin{array}{l}745,64 \\
608,28 \\
886,52\end{array}$ & $\begin{array}{l}831,98 \\
830,23 \\
813,39\end{array}$ & $\begin{array}{l}614,94 \\
596,55 \\
633,80\end{array}$ & $\begin{array}{l}243,50 \\
272,89 \\
211,06\end{array}$ & $\begin{array}{l}-130,70 \\
-11,73 \\
-252,71\end{array}$ & $\begin{array}{l}0,048 \\
0,895 \\
0,010\end{array}$ \\
\hline $\begin{array}{r}\text { Vitamina C (mg) } \\
\text { feminino } \\
\text { masculino }\end{array}$ & $\begin{array}{l}69,83 \\
64,28 \\
75,52\end{array}$ & $\begin{array}{l}86,59 \\
81,43 \\
91,58\end{array}$ & $\begin{array}{l}79,91 \\
69,84 \\
90,24\end{array}$ & $\begin{array}{l}41,62 \\
33,43 \\
46,83\end{array}$ & $\begin{array}{c}10,09 \\
5,56 \\
14,72\end{array}$ & $\begin{array}{l}0,103 \\
0,526 \\
0,096\end{array}$ \\
\hline $\begin{array}{r}\text { Cálcio (mg) } \\
\begin{array}{r}\text { feminino } \\
\text { masculino }\end{array}\end{array}$ & $\begin{array}{l}584,88 \\
481,30 \\
691,12\end{array}$ & $\begin{array}{l}384,17 \\
301,13 \\
429,83\end{array}$ & $\begin{array}{l}561,40 \\
507,00 \\
617,20\end{array}$ & $\begin{array}{l}223,49 \\
232,67 \\
201,63\end{array}$ & $\begin{array}{l}-23,48 \\
25,71 \\
-73,92\end{array}$ & $\begin{array}{l}0,386 \\
0,387 \\
0,105\end{array}$ \\
\hline $\begin{array}{r}\text { feminino } \\
\text { masculino }\end{array}$ & $\begin{array}{c}11,73 \\
9,09 \\
14,45\end{array}$ & $\begin{array}{l}5,62 \\
4,18 \\
5,62 \\
\end{array}$ & $\begin{array}{c}8,43 \\
8,44 \\
10,15\end{array}$ & $\begin{array}{l}2,49 \\
2,49 \\
2,79 \\
\end{array}$ & $\begin{array}{l}-2,45 \\
-0,65 \\
-4,29 \\
\end{array}$ & $\begin{array}{l}0,001 \\
0,209 \\
0,001\end{array}$ \\
\hline
\end{tabular}

${ }^{3}$ Teste $t$ - estudent emparelhado 
Tabela 7. Componentes de variância do consumo de energia e nutrientes, calculado a partir de 3 R24hs. Escola Pública Antonio Alves Cruz, São Paulo, 1999.

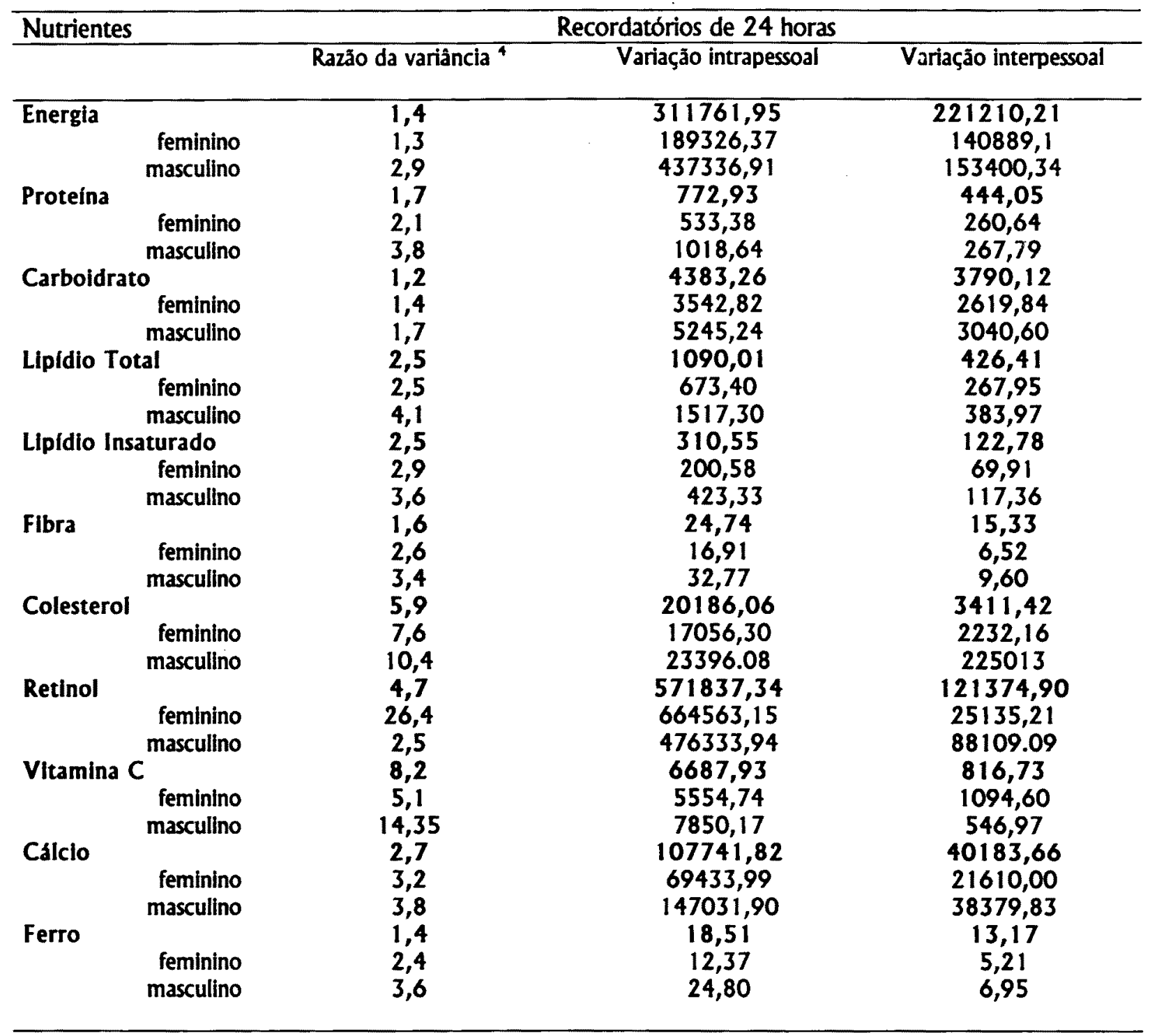

${ }^{4} \lambda=S^{2}{ }_{w} / S^{2}{ }_{b}$ 
Tabela 8. Consumo médio de energia e nutrientes e coeficientes de variação interpessoal e intrapessoal (CV\%), calculados a partir de 3 R24hs. Escola Pública Antonio Alves Cruz, São Paulo, 1999.

\begin{tabular}{lccccc}
\hline Nutrientes & \multicolumn{2}{c}{ Média } & CV T \% & CV $_{\mathrm{b}} \%^{5}$ & $\mathrm{CV}_{\mathrm{w}} \%^{6}$ \\
& \multicolumn{2}{c}{ Dp } & & & \\
\hline Energia (kcal) & 2004,4 & $(728,8)$ & 36,3 & 23,5 & 27,9 \\
Proteina (g) & 79,5 & $(38,8)$ & 43,8 & 26,5 & 34,9 \\
Carboidrato (g) & 242,2 & $(90,2)$ & 37,3 & 25,4 & 27,3 \\
Lipídio Total (g) & 78,6 & $(39,0)$ & 49,6 & 26,3 & 41,9 \\
Lipídio Insaturado (g) & 31,6 & $(20,8)$ & 65,7 & 35,1 & 55,7 \\
Fibra (g) & 10,6 & $(6,3)$ & 59,8 & 36,9 & 45,9 \\
Colesterol (mg) & 239,7 & $(153,5)$ & 64,0 & 24,4 & 59,3 \\
Retinol ( $\mu \mathrm{g}$ ER) & 745,6 & $(831,9)$ & 111,6 & 46,7 & 101,4 \\
Vitamina C (mg) & 69,8 & $(86,6)$ & 124,0 & 40,9 & 117,2 \\
Cálcio (mg) & 584,9 & $(384,2)$ & 65,7 & 34,3 & 56,1 \\
Ferro (mg) & 11,7 & $(5,6)$ & 47,9 & 30,0 & 36,8 \\
\hline
\end{tabular}

${ }^{5}\left(\mathrm{DP}_{\mathrm{b}} /\right.$ média $_{\mathrm{b})} \times 100$

${ }^{6}\left(\mathrm{DP}_{\mathrm{w}} /\right.$ média $\left._{\mathrm{w}}\right) \times 100$ 
Tabela 9. Coeficiente de correlação de Pearson entre o consumo díário de energia e nutrientes avaliado pelo ${ }^{8}$ QFAA e 3 recordatórios de 24 horas. Escola Pública Antonio Alves Cruz, Săo Paulo, 1999.

\begin{tabular}{|c|c|c|c|c|c|c|c|c|c|}
\hline \multirow[t]{4}{*}{ Nutrientes } & \multicolumn{9}{|c|}{ Coeficientes de correlação } \\
\hline & \multirow{2}{*}{\multicolumn{3}{|c|}{ Brutos $^{2}$}} & \multicolumn{3}{|c|}{ Ajustados pela energia } & \multirow{2}{*}{\multicolumn{3}{|c|}{ De- atenuados }} \\
\hline & & $r$ & & & $\mathbf{r}$ & & & & \\
\hline & Total & Fem. & Mas. & Total & Fem. & Mas. & Total & Fem. & Mas. \\
\hline Energia (kcal) & $0,87^{\circ}$ & $0,86^{\prime \prime}$ & $0,82^{* *}$ & -- & - & - & & & \\
\hline Proteina (g) & $0,63^{\circ *}$ & $0,47^{\circ *}$ & $0,66^{* *}$ & $0,31^{* *}$ & 0,17 & 0,21 & 0,38 & 0,22 & 0,32 \\
\hline Carboldrato(g) & $0,77^{*}$ & $0,70^{* *}$ & $0,71^{* *}$ & $0,58^{* *}$ & 0,12 & $0,43^{* *}$ & 0,68 & 0,15 & 0,53 \\
\hline Lipidio Total(g) & 0,72 & $0,68^{* *}$ & $0,69^{\circ *}$ & $0,40^{* *}$ & $-0,07$ & $0,33^{*}$ & 0,54 & $-0,10$ & 0,51 \\
\hline Lipidio insaturado (g) & $0,57^{\circ}$ & $0,46^{\circ \prime}$ & $0,60^{\prime \prime}$ & $0,35^{* *}$ & 0,26 & $0,37^{\prime \prime}$ & 0,48 & 0,36 & 0,55 \\
\hline Fibra (g) & $0,59^{* *}$ & $0,48^{\circ}$ & $0,56^{* *}$ & $0,56^{* *}$ & $0,48^{* *}$ & $0,62^{* *}$ & 0,69 & 0,66 & 0,91 \\
\hline Colesterol (mg) & $0,44^{* *}$ & $0,33^{*}$ & $0,44^{* *}$ & 0,26 & 0,20 & 0,30 & 0,52 & 0,37 & 0,64 \\
\hline Retinol ( $\mu \mathrm{g} E \mathrm{E}$ ) & $0,28^{\circ}$ & 0,18 & $0,39^{\circ}$ & 0,06 & 0,01 & 0,18 & 0,10 & 0.03 & 0,24 \\
\hline Vitamina C (mg) & $0,42^{* *}$ & 0,27 & $0,56^{\circ}$ & $0,47^{* *}$ & 0,37 & $0,56^{* *}$ & 0,91 & 0,61 & - \\
\hline Cálclo (mg) & $0,61^{* *}$ & $0,60^{\circ}$ & $0,50^{* *}$ & $0,51^{* *}$ & $0,50^{* *}$ & $0,46^{* *}$ & 0,70 & 0,72 & 0,69 \\
\hline Ferro (mg) & $0,46^{\circ}$ & 0,30 & $0.43^{\prime \prime \prime}$ & 0.17 & 0,10 & 0,11 & 0.22 & 0.13 & 0.16 \\
\hline Média & 0,57 & 0,48 & 0,58 & 0,37 & 0,23 & 0,36 & 0,52 & 0,34 & 0,51 \\
\hline
\end{tabular}

a transformaçăo logaritmica

- simnificativo a um nivel de $p<0,05$

* * significativo a um nivel de $p<0,01$ 
Tabela 10. Coeficientes de correlação de Pearson entre a caloria e os valores dos nutrientes brutos e ajustados de energia, segundo ambos os instrumentos. Escola Pública Antonio Alves Cruz, São Paulo, 1999.

\begin{tabular}{lcccc}
\hline \multicolumn{1}{c}{ Nutriente } & \multicolumn{2}{c}{ QFAA } & \multicolumn{2}{c}{ R24hs } \\
& bruto & ajustado & bruto & ajustado \\
\hline Energia & - & - & - & - \\
Proteína & 0,79 & $-0,05$ & 0,77 & 0,00 \\
Carboidrato & 0,95 & 0,00 & 0,88 & 0,00 \\
Lipídio total & 0,91 & $-0,02$ & 0,87 & 0,00 \\
Lipídio insat. & 0,79 & $-0,46$ & 0,71 & $-0,02$ \\
Fibra & 0,57 & 0,00 & 0,54 & 0,00 \\
Colesterol & 0,73 & $-0,02$ & 0,58 & 0,09 \\
Retinol & 0,41 & 0,00 & 0,24 & $-0,16$ \\
Vitamina C & 0,41 & $-0,07$ & 0,14 & $-0,02$ \\
Cálcio & 0,62 & 0,00 & 0,57 & 0,06 \\
\hline
\end{tabular}

Tabela 11. Classificação-cruzada de energia e nutrientes em quartis depois do ajuste pela energia em porcentagens. Dados referentes à média de 3 R24hs e do QFAA. Escola Pública Antonio Alves Cruz, São Paulo, 1999.

\begin{tabular}{|c|c|c|c|c|c|c|}
\hline \multirow[t]{2}{*}{ Nutrientes } & \multicolumn{2}{|c|}{$\begin{array}{l}\text { Primeiro quartil do } \\
\text { R24hss }\end{array}$} & \multicolumn{2}{|c|}{$\begin{array}{l}\text { Ultimo quartis } \\
\text { do R24hs }\end{array}$} & \multirow[t]{2}{*}{$\begin{array}{c}\text { Concordância } \\
\text { Bruta }\end{array}$} & \multirow[t]{2}{*}{$\begin{array}{l}\text { Quartis } \\
\text { opostos }\end{array}$} \\
\hline & $\begin{array}{c}\text { Primeiro } \\
\text { quartil } \\
\text { QFAA }\end{array}$ & $\begin{array}{l}\text { Último } \\
\text { quartil } \\
\text { QFAA }\end{array}$ & $\begin{array}{l}\text { Ultimo } \\
\text { quartil } \\
\text { QFAA }\end{array}$ & $\begin{array}{c}\text { Primeiro } \\
\text { quartil } \\
\text { QFAA }\end{array}$ & & \\
\hline Proteína & 26 & 16 & 30 & 20 & 30 & 9 \\
\hline Carboidrato & 42 & 11 & 45 & 10 & 35 & 5 \\
\hline Lipidio Total & 32 & 16 & 25 & 10 & 28 & 6 \\
\hline $\begin{array}{l}\text { Lipídio } \\
\text { Insaturado }\end{array}$ & 37 & 5 & 30 & 20 & 29 & 6 \\
\hline Fibra & 47 & 0 & 45 & 5 & 39 & 1 \\
\hline Colesterol & 26 & 16 & 30 & 5 & 23 & 5 \\
\hline Retinol & 32 & 21 & 30 & 10 & 25 & 8 \\
\hline Vitamina C & 47 & 0 & 55 & 5 & 43 & 1 \\
\hline Cálcio & 63 & 11 & 55 & 10 & 56 & 5 \\
\hline Ferro & 16 & 10 & 25 & 20 & 20 & 8 \\
\hline Media & 37 & 11 & 37 & 12 & 33 & 5 \\
\hline
\end{tabular}


Gráfico 2. Coeficiente de correlação entre a proteína e a caloria calculado pelo QFAA, antes do ajuste pela energia.

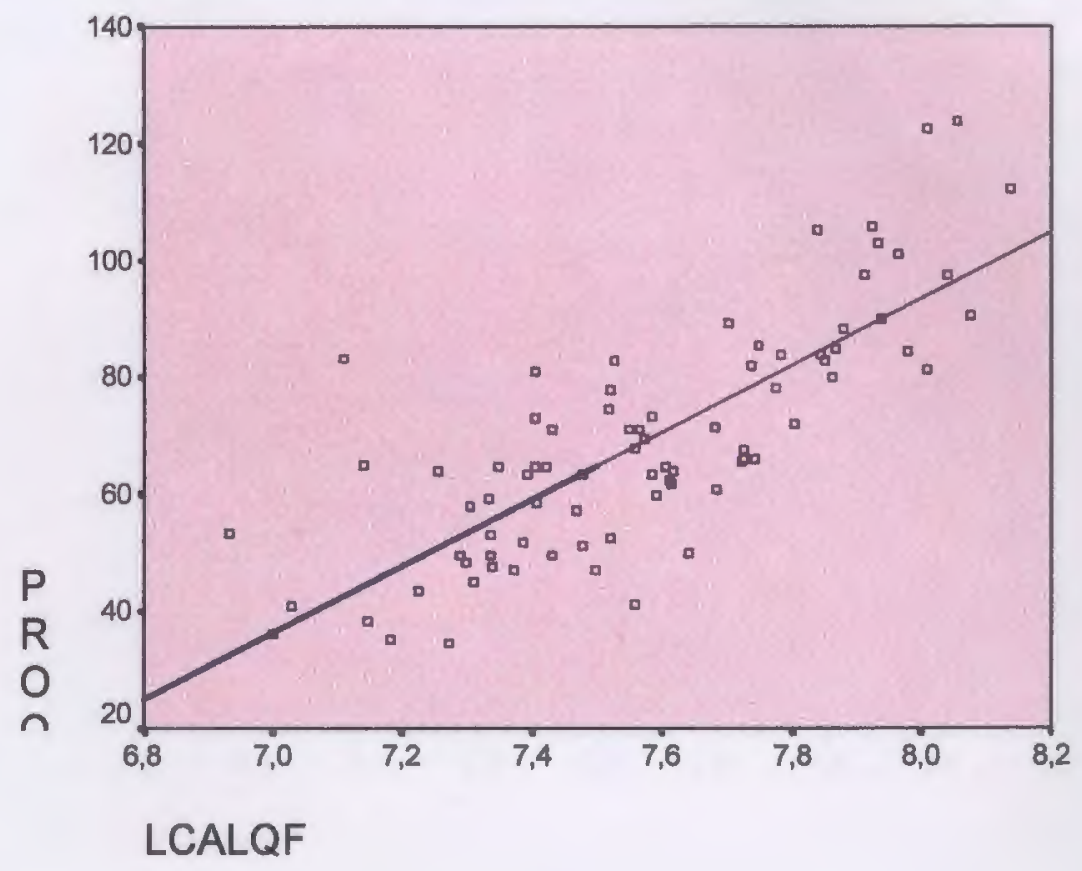

Gráfico 3. Coeficiente de correlaçăo entre a proteina e a caloria calculado pelo QFAA, depois do ajuste pela energia.

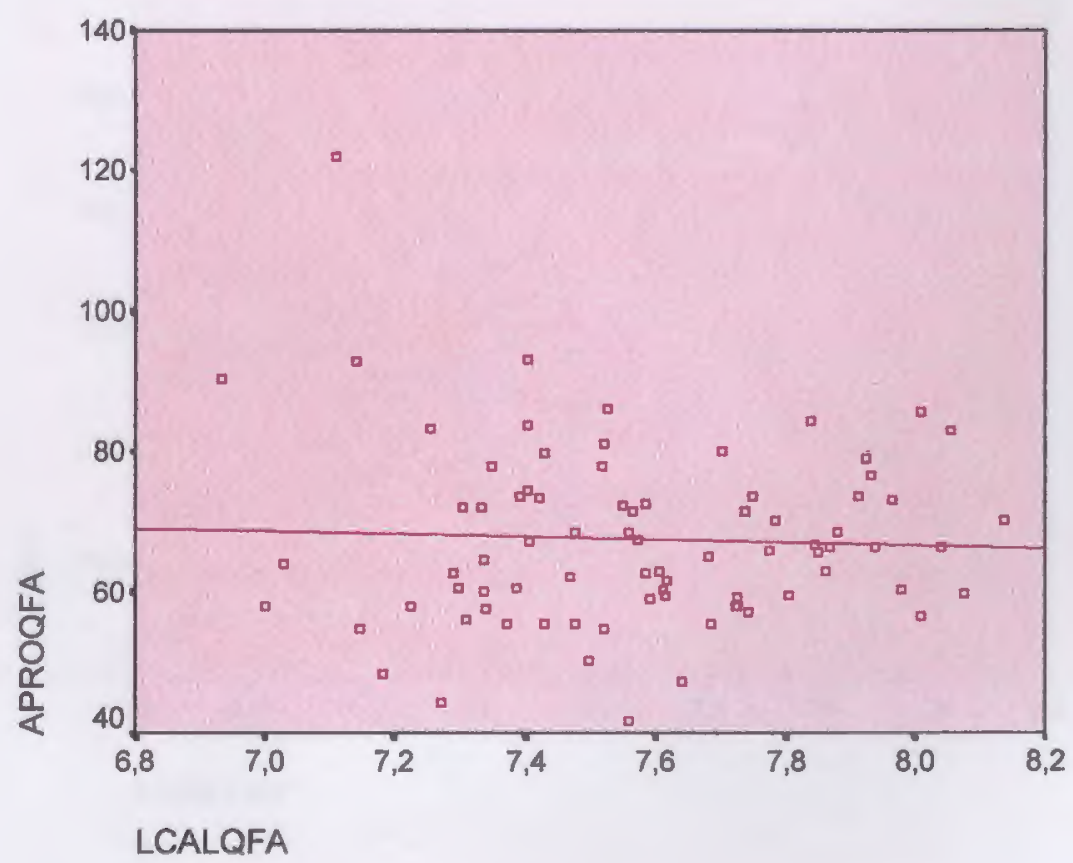


Gráfico 4. Coeficiente de correlação entre o colesterol e a caloria calculado pelo R24hs, antes do ajuste pela energia.

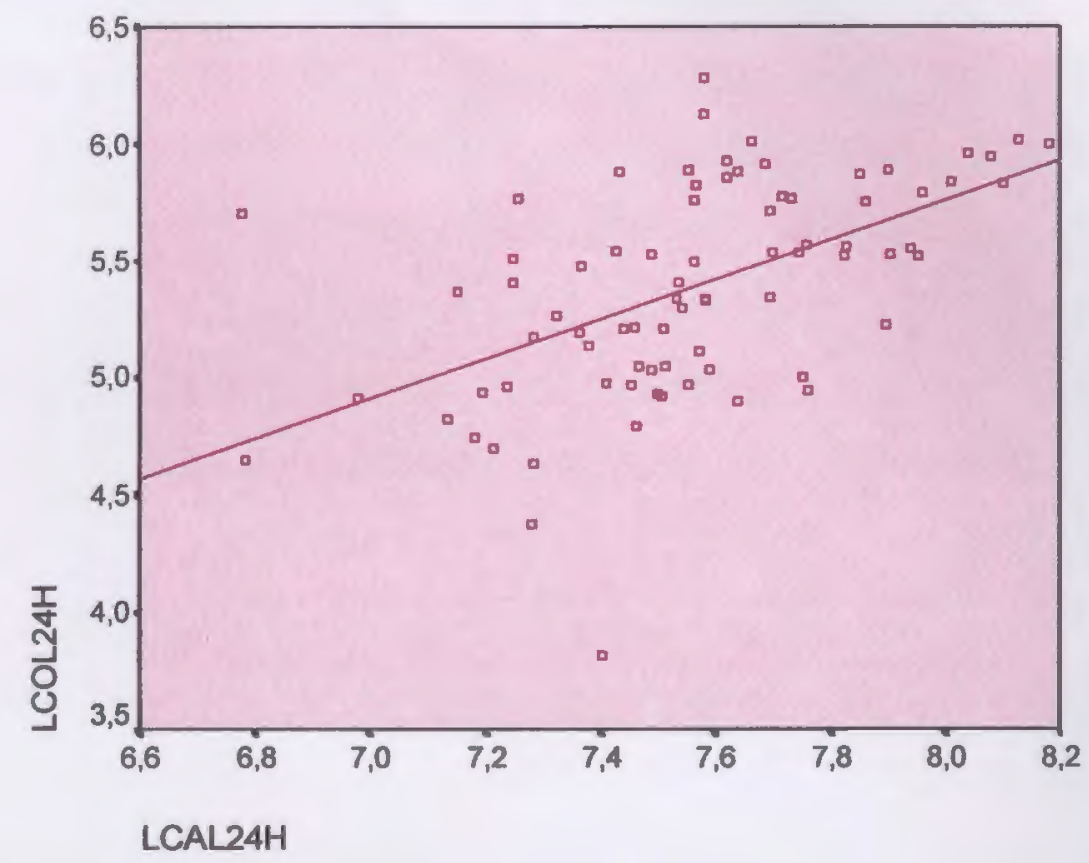

Gráfico 5. Coeficiente de correlaçăo entre o colesterol e a caloria calculado pelo R24hs, depois do ajuste pela energia.

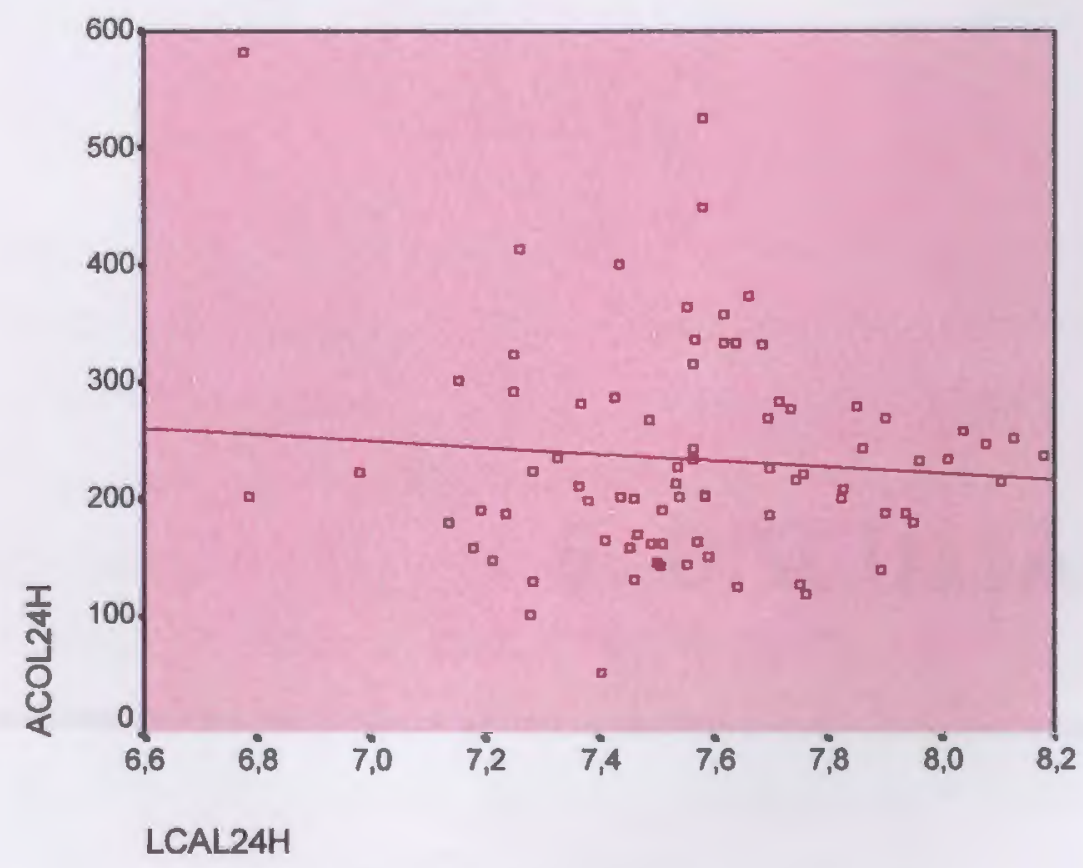


Sabe-se que a dieta desempenha um papel muito importante na prevenção das principais causas de mortalidade e morbidade em todas as sociedades. Alguns fatores da dieta estão associados com a proteção da saúde e outros, pelo contrário, com o incremento do risco a ECNT. Nos últimos anos têm surgido evidências das possíveis ligações entre a dieta das crianças e adolescentes e as enfermidades da vida adulta, principalmente quando se tratam de doenças do coração, câncer e osteoporose. Segundo WILLETT (1998), ROCKETT \& COLDITZ (1997b) e BERENSON et al. (1989) estas doenças provavelmente têm suas origens nos hábitos alimentares adquiridos durante a infância $e$ adolescência.

Transtornos nutricionais são freqūentes na adolescência, sendo a obesidade um dos mais comuns, com grande repercussão na vida adulta, no plano individual, econômico e social. O elevado aporte de energia procedente dos lipídios pode produzir um desequilíbrio que aumenta o acúmulo de gordura, especialmente naqueles individuos geneticamente predispostos (AMADOR 2000). Este fato tem sido uma constante preocupação e considerado em programas de prevenção que têm como objetivo fomentar mudanças no estilo de vida e no comportamento alimentar.

Pela potencial relação entre a dieta das crianças e adolescentes com muitas doenças na vida adulta, pela necessidade de se monitorar as práticas alimentares e devido à inexistência de estudos de base populacional, considerou-se necessário desenvolver um questionário de freqüência alimentar acurado, confiável, relativamente de baixo custo e que possa ser aplicado repetidas vezes em estudos que envolvam um grande número de indivíduos jovens.

Neste sentido, o presente estudo avaliou a validade relativa de um questionário de freqüência alimentar para adolescentes - QFAA. Este novo instrumento foi criteriosamente desenhado seguindo a técnica estatística 
proposta por BLOCK et al. (1985a e b), as recomendações de WILLETT (1998) e NELSON (1997) para se determinar uma porção usual e uma lista de alimentos de acordo com o gênero e coerente com os padrōes alimentares e hábitos de consumo do grupo populacional objeto deste estudo.

As características demográficas revelam um grupo bastante homogêneo quanto à idade, verificando-se que aproximadamente $83 \%$ dos indivíduos estariam concentrados entre 15 e 17 anos de idade, razão pela qual as análises posteriores não foram realizadas segundo esta variável.

O questionário deste estudo permitiu avaliar 79 adolescentes, de ambos os sexos ( 40 mulheres e 39 homens), número de participantes semelhante aos dos estudos de LIVINGSTONE et al. (1992) e TAYLOR \& GOULDING (1998), superior ao estudo de KOSKOUN et al. (1994) e inferior aos estudos de ROCKETT et al. (1995 e 1997a) e FIELD et al. (1999).

Uma das dificuldades deste estudo foi seguir os mesmos alunos durante os seis meses de pesquisa. As perdas foram em torno de $23 \%$, dadas principalmente pela ausência do aluno na escola durante as visitas. Para se manter o grau de interesse dos alunos, foi necessário explicar reiteradas vezes a importante contribuição que eles estavam dando, ao participar da pesquisa, para o conhecimento científico. Durante as 4 visitas foi oferecido um chocolate como forma de retribuiçăo à colaboração dada por eles. É importante salientar que a sugestão do chocolate foi apresentada pelos próprios alunos e concedida após consulta à direção da escola.

Embora a amostra não tenha sido estatisticamente planejada, o número de participantes do estudo não invalida os resultados, já que esta amostra estaria de acordo com as recomendações feitas na "IV Conferência Internacional sobre Métodos de Avaliação Dietética", realizada em Tucson-Arizona, no ano 2000, 
onde se afirmou que um número entre 50 e 100 pessoas seria suficiente para a realização de um estudo de validação (BURLEY \& CADE 2000).

O que se pode observar na literatura, no que se refere ao tópico "material e métodos", é que a grande maioria dos artigos apresenta o número de participantes sem mencionar se tal número foi calculado ou não. Somente quando o estudo de validação está inserido em um estudo epidemiológico mais amplo é que o número de indivíduos está representado por uma amostra aleatória de aproximadamente $10 \%$ a $20 \%$ da população objeto do estudo. Geralmente este número contempla dois fatores muito importantes: a adesão e as perdas durante o desenvolvimento do estudo (ANDERSEN et al. 1995; ROCKETT et al. 1995; ROCKETT et al. 1997a; FIELD et al. 1999).

Os resultados de consumo de energia e nutrientes mostram diferenças quando analisados segundo o gênero dos participantes da pesquisa. $O$ consumo das mulheres foi sempre inferior ao dos homens, por ambos os métodos e para todos os nutrientes estudados.

Os valores de consumo de energia $(1776,5 \mathrm{kcal})$, cálcio $(582,9 \mathrm{mg})$ e ferro $(9,5 \mathrm{mg})$ encontrados por DUNKER (1998) em adolescentes do sexo feminino são muito semelhantes aos resultados deste estudo. Cabe salientar que a autora coletou os dados com a mesma metodologia utilizada neste estudo.

Utilizando a mesma metodologia para coleta de dados (R24hs), FRUTUOSO et al. (2000) calcularam distribuições do consumo total de calorias $(1953 \mathrm{kcal})$, proteína $(69 \mathrm{~g})$, carboidrato $(264 \mathrm{~g})$, gordura $(69 \mathrm{~g})$, cálcio (516mg) e ferro $(9,8 \mathrm{mg})$, semelhantes a este estudo.

Quando se compara os resultados do QFAA com os de GAMA (1999), que utilizou QFAA para avaliar o consumo alimentar de adolescentes, 
observam-se valores superiores para o consumo de energia $(F=2331$,0kcal; $M=3366,8 \mathrm{kcal}) ; \quad$ cálcio $\quad(F=889,8 \mathrm{mg} ; \quad M=1157,4 \mathrm{mg})$, vitamina $C$ $(F=167,8 \mathrm{mg} ; M=181,0 \mathrm{mg})$ e retinol $(F=793,2 \mathrm{mcg} ; M=833,6 \mathrm{mcg})$.

O consumo de energia dos adolescentes avaliados por NUZZO (1998) também foi superior aos resultados deste estudo e no estudo de HALPERN et al. (1999), realizado em adolescentes de escolas privadas e públicas, encontraram-se consumos médios de cálcio de $795,5 \mathrm{mg}$ e de $728,84 \mathrm{mg}$, respectivamente. Em ambos estudos as diferenças podem estar dadas pelo desenho do estudo e pela metodologia empregada (Diário alimentar) na coleta dos dados.

Os resultados dos R24hs mostraram um consumo médio de energia proveniente dos lipidios de $30,5 \%$ para o sexo feminino e de $40,2 \%$ para o sexo masculino, concordando com os estudos de PASSAMAl et al. (1998) e DUNKER (1998), os quais mostraram consumos similares: $37,9 \%$ para adolescentes de ambos os sexos e de $36,7 \%$ para o sexo feminino, respectivamente.

A porcentagem de energia do lipídio total estimado pelo QFAA foi igual à obtida pelo R24hs $(30,5 \%)$, para as mulheres, e nos homens, de $37,8 \%$. Os valores calculados por ambas metodologias revelam consumos superiores ao recomendado há uma década pela monografia Healthy People 2000, que identificou as crianças e adolescentes como um grupo que requer especial atenção, principalmente quanto ao seu consumo de gordura total, (consumo menor que $30 \%$ do Valor Calórico Total), gordura saturada (menor que 10\% da energia) e cálcio ( 3 ou mais porções de alimentos fontes deste nutriente) (SLEPTT \& STORY 1991). 
O consumo médio de energia dado pelo $R 24$ hs e pelo QFAA possuem diferenças mínimas, enquanto os macronutrientes se distribuem inadequadamente em relação ao VCT. Embora se observe consumo elevado de proteína para os homens e baixo em carboidrato para as mulheres, os valores obtidos pelo QFAA não podem ser usados para avaliar a adequação da dieta, pois este instrumento substitui a quantificação exata do consumo de vários dias pela informação global da ingestão de um período prolongado de tempo.

Para introduzir a discussão estritamente relacionada à capacidade do QFAA em avaliar corretamente o consumo alimentar dos adolescentes, é necessário ter sempre presente a definição de validade relativa e que o objetivo subjacente do QFAA é categorizar os indivíduos segundo seu consumo alimentar pregresso dos nutrientes estudados.

A validade relativa pode ser avaliada pela diferença das médias (viés) entre o QFAA e a medida de referência (Média de $3 \mathrm{R} 24 \mathrm{hs}$ ) usando teste $t$ student para comprovar a significância estatística, tal como recomenda NELSON (1997).

Como é verificado por MELA \& AARON (1997), NELSON (1997), HANSSON et al. (2000) e FRASER et al. (2000), a idade, gênero, educação e condiçăo fisiológica dos indivíduos são fatores que afetam a reprodutibilidade e validade das estimativas quando se usam diferentes metodologias para avaliação dietética. De todos os nutrientes avaliados pelo QFAA, somente a energia, carboidrato, lipídio total e cálcio mostraram diferenças inferiores a $10 \%$, indicando alta consistência das estimativas para estes nutrientes.

Já para os 7 nutrientes restantes as diferenças foram significativas, observando-se que as mulheres mostraram melhor desempenho para responder aos formulários do que os homens. Este fato pode ser explicado, possivelmente, 
pelo comportamento alimentar e sociocultural das mulheres, associado ao estilo de vida. Segundo PIETINEN et al. (1988a) e HANSSON et al. (2000) as diferenças estão marcadas por dois fenômenos: primeiro, as mulheres dão mais atenção que os homens ao conteúdo nutricional dos alimentos que consomem; segundo, porque nessa faixa etária seguem-se altos padrões de consumo alimentar impostos pela mídia e pela alta sociedade. Acredita-se que este fato poderia também estar influenciado pelo maior contato que as mulheres têm com os alimentos, a forma de preparação, tamanho dos utensílios e tamanho das porções.

Como já foi mencionado, a informação da variabllidade intra e interpessoal do consumo de energia e nutriente é muito importante no desenho dos estudos epidemiológicos e também na análise dos estudos de validação. Em primeiro lugar, porque descrevem padrões de consumo na população; em segundo, porque é possível planejar o número de dias necessários para as avaliaçōes e corrigir as estimativas encontradas pelos componentes da variância.

Os resultados da análise de variância estão mostrados nas tabelas 7 e 8 . Estes valores explicam uma considerável variaçăo do consumo diário calculado a partir de 3 dias do R24hs. Nestas tabelas observa-se resultados próximos aos encontrados por LIU et al. (1978), BEATON et al. (1983), SEMPOS et al. (1985) e FIELD et al. (1999), embora somente um deles tenha sido realizado em crianças (Tabela 12).

Os valores $\lambda$ (razão de variância) superiores a 1 são amplamente aceitos $\mathrm{e}$ se explicam quando a variância intrapessoal é maior que a variância interpessoal. Estes altos padrões de variabilidade intrapessoal derivam principalmente do comportamento social dos indivíduos, mas também de outros fatores. 
Tabela 12. Razão de variância $(\lambda)$ dos componentes intrapessoal e interpessoal para consumo de nutrientes observados em estudos norteamericanos.

\begin{tabular}{|c|c|c|c|c|c|c|}
\hline \multirow[t]{2}{*}{ Nutrientes } & \multirow{2}{*}{$\begin{array}{c}\begin{array}{c}\text { Liu et.al } \\
(1978)\end{array} \\
M\end{array}$} & \multicolumn{2}{|c|}{$\begin{array}{c}\text { Beaton et al. } \\
\text { (1983) }\end{array}$} & \multirow{2}{*}{$\begin{array}{c}\begin{array}{c}\text { Sempos et.al. } \\
(1985)\end{array} \\
\mathbf{F}\end{array}$} & \multicolumn{2}{|c|}{$\begin{array}{l}\text { Field et .al. } \\
\text { (1999) }\end{array}$} \\
\hline & & $M$ & $F$ & & $5^{0}$ & $7^{0}$ \\
\hline Energia(kcal) & 1,8 & 1,1 & 1,2 & 1,6 & 2,8 & 2,6 \\
\hline Proteína & - & - & - & 2,1 & 2,8 & 3,2 \\
\hline Carboidrato & & 1,3 & 1,3 & & 3,2 & 3,4 \\
\hline Lipldio Total & & - & - & & 3,7 & 2,8 \\
\hline Lipldio Ins. & & - & - & 5,0 & - & - \\
\hline Fibra & & - & - & & 5,6 & 5,6 \\
\hline Colesterol & 3,8 & - & - & 6,8 & - & - \\
\hline Retinol & & $>100$ & 47,9 & 7,7 & - & - \\
\hline Vitamina C & & 4,0 & 2,3 & 2,3 & 7,8 & 5,2 \\
\hline Cálclo & & 2,6 & 2.3 & 1,1 & 4,4 & 4,7 \\
\hline Ferro & & 3,6 & 2,6 & 2,7 & 4,0 & 3,7 \\
\hline
\end{tabular}

A magnitude da variação se diferencia consideravelmente de nutriente para nutriente, concordando com os resultados de HARBOTTLE \& DUGGAN (1994), TSUBONO et al. (1998) e FRIIS et al. (1997). Os autores afirmam que o consumo regular de nutrientes (como, por exemplo, consumo de macro nutrientes) tem razões de variância $(\lambda)$ menores se comparados com nutrientes com alta variabilidade intrapessoal, como foi o caso do retinol, vitamina $\mathrm{C}$ e colesterol neste estudo. No estudo de PIWOZ et al. (1994), os pesquisadores mostraram que a variabilidade intra e interpessoal muda também com a idade e com a variedade de alimentos fontes de nutrientes na dieta.

Os altos padrões de variabilidade observados refletem, também, o comportamento alimentar do grupo segundo o gênero. Com exceção do nutriente retinol, a razăo da variância das mulheres foi inferior à dos homens, sugerindo que as mulheres possuem hábitos alimentares mais constantes e com menos variabilidade.

Outros fatores, entre eles os dias da semana e final de semana, o intervalo de tempo entre uma medição, bem como sazonalidade, contribuem 
para a variabilidade da dieta. Neste estudo avaliou-se o consumo alimentar dos alunos na segunda-feira, quarta-feira, quinta-feira e um feriado nos meses de junho, agosto, outubro e novembro.

Quando os dados foram examinados de forma independente, encontrouse que os dados correspondentes ao mês de Junho (R24hs de segunda feira) foram significativamente $(p<0,005)$ diferentes dos dados coletados nas outras datas.

As diferenças podem ser explicadas pelo comportamento dos alunos frente à primeira avaliação, dado pela inexperiência e algumas dificuldades para quantificar as porções consumidas. Estas dificuldades foram solucionadas com a ajuda de outro pesquisador treinado e com apresentação do "kit" de medidas caseiras antes e durante a coleta dos dados. Nas datas seguintes de coleta os alunos mostraram rapidez e bom desempenho para responder aos formulários.

TARASUK e BEATON (1991a) explicam que o consumo de energia e nutrientes varia com o início do inverno e do verão, estações significativamente diferentes do outono e primavera. BASIOTIS et al. (1989) mostraram também que o consumo médio de energia é significativamente maior durante os meses de julho, agosto, dezembro e janeiro. Pela informação obtida dos R24hs e QFAA, a freqüência de consumo de frutas e verduras foi maior entre as mulheres, o que pode explicar a exagerada variabilidade intrapessoal do consumo de retinol e vitamina $C$, que por sua vez é influenciada pelo período do ano em que foram coletados os dados, mostrando a possível influência da sazonalidade sobre o consumo (ZIEGLER et al. 1987). (Dados não apresentados neste trabalho)

É comum afirmar-se que padrões de consumo de energia e nutrientes são maiores nos dias de final de semana. Pelos resultados encontrados, esta 
afirmação é verdadeira, pois se observou que o consumo variou segundo o dia da coleta, especialmente com relação ao primeiro dia. Considerou-se que a magnitude da variância observada está influenciada por padrões culturais (ciclo de 7 dias) assim como por razões homeostáticas, que fazem um balanço "corretivo" entre os períodos em que se consome acima da média e os períodos em que se consome abaixo da média. Ambos, o ciclo cultural semanal e o efeito homeostático, estão implícitos no pressuposto fundamental de que erros sucessivos são independentes e, neste caso, fornece um maior grau de precisão esperado do que aquele sob independência (LOZY 1983).

Por outro lado, quando os padrões alimentares de longo período são tratados como variável contínua, a variação sazonal observada nem sempre explica as mudanças sistemáticas no consumo no decorrer do ano (TARASUK e BEATON 1991a). A cidade de São Paulo não mostra estaçōes do ano tão marcadas quanto nos paises do América do Norte e Europa, por exemplo. Certamente pode-se afirmar que as temperaturas de junho e novembro são diferentes, mas a disponibilidade de alimentos nestes meses não sofre tantas modificações, já que São Paulo, como grande metrópole, se abastece de alimentos sazonais produzidos em outras regiōes do país, como é o caso de frutas (mamão, banana, laranja) presentes durante todo o ano. São sazonais as mangas, morangos, caquis, entre outros.

É amplamente aceito que um dia de avaliação não reflete a verdadeira ingestão, sobretudo para alguns micronutrientes. A estimativa do consumo verdadeiro pode ser fornecida por um número representativo da população ou por múltiplas avaliaçōes por pessoa. Neste sentido, concorda-se com BEATON (1994), quando diz que é precipitado afirmar que 3 dias são suficientes e também com POTOSKY et al. (1990), os quais sugerem que estudos de validação com 4 dias ou menos proporcionariam estimativas pobres, já que não representariam a verdadeira ingestão. 
O número de dias planejado neste estudo considerou os coeficientes de correlação encontrados na prova piloto e os critérios propostos por DONNER \& ELIASZIW (1987). Cabe mencionar que o número de dias calculados foi de 5 , embora só se tenha conseguido realizar 4 avaliaçōes, por problemas de organização da escola onde o estudo foi realizado. Os resultados das tabelas 7 e 8 confirmam o amplamente referido na literatura, ou seja, que o número de dias necessários difere grandemente de nutriente para nutriente, devido aos componentes de variação intra e interpessoal do consumo. Este foi o caso do colesterol, retinol e vitamina $\mathrm{C}$, onde se observaram razões de variância maiores que 4, WILLETT (1998) assinala que, para se avaliar corretamente o colesterol e vitamina A, seriam necessários 9 e 26 dias de coleta de dados, respectivamente. Neste sentido, considera-se que, pela natureza variável da dieta e as características dos alimentos que são fontes destes nutrientes, o número de recordatórios aplicados na populaçăo foi insuficiente.

Como mencionado no capitulo III, a validade relativa de um questionário de freqüência alimentar está diretamente relacionada com a capacidade do instrumento "novo" em chegar a valores o mais próximo possível do valor verdadeiro. Em outras palavras, é a comparaçáo entre o QFAA e o padrão de referência, o qual deverá ser o mais exato e confiável possivel; portanto, qualquer erro de ambos os métodos deverá ser independente (WILLETT 1998). Idealmente, medidas independentes são obtidas pelo uso de marcadores bioquímicos ou de técnicas como a da ADM. Entretanto, estas metodologias requerem laboratórios sofisticados e de alto custo, além de prover informação somente para alguns nutrientes ou estritamente da energia.

A tabela 13 reúne estudos de validação realizados em adolescentes nos quais utilizou-se como padrão de referência múltiplos R24hs (ROCKETT et al. 1997a; FIELD et al. 1999; e YAROCH et al. 2000). Nestes estudos para a 
classificação relativa dos indivíduos segundo seu consumo de energia e nutrientes, foi usado coeficiente de correlação de Pearson e Spearman. De forma similar aos estudos em adultos, as correlaçōes foram realizadas antes e depois do ajuste pela caloria e corrigidas posteriormente pela variância intrapessoal.

Tabela 13. Coeficientes de correlação de consumo de energia e nutrientes observados em estudos norte-americanos e europeus.

\begin{tabular}{|c|c|c|c|c|c|}
\hline Nutriente & $\begin{array}{c}\text { Yarockt .et. } \\
\text { al.2000 }\end{array}$ & $\begin{array}{c}\text { Field" } \\
\text { et.al.1999 }\end{array}$ & $\begin{array}{c}\text { Taylor } \\
\text { \&Goulding } \\
(1998)\end{array}$ & $\begin{array}{l}\text { Rockett }^{* *} \\
\text { et.al. } 1997\end{array}$ & $\begin{array}{c}\text { Andersen et.al. } \\
1995\end{array}$ \\
\hline Energia & - & 0,44 & - & 0,45 & - \\
\hline Carboidrato & 0,64 & 0,56 & - & 0,47 & 0,55 \\
\hline Proteína & 0,27 & 0,31 & - & 0,44 & 0,31 \\
\hline Lipidio Total & 0,47 & 0,31 & - & 0,56 & 0,41 \\
\hline Lipídio Ins. & - & - & - & 0,30 & 0,46 \\
\hline Fibra & - & 0,33 & - & 0,35 & 0,27 \\
\hline Colesterol & 0,47 & - & - & 0,35 & - \\
\hline Retinol & - & - & - & 0,60 & 0,39 \\
\hline Vitamina C & - & 0,76 & - & - & 0,37 \\
\hline Cálcio & - & 0,47 & 0,52 & 0,55 & 0,54 \\
\hline Ferro & - & 0,40 & - & $0,26^{\circ}$ & 0,39 \\
\hline Média & 0,50 & - & - & 0,50 & \\
\hline
\end{tabular}

* ajustado pela energia

** de-atenuado

Neste estudo observaram-se correlaçōes brutas entre o QFAA e as médias de 3 R24hs amplamente distribuídas $r=0,18-0,87$ com média de $r=0,57$ superior ao estudo de ROCKETT et al. (1997) e FIELD et al. (1999), que apresentam médias de $r=0,39$ e $r=0,28$, respectivamente. Os valores encontrados aparentemente sugerem uma adequada habilidade do questionário para situar os indivíduos através da distribuição do consumo, mas depois do ajuste pela energia os coeficientes de correlação brutos decresceram em aproximadamente $50 \%$, obtendo-se correlações que variaram entre $r=-0,07$ e $r=0,62$, sendo a mais alta para fibra e a mais baixa para lipídio total.

O fato de que as correlações tenham diminuído consideravelmente conduziram à busca de possíveis respostas. Segundo WILLETT (1998), o ajuste pela caloria total incrementa o coeficiente de correlação quando a variabilidade 
do consumo do nutriente esta relacionado com a ingestão de energia mas decresce quando a variabilidade do nutriente depende de erros sistemáticos de superestimação e subestimação. Nos estudos em adultos de WILLETT et al. (1985), OVERVAD et al. (1991) e RIMM et al. (1992), este procedimento confere aos $r$ valores mais relevantes. Em estudos realizados na Grécia, por GNARDELLIS et al. (1994) e nos Estados Unidos (MUNGER et al. 1992) os dois efeitos (melhorando e decrescendo a correlação) acontecem simultaneamente para os diferentes nutrientes analisados. Já no estudos de MARTIN-MORENO et al. (1993), na Espanha, o efeito é particularmente insignificante.

A interpretação do procedimento "ajuste pelo total de energia ingerida" em estudos epidemiológicos é particularmente complexa. Em uma população sadia, o consumo de energia é conseqũência da variação da atividade física, tamanho corporal e eficiência metabólica. Neste sentido, uma pessoa pode consumir mais ou menos energia do que necessita durante um período de tempo, o que poderá ter efeitos sobre o peso ou no balanço de energia. Sendo que, dentre estes fatores, o tamanho corporal (em particular massa magra), é o principal determinante da variação de energia de indivíduos estudados sob condições predeterminadas de atividade física (WILLETT et al. 1997; RAVUSSIAN et al. 1986).

As razōes que a literatura traz para se realizar este procedimento são várias, cabendo destacar:

a) Controle da confusão.

Fatores de confusão podem ocorrer se o total de energia consumida está associado com o risco doença, talvez devido a diferenças individuais já mencionadas ou, em estudo caso - controle, devido a vieses na informação. 
Neste sentido muitos nutrientes estão associados com o consumo total de energia, tanto porque eles contribuem diretamente com a energia como porque as pessoas que consomem mais energia, têm mais probabilidade de consumir mais de todos os nutrientes.

\section{b) Remover as variaçōes externas.}

Se o total de energia consumida não está relacionado com o risco a doença, isto implica que a atividade fisica, eficiência metabólica e tamanho corporal năo săo os determinantes do risco à doença. $O$ grau com que estes fatores contribuem para a variação do consumo de um nutriente provavelmente deve ser considerado como externo.

Em uma situação de avaliação do consumo de um nutriente específico, erros de medição do nutriente estão fortemente correlacionados com os erros de medição do consumo total de energia. Para FREUDENHEIM (1999) e WILLETT (1998), as diferenças individuais (variabilidade interpessoal) no consumo de energia produzem variações no consumo de nutrientes específicos não relacionadas com a composição da dieta, porque o consumo da maioria dos nutrientes está positivamente correlacionado com o consumo total de energia. Quando o consumo de energia está associado com a doença mas não é causa direta, os efeitos de nutrientes específicos podem ser distorcidos ou confundidos pelo consumo total de energia. Exemplo deste tipo ocorreu com o carboidrato $(r=0,95)$ e lipídio total $(r=0,91)$, na tabela 10, e proteína e colesterol, nos gráficos 2 e 4 .

Além disso, devido ao fato de os erros de medição, na avaliação do consumo de nutrientes, estarem fortemente correlacionados com os erros na medição da energia total, o controle da variação ou remoção da variaçăo externa no consumo de energia total também reduzirá os erros de medição para os nutrientes estudados. 
Embora o método R24hs seja conceitualmente diferente do QFA (com perguntas indeterminadas, respostas que dependem de um período curto de memória e a não necessidade de que os indivíduos façam cálculos mentais para determinar as porçōes mais freqüentemente consumidas), ambos os métodos têm como característica comum a mesma fonte de erros. Neste sentido, correlaçōes artificialmente altas, como é o caso da energia (Fem. $r=0,87$ Mas. $r=0,82$ ), podem ser explicadas.

Presume-se que outra razão pela qual se observaram coeficientes de correlação artificialmente altos não ajustados, seja pelo uso da mesma base de dados para analisar a composição dos alimentos de ambos os métodos. Conceitualmente, erros sistemáticos do banco de dados aconteceram na mesma direção e grau de intensidade no momento em que se calculou a composição de um determinado alimento presente em ambos os métodos. ROCKETT et al. (1997) afirmam que para prevenir erro de tipo sistemático em seu estudo tiveram que usar bases de dados independentes.

Coeficientes de correlação elevados, tanto para estudos de reprodutibilidade quanto para estudos de validade, conduzem à suposiçăo de que há um consumo alimentar homogêneo, embora se saiba que existem erros de medição da informação. Segundo HANSSON et al. (2000), em um estudo de reprodutibilidade os coeficientes de correlaçăo podem ser elevados cada vez que aparece uma média junto com uma distribuição relativamente simétrica, como é o caso do leite, bife, arroz e feijāo. Médias baixas junto com distribuiçōes assimétricas -- característico de alimentos não consumidos por um grupo grande de pessoas -- são contrabalançadas por consumo elevado de alimentos (brócolis, peixe e bebida alcoólica, etc) de poucos consumidores.

Tais erros resultados de indivíduos que superestimam e outros que subestimam, podem ser reflexo de uma grande variabilidade da informação 
obtida por pelo QFAA e R24hs. Correlações baixas depois dos devidos ajustes são explicadas, segundo NELSON (1997), pela variância intrapessoal inerente às avaliaçōes dietéticas realizadas em períodos curtos $\mathrm{e}$ pelo uso de metodologias mais acuradas.

A superestimação ou subestimação extrema de energia geralmente podem levar a similares extremos na informação de outros nutrientes. Segundo FLEGAL (1999) uma maior informação de um determinado nutriente pode ser mais decorrência da superestimação do consumo da energia total do que do alto consumo verdadeiro do nutriente. Neste sentido, o valor absoluto do nutriente é um erro, que não pode ser corrigido, embora o valor do nutriente relativo ao consumo de energia possa ser calculado.

Se for assumido que todos os elementos da dieta são informados proporcionalmente, então o ajuste da energia poderia compensar os erros no nível geral da informação. Esta afirmação se baseia no fato de que os indivíduos informam o consumo de nutrientes em proporçóes similares em ambos instrumentos. No estudo de FLEGAL \& LARKIN (1990), eles verificaram que $46 \%$ dos respondentes (homens e mulheres entre 24 e 45 anos) reportaram seu consumo de gordura de forma desproporcional. A modesta correção pela estratégia do ajuste pela energia no estudo de FLEGAL \& LARKIN (1990) e a diminuição dos coeficientes de correlação neste estudo tornam esta suposição um pouco menos válida, pois pode-se pressupor que os indivíduos neste estudo não reportaram os nutrientes de forma similar para os dois métodos. Portanto, embora $o$ ajuste pela energia tenha possibilitado remover as diferenças gerais e comuns entre os métodos, não permitiu que se removesse as diferenças resultantes da informação desproporcional (FLEGAL 1999).

Outra razão pode ser a pouca informação de erro diferencial no R24hs. Se os alimentos referidos são de baixo valor nutritivo ou altamente calóricos 
(refrigerantes, alimentos fritos), 0 ajuste pela energia tende a exagerar 0 conteúdo do nutriente na dieta.

Entende-se que esta desproporcionalidade, que afeta também a concordância entre os métodos, pode ser resultado das diferenças da freqũência e do tamanho da porção informada, tópicos que não foram abordados, mas que se considera imprescindíveis, por enriquecerem a análise.

Segundo ROCKETT \& COLDITZ (1997b), outra fonte de erro (além destes problemas metodológicos) é que estudos dietéticos com crianças e adolescentes apresentam dificuldades adicionais, relacionadas com a habilidade cognitiva de registrar e lembrar seus consumos, assim como também as limitações dadas pela falta de conhecimento dos alimentos e algumas preparaçōes.

Erros de memória desempenham um papel muito importante na falta de concordância (valores baixos dos $r$ ) entre o consumo habitual estimado tanto pelo QFAA quanto pelos R24hs. A principal fonte consiste na falta de memória, elaboração cognitiva e confusão entre o usualmente consumido e o consumo atual (GARROW 1995). A isto se adicionam aspectos subjetivos: a percepção, quantificação do tamanho da porção e o valor social que alguns alimentos possuem. Segundo BARANOWSKI et al. (1991) e GORAN (1998), as crianças e adolescentes tendem a lembrar melhor os alimentos de sua preferência, informando porções grandes; por outro lado, esquecem ou subestimam o que não é de seu agrado.

Os valores dos coeficientes de correlação ajustados pela energia foram corrigidos posteriormente pela variância. Este procedimento permitiu retirar os efeitos da variância intrapessoal inerentes ao consumo de energia e nutrientes calculado pelos recordatórios de 24 horas. Após este ajuste, obtiveram-se 
estimativas mais precisas em todos os nutrientes, em especial para a fibra, vitamina $\mathrm{C}$ e cálcio, que mostraram correlaçōes bastante adequadas.

Embora mais precisas, as correlações para o restante de nutrientes mostraram-se razoáveis (entre $r=0,36-0,55$ ) e baixas $(<$ que $r=0,35$ ), 0 que sugere que o QFAA tem um aceitável desempenho para classificar os indivíduos de acordo com a grande maioria de nutrientes estudados, com exceção do retinol e ferro. No caso do sexo feminino, o questionário não classificou adequadamente os indivíduos segundo os nutrientes lipídio total e proteína. Observando-se também um valor irreal $(r>1)$ para o consumo de vitamina $\mathrm{C}$ nos homens. Atribuímos este valor a dois fatos: primeiro, a correlação ajustada pela energia já era adequada $(r=0,56)$; e segundo, a razão da variância $(14,4)$ era extremamente elevada.

Outras razões explicam correlações baixas, entre elas aspectos socioeconômicos do consumo de alimentos em populações de diferentes estratos de renda. Concorda-se com FIELD et al. (1999), quando afirmam que as desvantagens econômicas contribuem com menor variabilidade na dieta. Embora os adolescentes estudados freqüentem uma escola pública, a mesma está localizada em uma região de classe média da cidade de São Paulo. Segundo o coordenador pedagógico da escola, a mesma reúne adolescentes de distintos estratos sociais e muitos deles são moradores da mesma região. Infelizmente, este aspecto, embora muito importante, não foi considerado no delineamento da pesquisa.

Se forem observados os dados da tabela 6 , confrontados com os valores brutos da tabela 9, poder-se-ia afirmar que os resultados obtidos por ambos os métodos revelariam uma boa consistência dos dados (diferenças foram aproximadamente menores que 10\%, assim como coeficientes de correlação acima de 0,6). Entende-se que isso não significa que o QFAA esteja 
classificando corretamente os indivíduos, pois não há a certeza de que estes valores estejam sofrendo o efeito de variaçōes externas.

Recentemente, GARROW (1995) tem defendido o uso da simples classificação cruzada (cross-classification) de métodos para os estudos de validação, argumentando que esta abordagem faria com que diferentes métodos fossem mais facilmente comparados.

Os QFAs podem ser validados pela proporção de indivíduos que estão classificados em um mesmo quartil, isto é, $100 \%$ por um método e $0 \%$ no quartil oposto, pelo outro método. Estes valores representarão concordância perfeita.

Os valores encontrados neste estudo (tabela 13) levantam três pontos de discussão: as concordâncias no mesmo quartil (média $33 \%$ ) e no oposto (média 5\%) estão muito distantes da concordância ideal 100\%/0\%, e muito próximas do valor aleatório de $25 \% / 12,5 \%$. Embora seja importante salientar que é quase impossível se alcançar o ideal, pois o método de referência utilizado neste estudo não é totalmente confiável. O segundo tópico mostra que, para vitamina $C$, os $R 24$ hs tiveram um bom desempenho como padrão ouro, pois a porcentagem de indivíduos mal classificados (1\%) foi mínima. Concordando com GARROW (1995), o terceiro ponto refere-se à forma de apresentação mesmo/oposto em quartil. Considera-se que esta forma provê informação compacta da capacidade dos métodos em localizar os indivíduos na distribuição de consumo, sendo melhor que o coeficiente de correlação, que meramente informa sobre a possível conexão entre as variáveis estimadas por ambos os métodos. 
6. CONCLUSÕES 
1. Foi desenvolvido, com sucesso, um questionário de freqüência alimentar para adolescentes, com 76 itens alimentares, o qual teve por objetivo principal categorizar os indivíduos segundo seu consumo pregresso de energia, proteína, carboidrato, lipídio total, lipídio insaturado, fibra, colesterol, retinol, vitamina $C$, cálcio e ferro.

2. O QFAA teve um aceitável desempenho para classificar os indivíduos de acordo com a grande maioria de nutrientes estudados, com exceção do retinol e ferro.

2.1 Para o sexo feminino, o QFAA não mostrou o mesmo desempenho para classificar adequadamente os indivíduos segundo os nutrientes lipidio total e proteína.

2.2 O procedimento do ajuste pela energia, bem como a correção pela variância intrapessoal, permitiram obter estimativas do coeficiente de validade mais precisas.

2.3 A elevada variabilidade intrapessoal, especialmente no retinol e vitamina $C$, indica que o número de recordatórios de $24 \mathrm{~h}$ aplicados foi insuficiente.

3. Tanto o recordatório de $24 \mathrm{~h}$ quanto o QFAA foram capazes de medir o consumo habitual dos adolescentes. 
7. REFERÊNCIAS BIBLIOGRÁFICAS 
1. Abramson $\mathrm{JH}$, Slome $\mathrm{C}$, Kosovsky $\mathrm{C}$. Food frequency interview as an epidemiological tool. Am J Pub Health 1963; 53: 1093-1101.

2. Amador MA. La obesidad en la adolescencia. In: Peña $M$, Bacallao J, editores. La obesidad en la pobreza: un nuevo reto para la salud pública. Washington (DC): Organización Panamericana de la Salud; 2000. p. 125-32. (OPAS - Publicación Cientifica, 576).

3. Andersen LF. Nes M, Lillegaard IT, Sandstad B, B $\phi$ rneboe G-Eaa, Drevon CA. Evaluation of a quantitative food frequency questionnaire used in a group of Norwegian adolescents . Eur J of Clin Nutr 1995; 49: 543-54.

4. Armstrong BK, White E, Saracci R. Principles of exposure measurement in epidemiology. $2^{\text {nd }}$ ed. Oxford: Oxford University Press; 1995. v.21.

5. Bartrina JA, Peres RC. Dieaio o registro dietético. Métodos de doble pesada. In Majem LIS,Aranceta B], Verdú MJ. Nutrición y Salud Pública - Métodos, bases científicas y aplicaciones. España: MASSON, S.A.; 1995. p. 107-31.

6. Basiotis PP, Thomas RG, Kelsay JL, Mertz W. Sources of variation in energy intake by men and women as determined from one year's daily dietary records. Am J Clin Nutr 1989; 50: 448-53.

7. Beaton GH, Milner ], Corey P, McGuire V, Cousins M, Stewart E et al. Sources of variance in 24-hour dietary recall data: implications for nutrition study design and interpretation. Am J Clin Nutr 1979; 32: 2546-59.

8. Beaton GH, Milner J, McGuire V, Feather TE, Little JA. Source of variance in 24-hour dietary recall data: implications for nutrition study design and interpretation. Carbohydrate sources, vitamins, and minerals. Am J Clin Nutr 1983; 37: 986-95.

9. Beaton GH. Approaches to analysis of dietary data: relationship between planned analyses and choice of metodology. Am J Clin Nutr 1994; 59 Suppl: 253S-61S.

10. Beaton GH. Interpretation of result from diet history studies. In: Kohlmeir L. ed. The diet history method. Proceeding of the second international meeting on nutritional epidemiology. London SmithGordon, 1989: 15-36. 
11. Berenson GS, Strong WB, Williams C,Haley N], Mancini $M$, Nicklas TA, Spark A, Okuni $M$. et al. Coronary artery disease prevention: cholesterol, a pediatric perspective. Prev Med. 1989; 18: 323-409.

12. Bergamaschi DP. Correlação intraclasse de Pearson para pares repetidos - comparação entre dois estimadores. São Paulo; 1999. [Tese de Doutorado - Faculdade de Saúde Pública da USP].

13. BGA Commission on Nutritional Epidemiology. Recommendations for the design and analysis of nutritional epidemiologic studies with measurement errors in the exposure variables. Eur J Clin Nutr 1993; 47 Suppl 2: 53S-57S.

14. Black AE, Prentice AM, Goldberg GR, Jebb SA, Bingham SA, Livingstone $\mathrm{MBE}$ et al. Measurements of total energy expenditure provide insights into the validity of dietary measurement of energy intake. J Am Diet Assoc 1993; 93: 572-79.

15. Block G, Dresser CM, Hartman AM, Carroll MD. Nutrient sources in the American diet: quantitative data from the nhanes II survey. I. Vitamins and minerals. Am J Epidemiol 1985; 122: 13-26. a.

16. Block $G$, Dresser CM, Hartman AM, Carroll MD. Nutrient sources in the American diet: quantitative data from the nhanes II survey. II. Macronutrients and fats. Am J Epidemiol 1985; 122: 27-40. b.

17. Block G, Hartman AM, Dresser CM, Carroll MD, Gannon J, Gardner L. A data-based approach to diet questionnaire design and testing. Am J Epidemiol 1986; 124: 453-69.

18. Block $G$, Woods $M$, Potosky A, Clifford C. Validation of a selfadministered diet history questionnaire using multiple diet records. J Clin Epidemiol 1990; 43: 1327-35.

19. Block G. A review of validations of dietary assessment methods. Am J Epidemiol 1982; 115: 492-505.

20. Bonilha $E$, Egashira $E$. Avaliação antropométrica e maturação sexual em adolescentes de baixo poder aquisitivo do município de São Paulo. In: Anais do V Congresso Nacional da Sociedade Brasileira de Alimentação e Nutrição; 1999. Dezembro 05-08; São Paulo, Brasil. São Paulo: Sociedade Brasileira de Alimentação e Nutrição (SBAN); 1999. p. 124. 
21. Brown JE, Tharp TM, Dahlberg-Luby EM, Snowdon DA, Ostwald SK, Buzzard IM et al. Videotape dietary assessment: validity, reliability, and comparison of results with 24-hour dietary recalls from elderly women in a retirement home. J Am Diet Assoc 1990; 90: 1675-9.

22. Burke BS. The dietary history as a tool in research. J Am Diet Assoc 1947; 23: 1041-6.

23. Burley V, Cade J. Consensus document on the development, validation and utilization of food frequency questionnaires. [The Fourth International Conference on Dietary Assessment Methods; 2000 sep 17-20; Tucson, Arizona (USA)].

24. Buzzard M. 24-Hours Dietary Recall and Fod Record Methods In : Nutritional Epidemiology. $2^{\text {nd }}$ ed. Oxford: Oxford University Press; 1998.

25. Cardoso MA, Kida AA, Tomita RD, Stocco RD. Reproducibility and validity of a food frequency questionnaire among women od Japanese ancestry living in Brazil. Nut Res. 2001 (no prelo).

26. Carroll R], Pee D, Freedman LS, Brown CC. Statistical design of calibration studies. Am J Clin Nutr 1997; 65 Suppl: 1187S-9S.

27. Closas RG. Historia de la nutrición em la salud pública. In: Majem LIS,Aranceta B], Verdú M]. Nutrición y Salud Pública - Métodos, bases científicas y aplicaciones. España: MASSON, S.A.; 1995. p. 48-55.

28. Colucci ACA, Nuzzo L, Slater B, Philippi ST. Energia na dieta dos adolescentes. In: Anais do $1^{\circ}$ Congresso Latino-Americano de Nutriçăo Humana; 1999 jun 24-27; Gramado (RS). Porto Alegre: Plenarium Ltda.; 1999. p. 34.

29. Domel SB, Baranowski T, Leonard SB, Davis H, Riley P, Baranowski J. Accuracy of fourth- and fifth-grade students' food records compared with school-lunch observations. Am J Clin Nutr 1994; 59 Suppl: 218S-20

30. Donner A, Eliasziw $M$. Sample size requirements for reliability studies. Stat Med 1987; 6: 441-48.

31. Dunker KL. Avaliação nutricional e comportamento alimentar de adolescentes com sintomas de anorexia nervosa. São Paulo; 1999. 
[Tese de Mestrado- Faculdade de Saúde Pública/ Faculdade de Ciências Farmacêutica/Faculdade Economia e Administração da USP

32. Dunker KLL, Philippi ST. Recordatório alimentar de 24 horas "modificado" - avaliação do consumo alimentar de adolescentes. In: Anais do $1^{\circ}$ Congresso Latino-Americano de Nutrição Humana; 1999 jun 24-27; Gramado (RS). Porto Alegre: Plenarium Ltda.; 1999. p. 6

33. Faggiano $F$, Vineis $P$, Cravanzola $D$, Pisani $P$, Xompero $G$, Riboli $E$, Kaaks R. Validation of a method for the estimation of food portion size. Epidemiol 1992; 3: 379-8

34. Field $A E$, Peterson KE, Gortmaker SL, Cheung L, Rockett $H$, Fox MK et al. Reproducibility and validity of a food frequency questionnaire among fourth to seventh grade inner-city school children: implications of age and day-to-day variation in dietary intake. Public Health Nutrition. [serial on line] 1999; 2(3): [11 screens]. Avaliable from: <URL: http://saturn.bids.ac.uk> [2001 ]an 2

35. Fisberg $M$, Bandeira CRS, Bonilha EA, Halpern G, Hirschbruch MD. Hábitos alimentares na adolescência. Pediatria Moderna 2000; 36: 724-3

36. Flegal K. Evaluating epidemiologic evidence of the effects of food and nutrient exposures. Am ] Clin Nutr 1999; 69:(suppl) 139S-44

37. Flegal KM, Laarkin FA. Partitioning Macronutrient intake estimates from a food frequency questionnaire. Am J Epidemiol. 1990; 131: $1046-5$

38. Fornés NS, Müller Elias $B$, Stringhini ML. Development and validation of a dietary assessment method for brazilian low literacy population. [The Fourth International Conference on Dietary Assessment Methods; 2000 sep 17-20; Tucson, Arizona (USA)].

39. Frank G, Hollatz AT, Weber LS, Berenson GS. Effects of interviewer recording practices on nutrient intake - Bongalusa heart study. J Am Diet Assoc 1984; 84: 1432-

40. Frank GC, Nicklas TA, Webber LS, Major C, Miller JF, Berenson GS. A food frequency questionnaire for adolescents: Defining eating patterns. J Am Diet Assoc 1992; 92: 313-1 
41. Frank GC. Environmental influences on methods used to collect dietary data from children. Am J Clin Nutr 1994; 59 Suppl: 207S-11

42. Fraser GE, Welch A, Luben R, Bingham AS, Day NE. The effect of age, Sex, and education on food consumption of a middle-aged English cohort - EPIC in East Anglia. Preventive Medicine 2000; 30: 26-3

43. Frazier $\mathrm{AL}$, Willett $\mathrm{WC}$, Colditz GA. Reproducibility of recall of adolescent diet: Nurses' Health Study (United States). Cancer Causes and Control 1995; 6: 499-50

44. Freudenheim JoL, Johnson NE, Wardrop RL. Misclassification of nutrient intake of individuals and groups using one, two, three, and seven-day food records. Am J Epidemiol 1987; 126: 703-1

45. Freudenheim JoL, Johnson NE, Wardrop RL. Nutrient misclassification: bias in the odds ratio and loss of power in the mantel test for trend. Intern J Epidemiol 1989; 18: 232-

46. Freudenheim L]. Study design and hypothesis testing: issues in the evaluation of evidence from research in nutritional epidemiology. Am J Clin Nutr 1999; 69 (suppl):1315S-21

47. Friis S, Kruger Kjaer S, Stripp C, Overvad K. Reproducibility and relative validity of a self- administered semiquantitative food questionnair applied to younger women. J Clin Epidemiol. 1997; 50: $303-1$

48. Frutuoso MFP, Gambardella AMD. Evaluación del consumo alimentario de adolescentes de bajo nivel socioeconómico de la ciudad de São Paulo. In: Libro de resúmenes de trabajos libres. XII Congreso Latinoamericano de nutrición. SLAN 2000. 2000. 12-16 de Noviembre. Buenos Aires, Argentina. p.14

49. Fundação IBGE. Estudo Nacional da Despesa Familiar (dados preliminares). Consumo alimentar - antropometria. Rio de Janeiro; 1977. v. 1

50. Gallagher ML, Farrior E, Broadhead L, Gillette LS, Rowe ML, Somes G et al. Development and testing of a food frequency recall instrument for describing dietary patterns in adults and teenagers. Nutrition Research [serial on line] 1993; 13(2). Avaliable from: <URL: http://erl.sibi.usp.br > [2001 Jan 2 
51. Gama C. Consumo alimentar e estado nutricional de adolescentes em escolas da rede particular e estadual do bairro de Vila Mariana, SP. São Paulo 1999. [Tese de Doutorado - Escola Paulista de Medicina UNIFESP]

52. Garrow JS, Validation of methods for estimating habitual diet: proposed guidelines. Eur J Clin Nutr 1995; 49: 231-2.

53. Gibson RS. Principles of Nutritional Assessment. Oxford: Oxford University Press; 1990. Food consumption of individuals; p. 37-54.

54. Gnardellis C, Trichopouluu A, Katsouyanni K, Polychronopoulos E, Rimm EB, Trichopoulos D. Reproducibility and validity of an extensive semi-quantitativr food frequency questionnaire among teachers. Epidemiology, 1994; 6: 74-7.

55. Goran M], Measurement issues related to studies of childhood obesity: Assessment of body composition, body fat distribution, physical activity, and food intake. Pediatric 1998; 101 (suppl): 505-18,

56. Grande CF. Prólogo. In: Majem SLI, Aranceta B], Verdú M]. Nutrición y Salud Pública - Métodos, bases científicas y aplicaciones. España: MASSON S.A. 1995. p.XI.

57. Guenther PM, Kott OS, Carriquiry AL. Development of an approach for estimating usual nutrient intake distributions at the population level. J Nutr 1997; 127 (6): 1106-12.

58. Guthrie HA. Selection and qualification of typical food portions by Young adults. J Am Diet Assoc 1984; 84: 1440-4.

59. Halpern G, Freire R, Lei D, Chaves S, Lerner B, Paes AT. Consumo de cálcio na adolescência. In: Anais do $V$ Congresso Nacional da Sociedade Brasileira de Alimentação e Nutrição; 1999 dez 05-08; São Paulo, Brasil. São Paulo: Sociedade Brasileira de Alimentação e Nutrição (SBAN); 1999. p. 146.

60. Hankin JH, Stallones RA, Messinger HB. A short dietary method for epidemiological studies - III. Development of questionnaire. Am J Epidemiol 1968; 87: 285-93.

61. Hansson LM, Galanti MR, Bergström R. Factors affecting reproducibility of dietary reports using food frequency questionnaires. Eur J Clin Nutr 2000; 54: 658-64. 
62. Harbottle $L$, Duggan MB. Daily variation in food and nutrient intakes of Asian children in Sheffield. Eur J Clin Nutr 1994; 48: 66-70.

63. Hartman AM, Brown CC, Palmgren J, Pietinen P, Verkasalo M, Myer D, Virtamo J. Variability in nutrient and food intakes among older middle-aged men - Implications for design of epidemiological and validation studies using food recording. Am J Epidemiol 1990; 132: 999-1012.

64. Heady JA. Diets of bank clerks. Development of a method of classifying the diets of individuals for use in epidemiological studies. J R Statist Soc 1961; 124: 336-61.

65. Himes $\mathrm{JH}$, Dietz WH. Guidelines for overweight in adolescent preventive services: recommendations from an expert committee. Am J Clin Nutr 1994; 59: 307-16.

66. Howe GR, Harrison L, Jain M. A short diet history for assessing dietary exposure to n-nitrosamines in epidemiological studies. Am J Epidemiol 1986; 124: 595-602.

67. Hunter DJ. Biochemical indicators of dietary intake. In: Willett W. Nutritional epidemiology. $2^{\text {nd }}$ ed. Oxford: Oxford University Press; 1998. p. 174-243.

68. Jiménez LG, Martín-Moreno JM. Cuestionario de frecuencia de consumo alimentario. In: Majem LIS, Aranceta B], Verdú M]. Nutrición y Salud Pública - Métodos, bases científicas y aplicaciones. España: MASSON, S.A.; 1995. p. 120-5.

69. Johnson, R.K.; Goran,M.I.; Poehlman,E.T. Correlates of over- and underreporting of energy intake in healthy older men and women. Am] Clin Nutr. _ 1994; 59: 1286-90..

70. Kaaks R, Riboli E, Estève J, van Kappel AL, van Staveren WA. Estimating the accuracy of dietary questionnaire assessments: validation in terms of structural equation models. Stat Med 1994; 13: 127-42.

71. Kaskoun MC, Johnson RK, Goran MI. Comparison of energy intake by semiquantitative food-frequency questionnaire with total energy expenditure by doubly labeled water method in young children. Am ] Clin Nutr 1994; 60: 43-7. 
72. Krall EA, Dwyer JT, Coleman KA. Factors influencing accuracy of dietary recall. Nutr Res 1988; 8: 829-41.

73. Lissner L, Stevens J, Levitsky DA, Rasmussen KM, Strupp B]. Variations in energy intake during the menstrual cycle: implications for food-intake research. Am J Clin Nutr 1988; 48: 956-62.

74. Liu K, Cooper R, McKeever ], McKeever P, Byington R, Soltero I et al. Assessment of the association between habitual salt intake and high blood pressure: methodological problems. Am J Epidemiol 1979; 110: 219-26.

75. Liu K, Stamler ], Dyer A, McKeever ], McKeever P. Statistical methods to assess and minimize the role of intra-individual variability in obscuring the relationship between dietary lipids and serum cholesterol. J Chron Dis 1978; 31 : 399-418.

76. Liu K. Measurement error and its impact on partial correlation and multiple linear regression analyses. Am J Epidemiol 1988; 127: 86474.

77. Livingstone MBE, Prentice AM, Coward WA, Strain J], Black AE, Davies PSW et al. Validation of estimates of energy intake by weighed dietary record and diet history in children and adolescents. Am J Clin Nutr 1992; 56: 29-35.

78. LOPEZ,V.J. Validez de la evaluación de la ingesta dietética. In: Serra Majem LI. Nutrición y Salud Pública. Metodos, bases científicas y aplicaciones.Ed. Masson, España., 1995, p 132-40.

79. Lozy el M. Dietary variability and its impact on nutritional epidemiology. J Chron Dis 1983; 36: 237-49.

80. Majem LIS, Barbas LR. Recordatorio de 24 horas. In: Majem LIS, Bartrina]A, Verdú M]. Nutrición y Salud Pública - Métodos, bases científicas y aplicaciones. España: MASSON, S.A.; 1995. p. 113-9.

81. Majem L.I.S., Bartrina J.A. Introducción a la epidemiologia nutricional. In: Serra Majem SLl. Bartrina JA, Verdú M]. Nutrición y Salud Pública: métodos, bases científicas y aplicaciones. España: Masson; 1995. p. 59-65. 
82. Majem SLI. Tipos de estúdios em epidemiología nutricional. In: Majem SLI, Bartrina JA, Verdú M]. Nutrición y Salud Pública - Métodos, bases científicas y aplicaciones. España: MASSON, S.A.; 1995. p. 66-72.

83. Mc Pherson RS, Hoelscher DM, Alexander M, Scanlon KS, Serdula MK. Dietary Assessment Methods among school-age childrem : Validity and reability. Prev Med 2000; 31(suppl): S11-S33.

84. Margetts $B M$, Pietinen $P$, editors. European Prospective Investigation into Cancer and Nutrition (EPIC) - Validity studies on dietary assessment methods. Intern J Epidemiol 1997; 26 Suppl 1.

85. Marr JW Individual dietary survey: purposes and methods. World Rev Nutr Diet 1971; 13:106 - 164.

86. Martín-Moreno JM, Boyle P, Gorgojo L, Maisonneuve P, FernandezRodriguez JC, Salvini $S$, Willett WC. Development and validation of a food frequency questionnaire in Spain. Intern J Epidemiol 1993; 22: 512-19.

87. Mela DJ, Aaron Jl. Honest but invalid: what subjects say about recording their food intake. J Am Diet Assoc 1997; 97: 791-3.

88. Mertz W. Foods and nutrients. J Am Diet Assoc 1984; 84: 769-70.

89. Monteiro CA, Mondini L, de Souza ALM, Popkin BM. Da desnutrição para a obesidade: a transição nutricional no Brasil. In: Monteiro CA. Velhos e novos males da saúde no Brasil - A evolução do país e de suas doenças. São Paulo: Hucitec; 1995. p. 247-55. b

90. Monteiro CA. La treansición epidemiológica en el Brasil. In: Peña M, Bacallo ] editores. Organización Panamericana de la Salud (OPS) La obesidad en la pobreza. Un nuevo reto para la salud pública. Publicación cientifica No. 576 Washington, D.C. 2000, p. 73-83.

91. Monteiro CA. Saúde e nutrição das crianças de São Paulo: diagnóstico, contrastes sociais e tendências. São Paulo: Hucitec; 1988.

92. Morgan KJ, Johnson SR, Goungetas B. Variability of food intakes: an analysis of a 12-day data series using persistence measures. Am J Epidemiol 1987; 126: 326-35. 
93. Munger RG, Folsom AR, Kushi LH, Kaye SA, Sellers TA. Dietary assessment of older lowa women with a food frequency questionnaire: Nutrient intake, reproducibility and comparison with 24-hour dietary recal intrerviews.

94. Nelson $M$. The validation of dietary assessment. In: Margetts B, Nelson $M$. Design concepts in nutrition epidemiology. $2^{\text {nd }}$ ed. 1997. Oxford: Oxford University Express; p. 241-72.

95. Nuzzo, L. Avaliação do estado nutricional de adolescentes de uma instituição particular de ensino. São Paulo; 1998. [Tese de Mestrado Faculdade de Saúde Pública da USP].

96. Ocké MC, Bueno-de-Mesquita HB, Goddijn HE, Jansen A, Pols MA, Staveren WAV, Kromhout D. The Dutch EPIC food frequency questionaire. I. Description of the questionnaire, and relative validity and reproducibility for food groups. Intern J Epidemiol 1997; 26 Suppl 1:37S-48S.

97. Omran, A,R. The epidemiological transition: a theory of the epidemiology of population change. Milbank Memorial Fund Quaterly 49 (Part 1): 509-39, 1971 apud Laurenti, R.Transição demográfica e Transição Epidemiológica. Congresso Brasileiro de epidemiologia, Campinas, 1990.

98. Organización Panamericana de la Salud (OPS) e Oficina regional de la Organización Mundial de la Salud (OMS) 1996. Ed. Peña, M. Freire, $W$. Informe de la reunion tecnica sobre obesidad en la pobreza: Situación de América Latina. La Habana , Cuba, 15-19 de mayo 1995.

99. Organización Panamericana de la Salud (OPS) La obesidad en la pobreza. Un nuevo reto para la salud pública. Ed. Peña,M. Bacallo, J. Publicación cientídica No. 576 Washington,D.C. 2000.

100. Organización Panamericana de la Salud. Las condiciones de salud en las Américas. Washington (DC); 1994. (OPAS - Publicación cientifica $\mathrm{n}^{\circ}$ 549)

101. Organización Panamericana de la Salud. Una investigación sobre la naturaleza, las causas y la curación del escorbuto. In: Buck C, Llopis A, Nájares E, Temis M. El desafio de la epidemiologia - Problemas y lecturas selecionadas. Washington (DC); 1988. (OPAS - Publicación cientifica No 505, p. 20-7). 
102. Overvad K, Tjonneland a, Haraldsdottir J, Ewerte M. jensen OM. Devepment of semiquantitave food frequency questionnaire to asess food, energy and nutrien intake in Denmark. Int J Epidemiol. 1991; 20: $900-5$.

103. Passamai MPB, Almeida PC, Sampaio HAC. Adequação nutricional de dietas ingeridas por adolescentes de uma rede particular de ensino em Fortaleza - CE. In: Anais do $1^{\circ}$ Congresso Latino-Americano de Nutrição Humana; 1999 jun 24-27; Gramado (RS). Porto Alegre: Plenarium Ltda.; 1999. p. 34.

104. Pennington JAT. Methods for obtaining food consumption information. In: Macdonald I, editor. Monitoring Dietary Intakes. New York: Springer-Verlag; 1991. p. 4-8.

105. Perez RC. Fuentes de error en la evaluación del consumo de alimentos. In: Majem SLI, Aranceta B], Verdú M]. Nutrición y Salud Pública Métodos, bases científicas y aplicaciones. España: MASSON, S.A.; 1995. p.168-72.

106. Peto R, Doll R, Buckley JD, Sporn MB. Can dietary beta-carotene materially reduce human cancer rates? Nature 1981; 290: 201-08.

107. Philippi ST, Szarfarc SC, Latterza AR. Virtual Nutri [software]. Versāo 1.0 for Windows. Departamento de Nutrição/ Faculdade de Saúde Pública/ Universidade de São Paulo; 1996.

108. Pietinen P, Hartman AM, Haapa E, Rasanen L, Haapakoski J, Palmgren J et al. Reproducibility and validity of dietary assessment instrument. I. Self administered food use questionnaire with a portion size picture booklet. Am J Epidemiol 1988; 128: 655-66. a.

109. Pietinen P, Hartman AM, Haapa E, Rasanen L, Haapakoski J, Palmgren J et al. Reproducibility and validity of dietary assessment instrument. II. A qualitative food questionnaire. Am J Epidemiol 1988; 128: 66776. b.

110. Piwoz EG, de Kanashiro HC, de Romaña GL, Black RE, Brown KH. Within- and between-individual variation in energy intakes by lowincome Peruvian infants. Eur J Clin Nutr 1994; 48: 333-40. 
111. Popkin BM, Keyou G, Fengying Z, Guo X, Ma Haijiang, Zohoori N. The nutrition transition in China: a cross-sectional analysis. Eur J Clin Nutr 1993; 47: 333-46.

112. Popkin BM. Nutritional patterns and transitions. Population and Development Review 1993; 19: 138-57.

113. Potosky A, Block $G$, Hartman AM. The effect of the reference data in diet questionnaire validations ] Am Diet Assoc 1990; 810-813.

114. Prentice AM, Coward WA, Davies $\mathrm{HL}$, Murgatroyd PR, Black $A E$, Goldberg GR et al. Unexpectedly low levels of energy expenditure in healthy women. Lancet 1985; i: 1419-2

115. Priore SP, Sigulem DM. Importância da utilização da idade cronológica e do sexo na avaliação antropométrica e na composição corporal de adolescentes. In: Anais do V Congresso Nacional da Sociedade Brasileira de Alimentação e Nutrição; 1999 dez 05-08; São Paulo, Brasil. São Paulo: Sociedade Brasileira de Alimentação e Nutrição (SBAN); 1999. p. 16

116. Ravussian E, Lillioja S, Anderson TE, Christin L, Bogardus C. Determinants of 24-hour energiy expenditure in man. Methods and results using a respiratory chamber. J Clin Invest 1986; 78: 1568 -78.

117. Rimm EB, Giovannucci EL, Stampfer M], Colditz GA, Litin LB, Willett WC. Reproducibility and validity of an expanded self-administered semiquantitative food frequency questionnaire among male health professionals. Am J Epidemiol 1992; 135: 1114-26.

118. Rockett HRH, Breitenbach M, Frazier AL, Witschi ], Wolf AM, Field $\mathrm{AE}$ et al. Validation of a youth/adolescent food frequency questionnaire. Preventive Medicine 1997; 26: 808-16. a.

119. Rockett HRH, Wolf AM, Colditz GA. Development and reproducibility of a food frequency questionnaire to assess diets of older children and adolescents. J Am Diet Assoc 1995; 95: 336-340.

120. Rockett RH. Colditz GA. Assessing diets of children and adolescents. Am J Clin Nutr. 1997; 65(suppl): 1116S- 22S. b.

121. Rosner B, Willett WC. Interval estimates for correlation coefficients corrected for within-person variation: implications for study design and hypothesis testing. Am J Epidemiol 1988; 127: 377-86. 
122. St Jeor ST, Guthrie HA, Jones MB. Variability in nutrient intake in a 28-day period. J Am Diet Assoc 1983; 83: 155-62.

123. Sampson L. Food frequency questionnaires as a research instrument. Clin Nutr 1985; 4: 171-78.

124. Sempos CT, Johnson NE, Smith EL, Gilligan C. Effects of intraindividual and interindividual variation in repeated dietary records. Am J Epidemiol 1985; 121: 120-30.

125. Shils M, Olson J, Skike M. Modern Nutrition in Health and Disease. $8^{\text {th }}$. USA: Lea \& Febiger; 1994. $2 v$.

126. Sichieri R. Epidemiologia da obesidade. Rio de Janeiro: EdUERJ; 1998. Estudo de validação do questionário de frequeência de consumo de alimentos; p. 25-34.

127. Silva MV, Sturion GL, Pipitone MAP, Caroba DCR. Atitudes de pais e alunos de escolas públicas relacionadas à saúde e consumo de alimentos. In: Anais do V Congresso Nacional da Sociedade Brasileira de Alimentação e Nutriçáo; 1999 dez 05-08; São Paulo, Brasil. São Paulo: Sociedade Brasileira de Alimentação e Nutrição (SBAN); 1999. p. 121 . (a)

128. Silva MV, Sturion GL, Pipitone MAP, Caroba DCR. Avaliação quantitativa e qualitativa do consumo alimentar de escolares da rede pública de ensino. In: Anais do V Congresso Nacional da Sociedade Brasileira de Alimentação e Nutrição; 1999 dez 05-08; São Paulo, Brasil. São Paulo: Sociedade Brasileira de Alimentação e Nutrição (SBAN); 1999. p. 136. (b)

129. Splett, PL. Story,M. Child Nutrition: Objective for the decade. J. Am.Diet. Assoc. 1991; 91: 665-69.

130. Stram DO, Longnecker MP, Shames L, Kolonel LN, Wilkens LR, Pike $M C$ et al. Cost-efficient design of a diet validation study. Am J Epidemiol 1995; 142: 353-62.

131. Tarasuk V, Beaton GH. Menstrual cycle patterns in energy and macronutrient intake. Am J Clin Nutr 1991; 53: 442-7. b.

132. Tarasuk V, Beaton GH. Statistical estimation of dietary parameters: 
implications of patterns in within-subject variation - a case study of sampling strategies. Am J Clin Nutr 1992; 55:22-7.

133. Tarasuk V, Beaton GH. The nature and individuality of within-subject variation in energy intake. Am J Clin Nutr 1991; 54: 464-70. a.

134. Taylor RW, Goulding A. Validation of a short food frequency questionnaire to assess calcium intake in children aged 3 to 6 years. Eur J Clin Nutr 1998; 52: 464-5.

135. Thompson FE, Byers T. Dietary Assessment Resource Manual [supplement]. ] Nutr 1994; 124 Suppl 11.

136. Treiber FA, Leonard SB, Frank G, Musante L, Davis $H$, Strong WB, Levy $M$. Dietary assessment instruments for preschool children: Reability of parental responses to the 24-hour recall and a food frequency questionnaire. J Am Diet Assoc 1990; 90 (6): 814-20.

137. Tsubono $Y$, Fahey MT, Takahashi $T$, Iwase $Y$, litoi $Y$, Akabane $M$, Tsugane $S$. Interpopulation and intrapopulation variability of nutrient intake in five regions of Japan. Eur J Clin Nutr 1998; 52: 176-9.

138. Uauy R. Nutrition throughout the life cycle. Eur ] Clin Nutr 1999; 53 Suppl: 8 S.

139. Van Horn LV, Gernhofer N, Moag-Stahlberg A. Farris R. Hartmuller $\mathrm{G}$, Lasser VI. Dietary assessment in children using electronic methods: telephone and tape recorders. J Am Diet Assoc 1990; 90®3) 412-6.

140. van Staveren WA, Deurenberg P, Katan MB, Burema J, de Groot LCPG, Hoffmans MDAF. Validity of the fatty acid composition of subcutaneous fat tissue microbiopsies as an estimate of the long-term average fatty acid composition of the diet of separate individuals. Am J Epidemiol 1986; 123: 455-63.

141. Vioque LJ. Validez de la evaluacioón de la ingesta alimentar. Nutrición y Salud Pública - Métodos, bases cientificas y aplicaciones. España: MASSON, S.A.; 1995. p 132-36.

142. Wei EK, Gardner ], Field AE, Rosner BA, Colditz GA, Suitor CW. Validity of a food frequency questionnaire in assessing nutrient intakes of low-income pregnant women. Matern Child Health ]. [serial on line] 1999; 3(4). Available from: <URL: http://www.ncbi.nlm.nih.gov> [2001 Jan 31] 
143. Willet WC. Nutritional Epidemiology. $2^{\text {nd }}$ ed. Oxford: Oxford University Press; 1998.

144. Willett WC, Howe GR, Kushi LH. Adjustment for total energy intake in epidemiological studies. Am J Clin Nutr 1997(suppl): 1220S-8S.

145. Willett WC, Sampson L, Stampfer M], Rosner B, Bain C, Witschi J et al. Reproducibility and validity of a semiquantitative food frequency questionnaire. Am J Epidemiol 1985; 122: 51-65.

146. Willett WC, Stampfer MJ. Total energy intake: implications for epidemiological analyses. Am J Epidemiol 1986; 124: 17-27.

147. Willett WC. Diet and nutrition. In: Schottenfeld D, Fraumeni JF. Cancer epidemiology and prevention. $2^{\text {nd }}$ ed. Oxford: Oxford University Press; 1996. p. 438-61.

148. Willett WC. Future directions in the development of food-frequency questionnaires. Am J Clin Nutr 1994; 59 Suppl: 171S-4S.

149. Willett WC. Nutritional Epidemiology. In: Rothman K], Greenland S. Modern Epidemiology. Lippincot (USA): Williams \& Wilkins; 1998. p. 623-42. (a)

150. Whitney NE, Rolfes SR. Understanding Nutrition. Minneapolis/St Paul (USA): West Publishing Company; 1993. P (E-7).

151. World Health Organization. Nutrition: highlights of recent activities in the context of the World Declaration and Plan of action for Nutrition. Geneva; 1995. (WHO/NUT/95.2).

152. Yaroch AL, Resnicow K, Davis $M$, Davis A, Smith $M$, Khan LK. Development of a modified picture-sort food frequency questionnaire administered to low-income, overweight, African-American adolescent girls. J Am Diet Assoc 2000; 100 (9): 1050-6.

153. Ziegler RG, Wilcox III HB, Mason T], Bill JS, Virgo PW. Seasonal variation in intake of carotenoids and vegetables and fruits among white men in New Jersey. Am J Clin Nutr 1987; 45:107-14.

154. Zulkifli SN, YU SM. The food frequency method for dietary assessment. J Am Diet Assoc. 1992; 92: 681-5. 
Anexo 1

Recordatório de 24 horas.

UNIVERSIDADE DE SÃO PAULO
FACULDADE DE SAÚDE PÚBLICA
DEPARTAMENTO DE NUTRIÇÃO
Av. Dr. Amaldo, 715 - Cerqueira César - São Paulo/SP
CEP: 01246-904
(011) 3066-7701/7705 - Fax (011) 852-6748

NOME

SEXO IDENTIFICAÇÃO

DATA DE

NASCIMENTO

DATA DA ENTREVISTA

11

DIA DA SEMANA

Anote o horário, relacione os alimentos e/ou preparaçōes( ingredientes) de cada refeição feita no dia anterior, iniciando pelo horário da manhã até antes de dormir.

\begin{tabular}{|c|c|c|c|}
\hline $\begin{array}{l}\text { HORÁRIO DA } \\
\text { REFEICÃO }\end{array}$ & $\begin{array}{l}\text { ALIMENTOS } \\
\text { /PREPARACŌES }\end{array}$ & QUANTIDADE & OBSERVAÇŌES \\
\hline & & & \\
\hline & & & \\
\hline & & & \\
\hline & & & \\
\hline & & & \\
\hline & & & \\
\hline & & & \\
\hline & & & \\
\hline & & & \\
\hline & & & \\
\hline & & & \\
\hline & & & \\
\hline & & & \\
\hline & & & \\
\hline & & & \\
\hline & & & \\
\hline
\end{tabular}




\section{Anexo 2}

Alimentos de maior freqũência de consumo, por adolescentes de ambos os sexos de uma escola particular de ensino (COLUCCl et al. 1999).

\begin{tabular}{|c|c|c|c|c|}
\hline$n$ & Itens de alimento & $\begin{array}{c}\text { Consumo } \\
\text { médio } \\
\text { em gramas }\end{array}$ & $\begin{array}{l}n^{\circ} \text { de respostas em } \\
400 \text { inquéritos }\end{array}$ & freq. ((\%) \\
\hline 1 & Arroz branco cozido & 123,5 & 387 & 96,75 \\
\hline 2 & Água mineral & 337,42 & 376 & 94,00 \\
\hline 3 & Päo (francês, forma) & 74,50 & 376 & 94,00 \\
\hline 4 & Refrigerante & 344,50 & 331 & 82,75 \\
\hline 5 & Feijäo (outras leguninosas) & 124,80 & 293 & 73,25 \\
\hline 6 & Balas & 8,39 & 258 & 64,50 \\
\hline 7 & Carne bovina (bife,etc) & 116,09 & 218 & 54,50 \\
\hline 8 & Bebida láctea, iogurtes & 180,00 & 207 & 51,75 \\
\hline 9 & Sucos de frutas & 240,22 & 202 & 50,50 \\
\hline 10 & Leite integral, desnatado & 259,50 & 200 & 50,00 \\
\hline 11 & Biscoitos e bolachas & 40,22 & 180 & 45,00 \\
\hline 12 & Batatas fritas (palito) & 77,84 & 146 & 36,50 \\
\hline 13 & Salgados (coxinha, pastel, etc.) & 99,44 & 118 & 29,50 \\
\hline 14 & Chocolates e bambons & 35,29 & 113 & 28,25 \\
\hline 15 & Agriāo, alface, almeirāo, etc. & 43,09 & 109 & 27,25 \\
\hline 16 & Frango (frito, grelhado, cozido) & 105,71 & 106 & 26,50 \\
\hline 17 & Queijo minas, ricota etc. & 33,10 & 88 & 22,00 \\
\hline 18 & Bolo comum, chocolate etc. & 67,38 & 85 & 21,25 \\
\hline 19 & Margarinas & 15,02 & 81 & 20,25 \\
\hline 20 & Alimento achocolatado & 25,60 & 78 & 19,50 \\
\hline 21 & Gafé com açúcar & 51,18 & 77 & 19,25 \\
\hline 22 & Pipoca salgada estourada & 83,00 & 73 & 18,25 \\
\hline 23 & Macarrāo (ao sugo, manteiga) & 158,17 & 70 & 17,50 \\
\hline 24 & Batatas chips, salgadinhos & 44,66 & 63 & 15,75 \\
\hline 25 & Tomate & 63,39 & 63 & 15,75 \\
\hline 26 & Sopas (canja, de feijāo etc.) & 225,71 & 57 & 14,25 \\
\hline 27 & Sorvete & 95,43 & 50 & 12,50 \\
\hline 28 & Ovos (frito, omelete) & 55,55 & 48 & 12,00 \\
\hline 29 & Massas & 185,15 & 47 & 11,75 \\
\hline 30 & Salada de legumes & 77,76 & 47 & 11,75 \\
\hline 31 & Requeijão & 37,50 & 45 & 11,25 \\
\hline 32 & Açúcar refinado & 33,80 & 44 & 11,00 \\
\hline 33 & Hambúrguer & 193,66 & 44 & 11,00 \\
\hline 34 & Maçä/pêra & 120,68 & 42 & 10,50 \\
\hline 35 & Laranja Bahia/suco & 235,48 & 41 & 10,25 \\
\hline 36 & Croissant & $99,26^{\circ}$ & 39 & 9,75 \\
\hline 37 & $\begin{array}{l}\text { Came de porco (bisteca, lombo, } \\
\text { etc.) }\end{array}$ & 116,06 & 38 & 9,50 \\
\hline 38 & Figado de boi & 32,79 & 34 & 8,50 \\
\hline 39 & Misto quente/ frio & 103,03 & 33 & 8,25 \\
\hline 40 & Embutidos & 37,21 & 29 & 7,25 \\
\hline 41 & Refrigerante diet & 345,00 & 28 & 7,00 \\
\hline 42 & Azeite de oliva & 1,85 & 23 & 5,75 \\
\hline 43 & Cachorro quente & 247,59 & 23 & 5,75 \\
\hline 44 & Mamão & 138,00 & 22 & 5,50 \\
\hline 45 & Salsicha & 63,64 & 22 & 5,50 \\
\hline
\end{tabular}




\begin{tabular}{llccc}
\hline 46 & Cereal Matinal & 38,10 & 21 & 5,25 \\
47 & Vitamina de frutas & 266,98 & 21 & 5,25 \\
48 & Banana & 98,60 & 20 & 5,00 \\
49 & Couve manteiga & 57,00 & 17 & 4,50 \\
50 & Peixe & 111,65 & 17 & 4,50 \\
51 & Gelatina preparada & 120,83 & 12 & 3,00 \\
52 & Pepino & 45,75 & 12 & 3,00 \\
53 & Abobrinha & 62,00 & 10 & 2,25 \\
54 & Brócoli & 43,92 & 10 & 2,25 \\
55 & Melão & 178,43 & 7 & 1,75 \\
56 & Abacaxi & 205,00 & 6 & $1,50 \ldots$ \\
\hline
\end{tabular}




\section{Anexo 3 \\ Alimentos de maior contribuição energética de adolescentes de ambos os sexos de uma escola particular de ensino (COLUCCl et al. 1999).}

\begin{tabular}{|c|c|c|c|}
\hline $\mathbf{n}$ & Itens de Alimentos & média de caloria / porção & $\%$ do total de caloria \\
\hline 1 & Bife & 377,13 & 9,67 \\
\hline 2 & Pão (francês, forma, integral) & 193,51 & 8,56 \\
\hline 3 & Arroz Branco Cozido & 116,81 & 5,32 \\
\hline 4 & Pipoca Salgada & 576,19 & 4,95 \\
\hline 5 & Refrigerante & 125,51 & 4,89 \\
\hline 6 & Bebida Láctea, logurte & 190,22 & 4,63 \\
\hline 7 & Biscoito / bolacha & 194,13 & 4,11 \\
\hline 8 & Salgados (coxinha, pastel etc.) & 268,90 & 3,73 \\
\hline 9 & Batata fritas palito & 198,68 & 3,41 \\
\hline 10 & Leite Esterilizado Integral & 135,68 & 3,19 \\
\hline 11 & Suco de frutas & 129,78 & 3,08 \\
\hline 12 & Feijão (outras leguminosas) & 75,10 & 2,59 \\
\hline 13 & Bolo comum, chocolate & 253,80 & 2,54 \\
\hline 14 & Frango (frito, grelhado, cozido) & 203,36 & 2,53 \\
\hline 15 & Bombom, chocolate & 184,75 & 2,46 \\
\hline 16 & Hambúrguer & 457,89 & 2,37 \\
\hline 17 & Мacarrão, (ao sugo, manteiga) & 260,66 & 2,15 \\
\hline 18 & Came de porco (bisteca, lombo) & 476,88 & 2,13 \\
\hline 19 & Massas & 376,31 & 2,08 \\
\hline 20 & Cachorro quente & 713,21 & 1,93 \\
\hline 21 & Croissant & 410,91 & 1,88 \\
\hline 22 & Salgadinho baconzito, batatas tipo Chips & 210,94 & 1,56 \\
\hline 23 & Sorvete & 192,40 & 1,13 \\
\hline 24 & Misto & 278,51 & 1,08 \\
\hline 25 & Bala & 34,71 & 1,05 \\
\hline 26 & Queijo Minas & 100,92 & 1,04 \\
\hline 27 & Sopas (canja, feijão) & 155,53 & 1,04 \\
\hline 28 & Margarina & 108,99 & 1,04 \\
\hline 29 & Mitho pipoca & 527,94 & 0,62 \\
\hline 30 & Alimento achocolatado & 66,51 & 0,61 \\
\hline 31 & Ovos (omelete, frito etc.) & 106,46 & 0,60 \\
\hline 32 & Laranja Bahia (suco) & 107,85 & 0,52 \\
\hline 33 & Salada de legumes & 89,86 & 0,50 \\
\hline 34 & Doces de frutas & 175,64 & 0,50 \\
\hline 35 & Açúcar refinado & 93,01 & 0,48 \\
\hline 36 & Salsicha & 180,43 & 0,47 \\
\hline 37 & Requeijão & 83,94 & 0,44 \\
\hline 38 & Vitamina com leite & 173,52 & 0,43 \\
\hline 39 & Embutidos & 109,19 & 0,37 \\
\hline 40 & Cereal matinal & 139,68 & 0,34 \\
\hline 41 & Maçā/pêra & 69,67 & 0,34 \\
\hline 42 & Farinha de mandioca & 225,84 & 0,32 \\
\hline 43 & Trigo para quibe & 266,97 & 0,31 \\
\hline 44 & Peixe cozido & 155,32 & 0,31 \\
\hline \multirow[t]{2}{*}{45} & Café com açúcar & 32,68 & 0,30 \\
\hline & Total & & 93,58 \\
\hline
\end{tabular}




\section{Anexo 4}

\section{Porções de alimentos e preparaçōes que integram o Questionário de Freqũência Alimentar para Adolescentes (QFAA)}

\begin{tabular}{|c|c|c|}
\hline II & Itens de alimentos & médio em \\
\hline 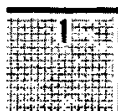 & $\begin{array}{l}\text { Batatinhas tipo Chips/Salgadinhos tipo Chee-, th } 1 / 2 \text { pacote } \\
\text { tos }\end{array}$ & $\frac{45,00}{4}$ \\
\hline 2 & 1 tablete/ 3 unidades & 30,00 \\
\hline 3] & ocomum/puliman & 10 \\
\hline 4 & 2 bola $/ 1$ unidade & \\
\hline 5 & hocolatado em pó * t & 10 \\
\hline 6 & oca estourada & \\
\hline$\frac{7}{8}$ & 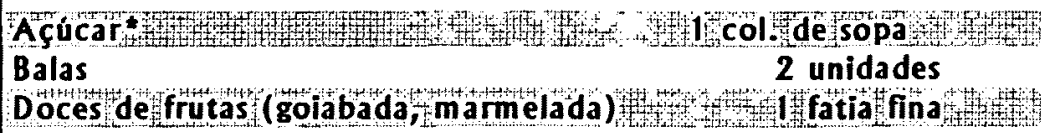 & $\begin{aligned} 28 \\
8 \\
78\end{aligned}$ \\
\hline 10 & bremesas tipo mousse $\quad$ I taça & \\
\hline $111+4$ & urger de carne/fra & 14 \\
\hline 12 & he (Misto, queijo, & 00 \\
\hline 13 & he natural & 11 \\
\hline 14 & sfiha/rissolis/pastel & 00 \\
\hline 15 & elbatata c/maionese] & P7 \\
\hline 16 & oca) 1 prato & \\
\hline 18 & queijo/batata & \\
\hline 19 & W & 113 \\
\hline 20 & quente & \\
\hline 21 & (1) & \\
\hline 22 & ido Integra ${ }^{*}$ & \\
\hline 23 & $1 \mathrm{copode}$ & \\
\hline 24 & atural/frutas* & \\
\hline 25 箫 & urte diet $\mathbf{T}$ & 418 \\
\hline 26 & inas frescal/ricota, cottage & \\
\hline 27 & olherde & $\frac{1}{2}$ \\
\hline 28 & 1 ponta $c$ & \\
\hline 29 & 1 ponta & \\
\hline 30 & Oliva & \\
\hline 311 & lcolher d & 2 \\
\hline 32 & 3 col & \\
\hline 33 & 3. & \\
\hline 34 & 1 peda & \\
\hline 35 & W. & 牃4 \\
\hline 36 & 5 unid & \\
\hline 37 & $1 / 2$ 看unida & ot \\
\hline 38 & sucrilhos & \\
\hline 39 & 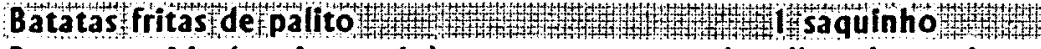 & 6 \\
\hline 40 & ziod (pure, sautee) & \\
\hline 411$]^{7}$ & ace & 10 \\
\hline 42 & 2 colhe & \\
\hline 43 & 4 & 0 \\
\hline 44 & 2 ram & \\
\hline 46 & 1 & \\
\hline
\end{tabular}




\begin{tabular}{|c|c|}
\hline 42 & 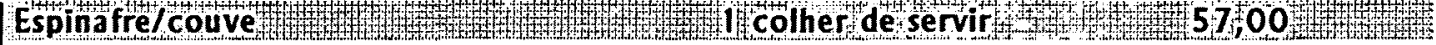 \\
\hline 48 & 2 colheres de sopa \\
\hline 49 & ilho verde \\
\hline 50 & 6 fatias \\
\hline 51 & Tomate \\
\hline 52 & 1 fatia \\
\hline 53 & 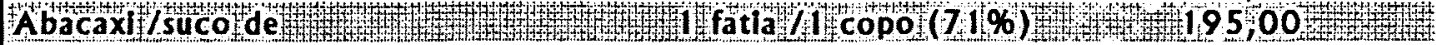 \\
\hline 54 & 1 unidade \\
\hline 55 & 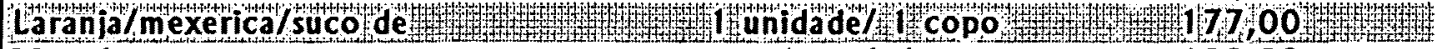 \\
\hline 56 & Maçä/péra \\
\hline 57 & 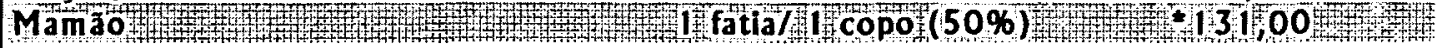 \\
\hline 58 & 1 fatial 1 copo $(86 \%)$ \\
\hline 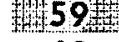 & Manga \\
\hline 60 & 1/ xicara de chá \\
\hline $61+14$ & 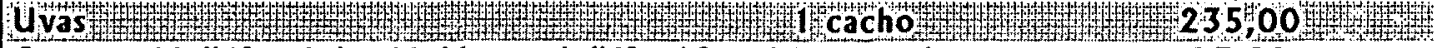 \\
\hline 62 & $\begin{array}{l}\text { Came cozida(bife role/moida/de panela/bife } 1 \text { fatia/ } / \text { colher de servir } \\
\text { frito }\end{array}$ \\
\hline 63 & Frango cozido/assado/grelliado/frito w 1 pedaçof \\
\hline 64 & Peixe frito/ cozido \\
\hline 65 & 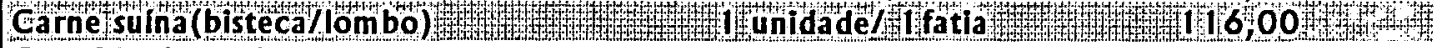 \\
\hline 66 & Ovo frito/mexido/omelete \\
\hline $67+2$ & esuntolpeito de peruet \\
\hline 68 & 1 1/2 unidade \\
\hline 69 & 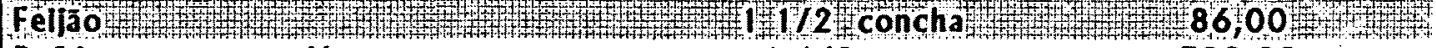 \\
\hline 70 & Refrigerante normal* \\
\hline m1 & Refrigerante diet -4 \\
\hline 72 & Chá mate com sabor \\
\hline 19 & Sucos naturais com leite (vitaminas) \\
\hline 74 & 1 xícara pequena \\
\hline 75 & 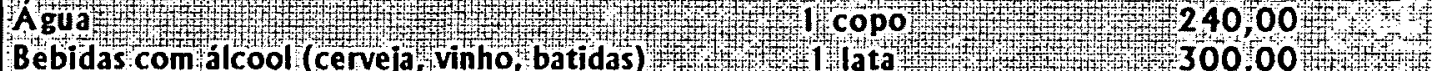 \\
\hline & \\
\hline
\end{tabular}

\footnotetext{
* valor mediano
} 


\section{Anexo 5}

Média, desvio padrão e coeficiente de correlação de Pearson de energia e nutrientes estimados pelos recordatórios de $\mathbf{2 4}$ horas e o Questionário de freqūência alimentar para adolescentes - QFAA. São Paulo, 1999.

\begin{tabular}{lccccc}
\hline \multicolumn{1}{c}{ Nutrientes } & X R24 & DP & XQFAA & DP & $\mathrm{r}$ \\
& \multicolumn{5}{c}{} \\
& 1693,7 & 428,3 & 1562,2, & 609,7 & 0,10 \\
\hline Energia (Kcal) & 91,3 & 23,2 & 62,1 & 33,16 & 0,10 \\
Proteína (g) & 210,0 & 47,7 & 202,7 & 75,03, & 0,40 \\
Carboidratos(g) & 56,6 & 26,6 & 53,5 & 28,0 & 0,20 \\
Lipídios Totais(g) & 24,5 & 15,1 & 24,6 & 13,5 & 0,18 \\
Lip. insaturados) & 189,3 & 154,9 & 154,6 & 131,9 & 0,31 \\
Colesterol & 988,7 & 510,7 & 864,3 & 1772,4 & 0,05 \\
Retinol(g) & 275,1 & 120,3 & 179,5 & 153,5 & 0,42 \\
Vitamina,C(g) & 665,2 & 217,9 & 742,3 & 301,1 & 0,23 \\
Cálcio(g) & 19,3 & 6,5 & 9,8 & 4,6 & 0,11 \\
Ferro (g) & & & & & \\
\hline
\end{tabular}


Anexo 6

Questionário de Freqũência Alimentar para Adolescentes - QFAA

\begin{tabular}{ll} 
UNIVERSIDADE DE SÄO PAULO \\
FACULDADE DE SAÚDE PÚBLICA \\
DEPARTAMENTO DE NUTRIÇÃO \\
Av. Dr. Arnaldo, 715 - Cerqueira César - São Paulo/SP \\
CEP: 01246-904 \\
(011) 3066-7701/7705 - Fax (011) $852-6748$ \\
\hline
\end{tabular}

\section{Avaliação do consumo alimentar de adolescentes}

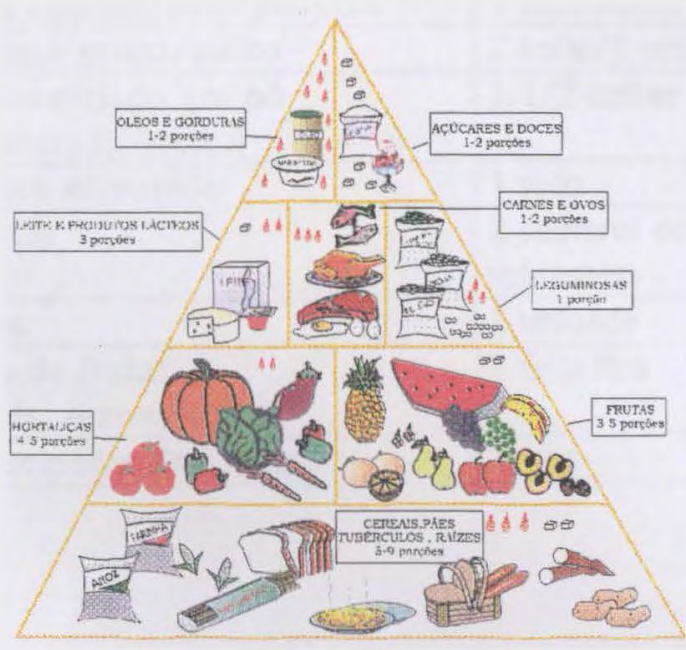

PHILIPPI e col. 1996

\section{Instruções:}

- Este é um questionário que avaliará seu consumo alimentar dos últimos 6 meses. Faça um esforço para lembrar o que você costuma comer e os alimentos que você mais gosta.

- Leia com atenção cada nome do alimento, a medida $e$ as vezes que você costuma consumir o alimento.

- Por favor indique seu consumo habitual. Se você consome $1 / 2$ copo de leite duas vezes por semana, registre 1 copo por semana para representar seu consumo de leite.

- Não esqueça de marcar aqueles alimentos que são consumidos somente em algumas épocas do ano. Exemplo, sorvete durante o verão.

- Todos os alimentos devem ser preenchidos. Aqueles alimentos que você não gosta ou não come assinale em nunca. 
Assinale com $X$ a quantidade de alimento que você costuma consumir habitualmente. Lembre-se que esta quantldade representa seu consumo médio nos últ Imos 6 meses.

Quantas vezes vocé comeu estes allmentos nos últimos 6 meses?

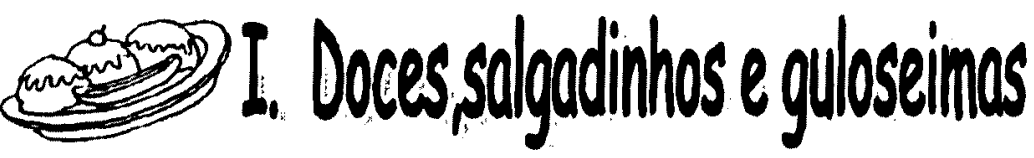

\begin{tabular}{|c|c|c|c|c|c|c|c|c|}
\hline \multirow[t]{2}{*}{ ALIMENTO } & \multirow[t]{2}{*}{ QUANTIDADE } & \multicolumn{7}{|c|}{ CONSUMO } \\
\hline & & Nunca & \begin{tabular}{|l|} 
menos de 1 \\
$\times$ mes \\
\end{tabular} & $\begin{array}{l}1 \text { a } 3 X \\
\text { mes }\end{array}$ & $\begin{array}{l}1 \text { X por } \\
\text { semana }\end{array}$ & $\begin{array}{l}2 \text { a } 4 X \\
\text { semana }\end{array}$ & $1 \times$ dla & $\begin{array}{l}2 \text { ou mals } \\
X \text { dla }\end{array}$ \\
\hline 1. Batatlnha tlpo chlps ou salgadinho & $1 / 2$ pacote & & & & & & & \\
\hline 3. Bolo comum/bolo pullman & 1 fatla médla & & & & & & & \\
\hline 4. Sorvete massa/palito & 2 bolas/1 unidade & & & & & & & \\
\hline 6. Plpoca estourada & I saco & & & & & & & \\
\hline 7. Açúcar & $\begin{array}{l}2 \text { colheres de } \\
\text { sobremesa }\end{array}$ & & & & & & & \\
\hline 8. Balas & 2 unidade & & & & & & & \\
\hline $\begin{array}{l}\text { 9.Doces de frutas } \\
\text { (golabada, marmelada }{ }_{l} \text { ) }\end{array}$ & I fatia fina & & & & & & & \\
\hline 10. Sobremesas tlpo musse & I taça & & & & & & & \\
\hline
\end{tabular}


Assinale com $X$ a quantidade de alimento que você costuma consumir habitualmente. Lembre-se que esta quantidade representa seu consumo médio nos últimos 6 meses

Quantas vezes vocé comeu estes allmentos nos últimos 6 meses?

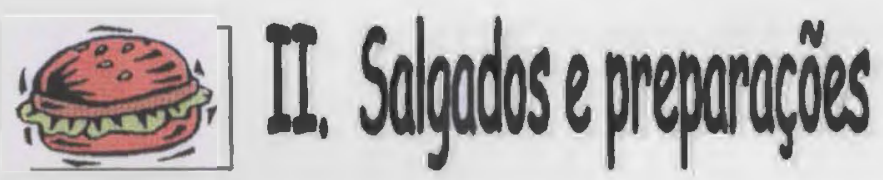

\begin{tabular}{|c|c|c|c|c|c|c|c|c|}
\hline \multirow[t]{2}{*}{ ALIMENTO } & \multirow[t]{2}{*}{ QUANTIDADE } & \multicolumn{7}{|c|}{ CONSUMO } \\
\hline & & Nunca & \begin{tabular}{|l|} 
menos de 1 \\
$\mathrm{X}$ mês
\end{tabular} & $\begin{array}{l}1 \text { a } 3 X \\
\text { més }\end{array}$ & $\begin{array}{l}1 \mathrm{X} \text { por } \\
\text { semana }\end{array}$ & $\begin{array}{l}2 \text { a } 4 X \\
\text { semana }\end{array}$ & $1 \times$ dia & $\begin{array}{l}2 \text { ou mais } \\
\mathrm{X} \text { dia }\end{array}$ \\
\hline 11. Cheesebúrger de carne/frango & 1 sandulche & & & & & & & \\
\hline $\begin{array}{l}\text { 12. Sanduiche (misto, queljo, frios } \\
\text { ou quentes) }\end{array}$ & 1 sandulche & & & & & & & \\
\hline 13. Sanduíche natural & 1 sanduiche & & & & & & & \\
\hline 14. Coxinha/esflha/rissolis/ pastel & 1 unidade & & & & & & & \\
\hline 15. Salada de batata $\mathrm{c} / \mathrm{maionese}$ & 1 colher de servir & & & & & & & \\
\hline 16. Sopa (canja, feljăo, legumes) & 1 prato & & & & & & & \\
\hline $\begin{array}{l}\text { 17. Farofa (de farinha de } \\
\text { mandioca) }\end{array}$ & 1 colher de servir & & & & & & & \\
\hline 18. Păo de quello/batata & 1 unidade & & & & & & & \\
\hline 19. Plzza & 1 fatia & & & & & & & \\
\hline 20. Cachorro quente & 1 sanduiche & & & & & & & \\
\hline 21. Crolssant & 1 unidade & & & & & & & \\
\hline
\end{tabular}


Assinale com $X$ a quantidade de alimento que você costuma consumir habltualmente Lembre-se que esta quantidade representa seu consumo médio nos últimos 6 meses.

Quantas vezes você comeu estes allmentos nos últimos 6 meses?

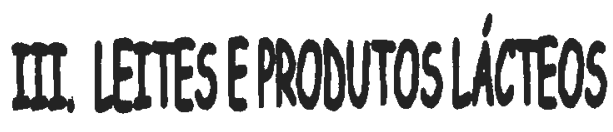

\begin{tabular}{|c|c|c|c|c|c|c|c|c|}
\hline \multirow[t]{2}{*}{ ALIMENTO } & \multirow[t]{2}{*}{ QUANTIDADE } & \multicolumn{7}{|c|}{ CONSUMO } \\
\hline & & Nunca & \begin{tabular}{|l|} 
menos de 1 \\
$X$ més
\end{tabular} & $\begin{array}{l}1 \text { a } 3 x \\
\text { mes }\end{array}$ & $\begin{array}{l}1 X \text { por } \\
\text { semana }\end{array}$ & $\begin{array}{l}2 \text { a } 4 X \\
\text { semana }\end{array}$ & $1 \times$ dla & $\begin{array}{l}2 \text { ou mals } \\
X \text { dla }\end{array}$ \\
\hline 22. Lelte fluldo integral & 1 copo chelo & & & & & & & \\
\hline 23. Lelte fluldo desnatado & 1 copo chelo & & & & & & & \\
\hline 24. logurte natural/frutas & 1 copo & & & & & & & \\
\hline 25. logurte dlet & 1 copo & & & & & & & \\
\hline $\begin{array}{l}\text { 26. Quello minas frescal } \\
\text { /rlcota, cottage }\end{array}$ & 1 fatia & & & & & & & \\
\hline 27. Requeljăo & 1 colher de sopa & & & $!$ & & & & \\
\hline 28. Mantelga & 1 ponta de faca & & & & & & & \\
\hline 29. Margarlna & 1 ponta de faca & & & & & & & \\
\hline 30. Azeite de Ollva & 1 colher de café & & & & & & & \\
\hline 31. Malonese tradicional & 1 colher de sopa & & & & & & & \\
\hline
\end{tabular}


Assinale com $X$ a quantldade de allmento que você costuma consumlr habltualmente. Lembre-se que esta quantldade representa seu consumo médlo nos últimos 6 meses.

Quantas vezes você comeu estes allmentos nos últimos 6 meses?

\section{E IV. Cereais, peese tubererdos}

\begin{tabular}{|c|c|c|c|c|c|c|c|c|}
\hline \multirow[t]{2}{*}{ ALIMENTO } & \multirow[t]{2}{*}{ QUANTIDADE } & \multicolumn{7}{|c|}{ CONSUMO } \\
\hline & & Nunca & \begin{tabular}{|l|} 
menos de 1 \\
$\mathrm{X}$ més
\end{tabular} & \begin{tabular}{|l|} 
a $3 X$ \\
mes \\
\end{tabular} & $\begin{array}{l}1 \mathrm{X} \text { por } \\
\text { semana }\end{array}$ & $\begin{array}{l}2 \text { a } 4 \text { X } \\
\text { semana }\end{array}$ & $1 \times \mathrm{dla}$ & $\begin{array}{l}2 \text { ou mals } \\
X \mathrm{dla}\end{array}$ \\
\hline 32. Arroz cozldo & 4 colheres de sopa & & & & & & & \\
\hline $\begin{array}{l}\text { 33. Macarråo/Instantáneo/sugo/m } \\
\text { telga }\end{array}$ & 3 colheres de servir & & & & & & & \\
\hline $\begin{array}{l}\text { 34. Massas } \\
\text { (lasanha, ravlole, capeletl) }\end{array}$ & 1 pedaço/l prato & & & & & & & \\
\hline $\begin{array}{l}\text { 35. Blscoltos sem rechelo /cream } \\
\text { craker }\end{array}$ & 6 unidades & & & & & & & \\
\hline 36. Biscoltos com rechelo & 5 unidades & & & & & & & \\
\hline $\begin{array}{l}\text { 37. Păo francês/forma } \\
\text { /Integral }\end{array}$ & $11 / 2$ unldade/ 3 fatlas & & & & & & & \\
\hline $\begin{array}{l}\text { 38. Cereal matinal tlpo } \\
\text { sucrilhos }\end{array}$ & 1 xicara & & & & & & & \\
\hline 39. Batatas fritas de palito & 1 saquinho & & & & & & & \\
\hline $\begin{array}{l}\text { 40. Batatas cozlda (purê, } \\
\text { sautée) }\end{array}$ & I colher de servir & & & & & & & \\
\hline
\end{tabular}


Assinale com $X$ a quantidade de allmento que você costuma consumir habitualmente. Lembre-se que esta quantidade representa seu consumo médio nos últimos 6 meses

Quantas vezes você comeu estes allmentos nos últımos 6 meses?

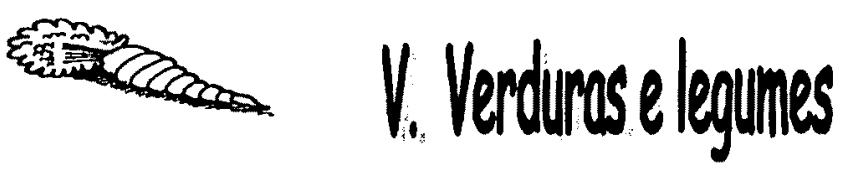

\begin{tabular}{|c|c|c|c|c|c|c|c|c|}
\hline \multirow[t]{2}{*}{ ALIMENTO } & \multirow[t]{2}{*}{ QUANTIDADE } & \multicolumn{7}{|c|}{ CONSUMO } \\
\hline & & Nunca & \begin{tabular}{|l|} 
menos de 1 \\
$\mathrm{X}$ mês
\end{tabular} & $\begin{array}{l}1 \text { a } 3 X \\
\text { mês }\end{array}$ & $\begin{array}{l}1 \mathrm{X} \text { por } \\
\text { semana }\end{array}$ & $\begin{array}{l}2 \text { a } 4 X \\
\text { semana }\end{array}$ & $1 \mathrm{Xdla}$ & $\begin{array}{l}2 \text { ou mals } \\
X \text { dla }\end{array}$ \\
\hline 41. Alface & 1 porção /6 folhas & & & & & & & \\
\hline 42. Acelga/repolho & 2 colheres de servir & & & & & & & \\
\hline 43. Agrlåo/rúcula & 3 ramos $/ 5$ folhas & & & & & & & \\
\hline 44. Couve-flor & 2 ramos médlos & & & & & & & \\
\hline 45. Beterraba & 1 colher de servlr & & & & & & & \\
\hline 46. Cenoura & 1 colher de servir & & & & & & & \\
\hline 47. Esplnafre/couve & 1 colher de servir & & & & & & & \\
\hline 48. Ervilha & 2 colheres de sopa & & & & & & & \\
\hline 49. Milho verde & 1 colher de sopa & & & & & & & \\
\hline 50. Pepino & 6 fatias & & & & & & & \\
\hline 51. Tomate & 3 fatias & & & & & & & \\
\hline
\end{tabular}


Assinale com $\mathrm{X}$ a quantidade de alimento que você costuma consumir habitualmente. Lembre-se que esta quantidade representa seu consumo médio nos últimos 6 meses

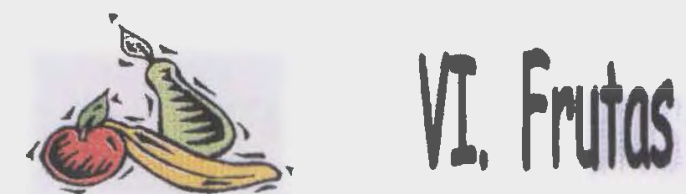

Quantas vezes você comeu estes alimentos nos últimos 6 meses?

\begin{tabular}{|c|c|c|c|c|c|c|c|c|}
\hline \multirow[t]{2}{*}{ ALIMENTO } & \multirow[t]{2}{*}{ QUANTIDADE } & \multicolumn{7}{|c|}{ CONSUMO } \\
\hline & & Nunca & $\begin{array}{l}\text { menos de } 1 \\
\mathrm{X} \text { mês }\end{array}$ & $\begin{array}{l}1 \text { a } 3 X \\
\text { mês }\end{array}$ & $\begin{array}{l}1 \mathrm{X} \text { por } \\
\text { semana }\end{array}$ & $\begin{array}{l}2 \text { a } 4 X \\
\text { semana }\end{array}$ & $1 \times$ dia & $\begin{array}{l}2 \text { ou mais } \\
X \text { dia }\end{array}$ \\
\hline 52. Abacate & 1 fatia & & & & & & & \\
\hline 53. Abacaxi /suco de & 1 fatia/ 1 copo & & & & & & & \\
\hline 54. Banana & 1 unidade & & & & & & & \\
\hline $\begin{array}{l}\text { 55. Larania/mexerica/suco } \\
\text { de }\end{array}$ & 1 unidade/ 1 copo & & & & & & & \\
\hline 56. Maçāa pêra & 1 unidade & & & & & & & \\
\hline 57. Mamāo/suco de & 1 fatia / 1 copo & & & & & & & \\
\hline $\begin{array}{l}\text { 58. Melão/Melancia suco } \\
\text { de }\end{array}$ & 1 fatia / 1 copo & & & & & & & \\
\hline 59. Manga & $1 / 2$ unidade & & & & & & & \\
\hline 60. Morangos & 1/2 xícara de chá & & & & & & & \\
\hline 61. Uvas & 1 cacho & & & & & & & \\
\hline
\end{tabular}


Assinale com $\mathrm{X}$ a quantidade de alimento que você costuma consumir habitualmente, lembre-se que esta quantidade representa seu consumo médio nos últimos 6 meses

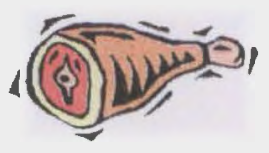

\section{Carnes e Ovos}

Quantas vezes você comeu estes alimentos nos últimos 6 meses?

\begin{tabular}{|c|c|c|c|c|c|c|c|c|}
\hline \multirow[t]{2}{*}{ ALIMENTO } & \multirow[t]{2}{*}{ QUANTIDADE } & \multicolumn{7}{|c|}{ CONSUMO } \\
\hline & & Nunca & $\begin{array}{l}\text { menos de } 1 \\
\mathrm{X} \text { mês }\end{array}$ & $\begin{array}{l}1 \text { a } 3 X \\
\text { mês }\end{array}$ & $\begin{array}{l}1 \mathrm{X} \text { por } \\
\text { semana }\end{array}$ & $\begin{array}{l}2 \text { a } 4 X \\
\text { semana }\end{array}$ & I X dia & $\begin{array}{l}2 \text { ou mais } \\
\mathrm{X} \text { dia }\end{array}$ \\
\hline $\begin{array}{l}\text { 62. Carne cozida (bife } \\
\text { role/moida/de panela/ } \\
\text { bife frito }\end{array}$ & $\begin{array}{l}1 \text { fatia/ I C. de servir/ } \\
1 \text { unidade }\end{array}$ & & & & & & & \\
\hline $\begin{array}{l}\text { 63. Frango cozido/assado } \\
\text { grelhado/frito }\end{array}$ & 1 pedaço/ 1 unidade & & & & & & & \\
\hline 64. Peixe frito/cozido & 1 file/posta & & & & & & & \\
\hline $\begin{array}{l}\text { 65. Carne suína(bisteca } \\
\text { /lombo) }\end{array}$ & 1 unidade/ 1 fatia & & & & & & & \\
\hline $\begin{array}{c}\text { 66. Ovo frito/mexido } \\
\text { /omelete }\end{array}$ & 1 unidade/ 1 pedaço & & & & & & & \\
\hline $\begin{array}{l}\text { 67. Embutidos (presunto/ } \\
\text { pelto de peru etc.) }\end{array}$ & 2 fatias & & & & & & & \\
\hline 68. Salsicha & $11 / 2$ unidade & & & & & & & \\
\hline
\end{tabular}


Assinale com $\mathrm{X}$ a quantidade de alimento que você costuma consumir habitualmente, lembre-se que esta quantidade representa seu consumo médio nos últimos 6 meses

\section{Feijão}

Quantas vezes voce comeu este alimento nos últimos 6 meses?

\begin{tabular}{|c|c|c|c|c|c|c|c|c|}
\hline \multirow[t]{2}{*}{ ALIMENTO } & \multirow[t]{2}{*}{ QUANTIDADE } & \multicolumn{7}{|c|}{ CONSUMO } \\
\hline & & Nunca & $\begin{array}{l}\text { menos de } 1 \\
X \text { mes }\end{array}$ & $\begin{array}{l}1 \text { a } 3 X \\
\text { més }\end{array}$ & $\begin{array}{l}1 \mathrm{X} \text { por } \\
\text { semana }\end{array}$ & $\begin{array}{l}2 \text { a } 4 X \\
\text { semana }\end{array}$ & $1 \times$ dla & $\begin{array}{l}2 \text { ou mals } \\
X \text { dla }\end{array}$ \\
\hline 69. Fellāo & 1 1/2 concha & & & & & & & \\
\hline
\end{tabular}


Assinale com $X$ a quantidade de alimento que você costuma consumir habitualmente, lembre-se que esta quantidade representa seu consumo médio nos últimos 6 meses

Quantas vezes você comeu estes allmentos nos últimos 6 meses?

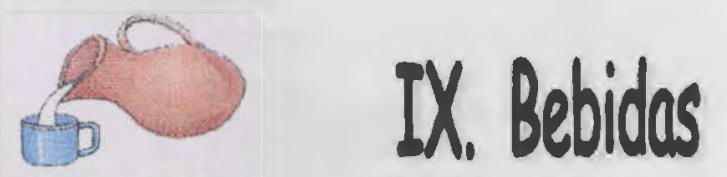

\begin{tabular}{|c|c|c|c|c|c|c|c|c|}
\hline \multirow[t]{2}{*}{ ALIMENTO } & \multirow[t]{2}{*}{ QUANTIDADE } & \multicolumn{7}{|c|}{ CONSUMO } \\
\hline & & Nunca & $\begin{array}{l}\text { menos de } 1 \\
\mathrm{X} \text { més }\end{array}$ & $\begin{array}{l}1 \text { a } 3 X \\
\text { mes }\end{array}$ & $\begin{array}{l}1 X \text { por } \\
\text { semana }\end{array}$ & $\begin{array}{l}2 \text { a } 4 X \\
\text { semana }\end{array}$ & $1 \mathrm{X}$ dia & $\begin{array}{l}2 \text { ou mais } \\
X \text { dia }\end{array}$ \\
\hline 70. Refrigerante normal & $11 / 2$ copo & & & & & & & \\
\hline 71. Refrigerante dlet & $11 / 2$ copo & & & & & & & \\
\hline 72. Chá mate com sabor & 1 lata & & & & & & & \\
\hline $\begin{array}{l}\text { 73. Sucos naturals com lelte } \\
\text { (vitaminas) }\end{array}$ & 1 copo & & & & & & & \\
\hline 74. Café & 1 xicara pequena & & & & & & & \\
\hline $\begin{array}{l}\text { 75. Bebida com álcool (cerveja, } \\
\text { vinho, batidas) }\end{array}$ & 1 copo & & & & & & & \\
\hline 76. Água & 1 copo & & & & & & & \\
\hline
\end{tabular}




\section{ANEXO 7}

\section{Transformação logarítmica de algumas variáveis estudadas.}
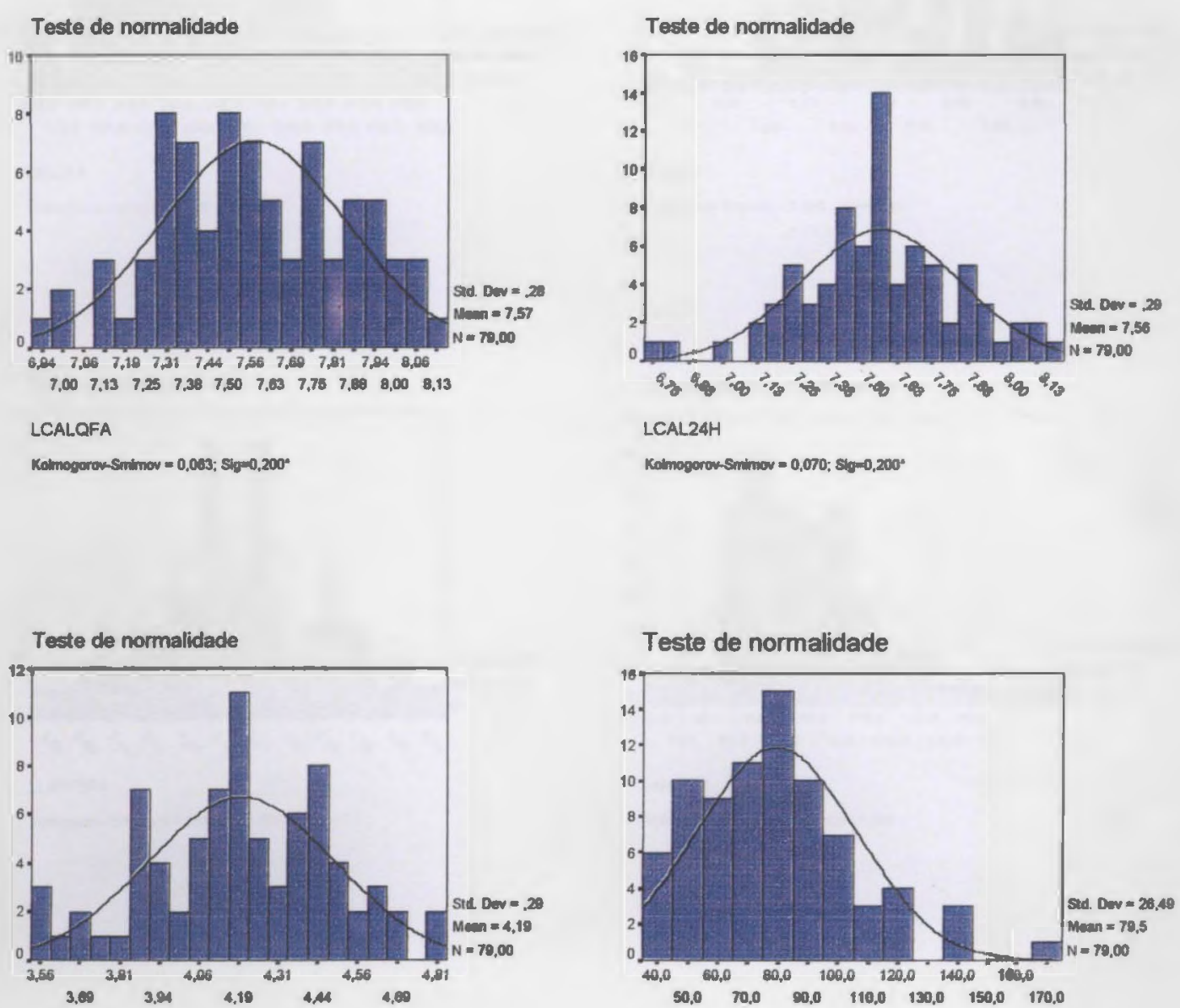

LPROCFA

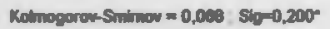

PRO244

Kotmogerou Sminom 0,$077 ; 500,200$ 
Teste de nomalidade

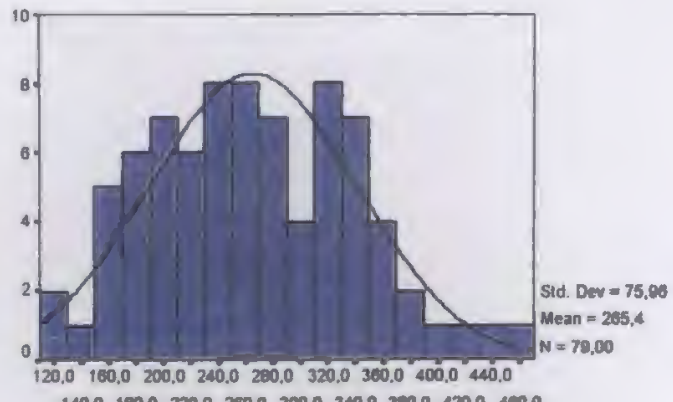

$140,0 \quad 160,0 \quad 200,0 \quad 260,0 \quad 300,0 \quad 340,0 \quad 300,0 \quad \$ 20,0 \quad 400,0$

HCAFA

Matragarou Sumber $=0,073 ; 5 ; 0,200$

Teste de normalidade

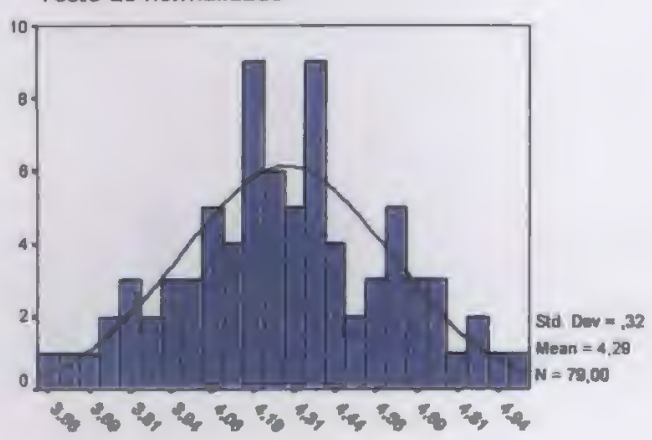

LLPTOFA

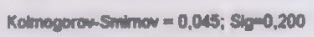

Teste de normalidade

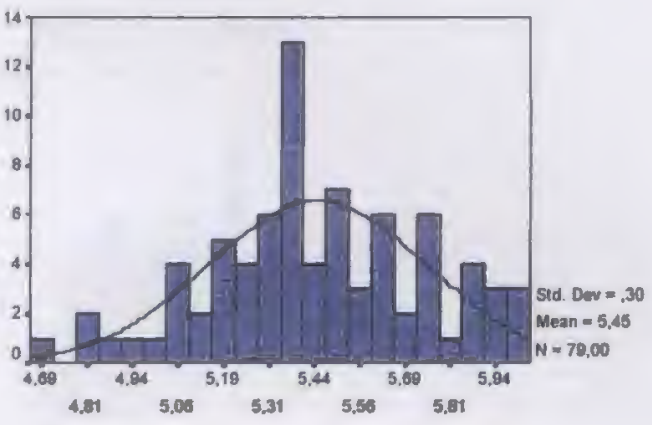

LHC24H

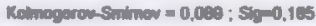

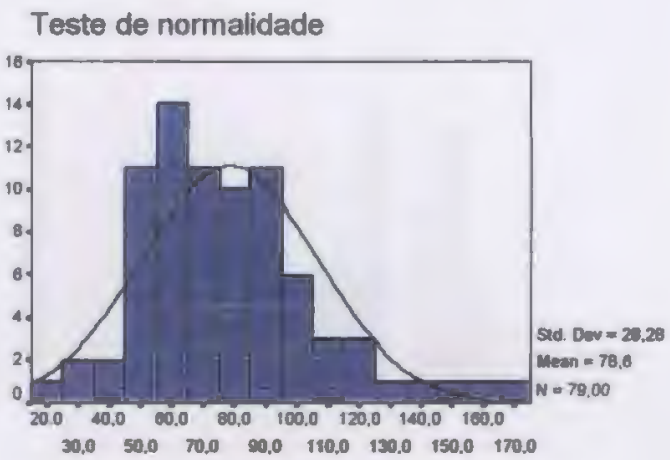

24HLPT

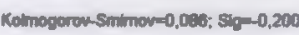

Teste de normalidade

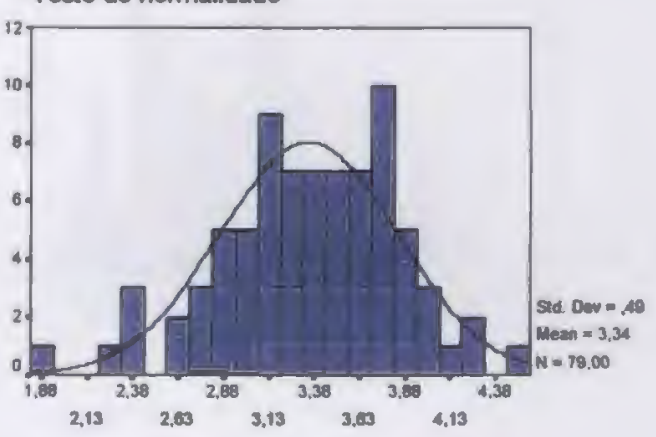

LLINS24H

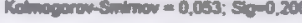

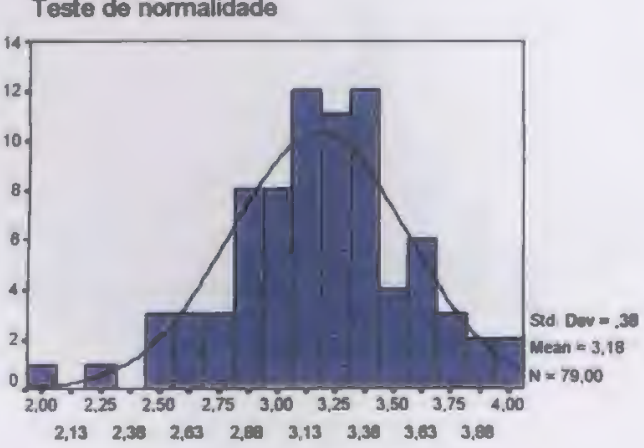

LLNSOFA

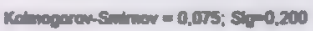


Teste de normalidade

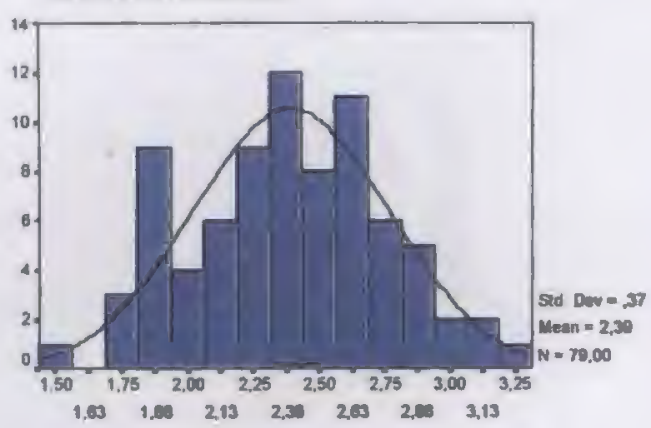

LFIBCFA

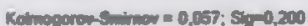

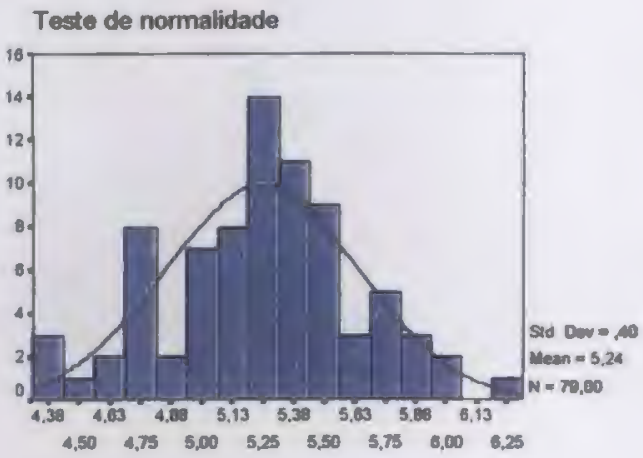

LCOLOFA

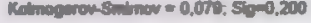

Teste de nomalidade

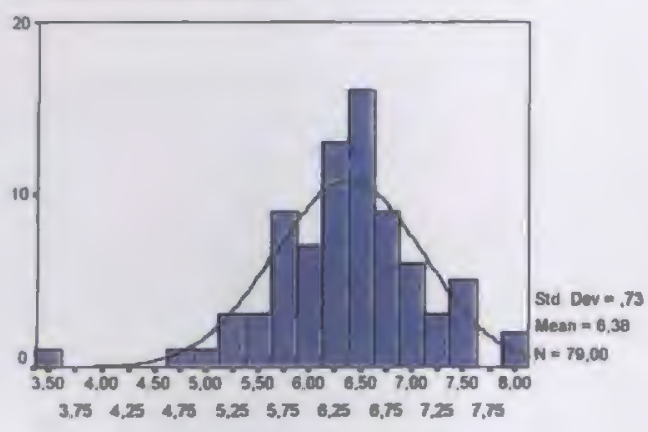

LRET24H

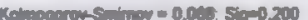

Teste de normalidade

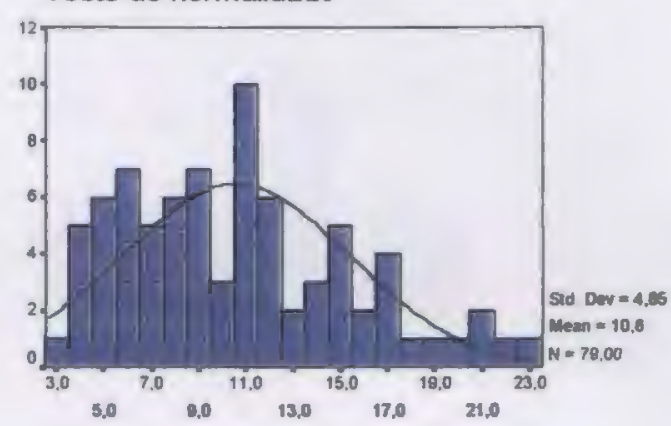

24HFERA

(1)

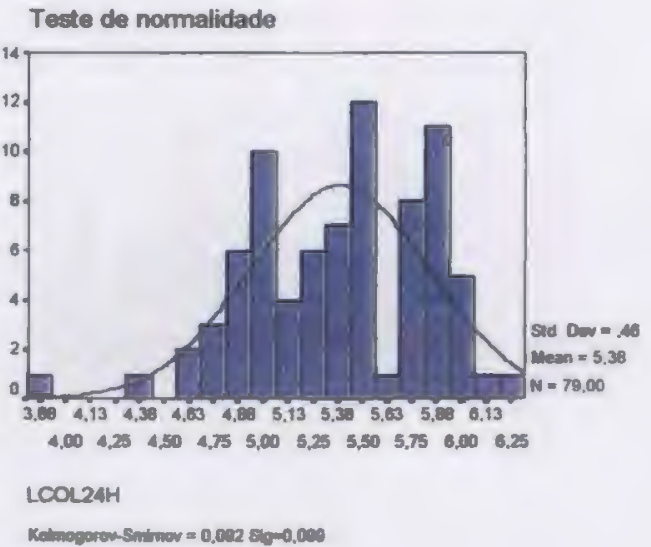

Teste de normalidade

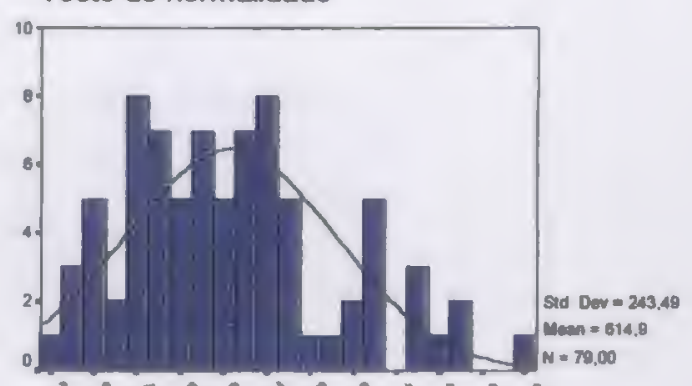

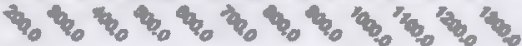

RETWNOL

Ron 


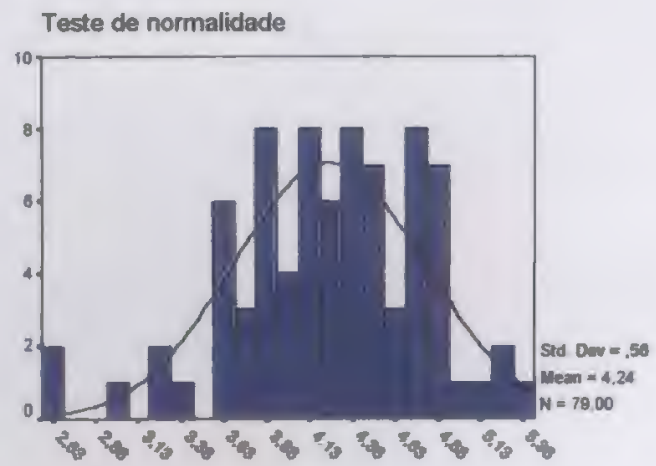

LVITCOFA

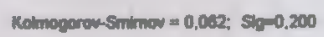
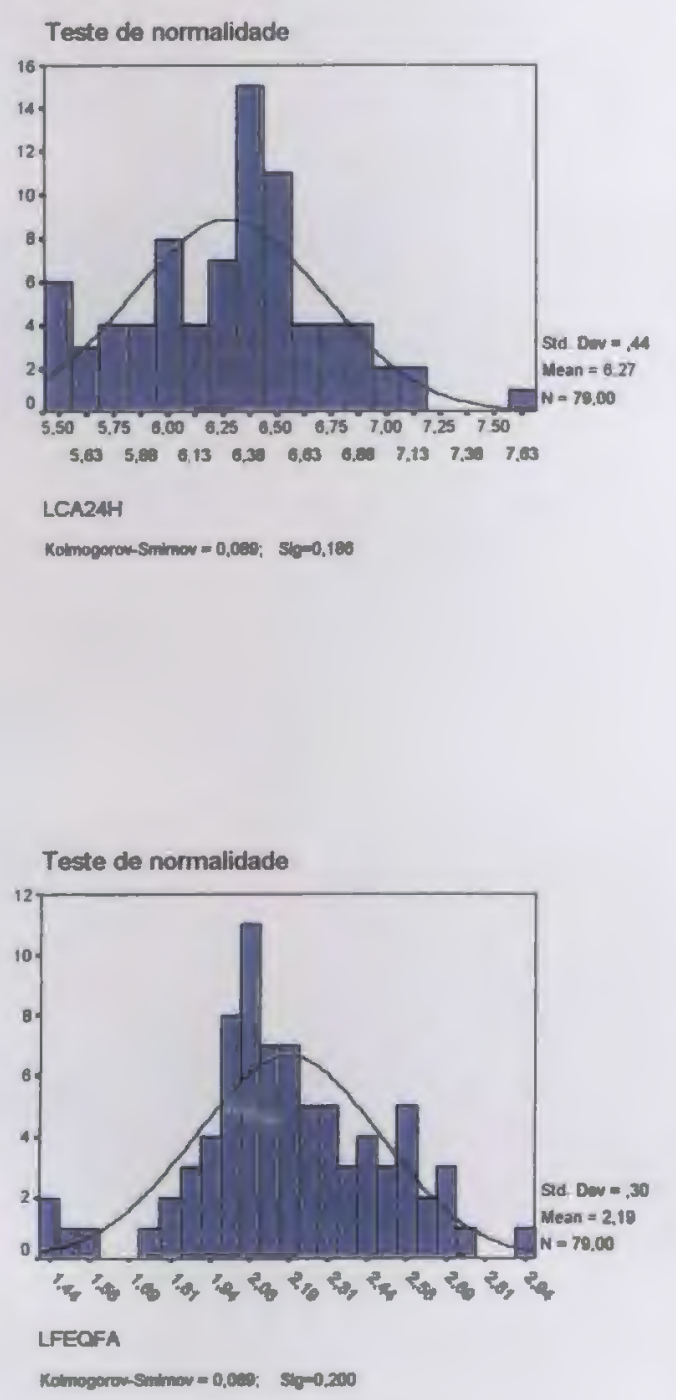

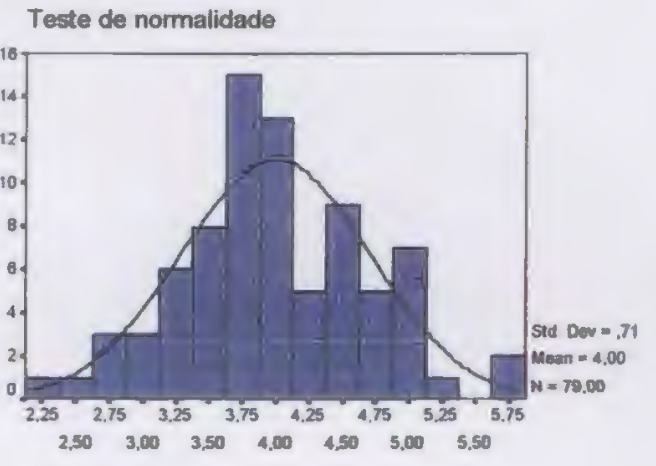

\section{LVITC24H}

Katnogorom Smimor $=0,073$; $\mathrm{SP}=0,200$

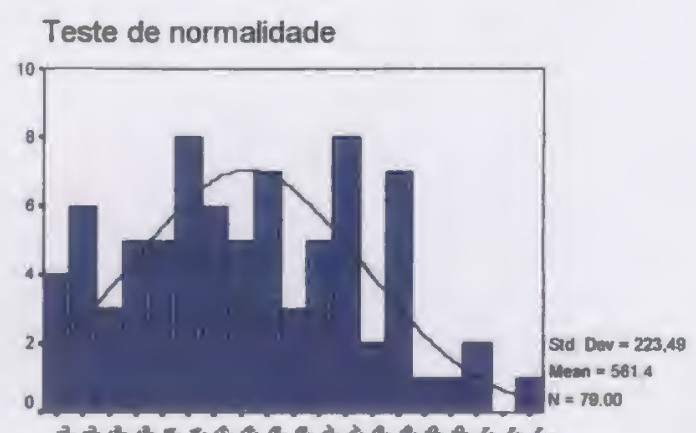

50

CA

Kolmogoron-Snmove $0,0045-0.200$

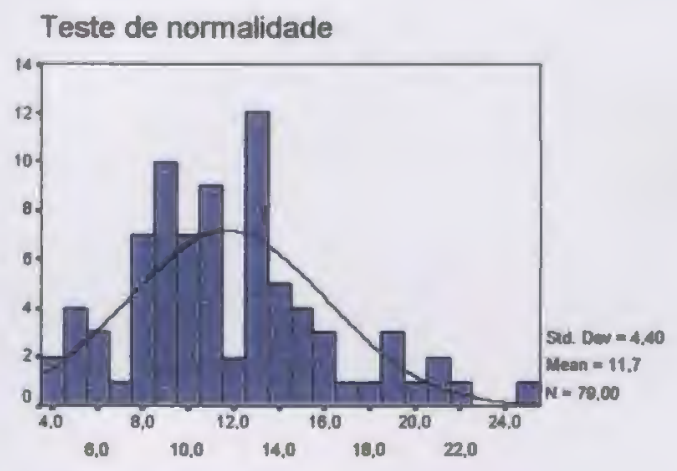

2AHFE

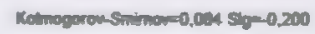

